\title{
Small Firms and Innovation Policy in Japan
}

This book discusses the extent to which the Japanese economy encourages entrepreneurship and innovation.

Although Japan has a strong reputation as an innovator, some people argue that this reputation is misplaced. Contrary to earlier expectations, the USA rather than Japan emerged as the leader in the biotech industries in the 1990s. Moreover, many small firms in Japan supply only few companies, thereby limiting their view of the marketplace and the commercial opportunities within it. Despite the increase of international patents, international scientific citations and a positive technology trade balance, the Japanese innovation system is weak in giving birth to radical innovations.

The book explores fully these issues, making comparisons with other countries where appropriate. It concludes that the Japanese innovation system has both advantages and disadvantages and contributes to a better understanding of how policy changes take place.

Cornelia Storz is Professor of Japanese Economy at the Faculty of Economics and Business Administration as well as at the Centre for Japanese Studies, University of Marburg. Her research focuses on the comparison of economic systems; genesis and change of institutions; comparative institutional analysis; innovation systems; entrepreneurship in the modern Japanese economy. 


\section{Routledge Contemporary Japan Series}

1 A Japanese Company in Crisis Ideology, strategy, and narrative Fiona Graham

\section{Japan's Foreign Aid}

Old continuities and new directions

Edited by David Arase

3 Japanese Apologies for World War II

A rhetorical study

Jane W. Yamazaki

4 Linguistic Stereotyping and Minority Groups in Japan Nanette Gottlieb

\section{Shinkansen}

From bullet train to symbol of modern Japan

Christopher P. Hood

6 Small Firms and Innovation Policy in Japan

Edited by Cornelia Storz 


\section{Small Firms and Innovation Policy in Japan}

Edited by Cornelia Storz 
First published 2006

by Routledge

Published 2017 by Routledge

2 Park Square, Milton Park, Abingdon, Oxon OX14 4RN

711 Third Avenue, New York, NY 10017, USA

Routledge is an imprint of the Taylor \& Francis Group, an informa business

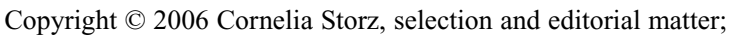
the contributors, their own chapters

Typeset in Times New Roman by Newgen Imaging Systems (P) Ltd, Chennai, India

The Open Access version of this book, available at www.tandfebooks.com, has been made available under a Creative Commons Attribution-Non Commercial-No Derivatives 4.0 license.

British Library Cataloguing in Publication Data

A catalogue record for this book is available from the British Library

Library of Congress Cataloging in Publication Data

A catalog record for this book has been requested

ISBN 978-0-415-36812-4 (hbk) 


\section{Contents}

List of figures vii

List of tables $\quad$ ix

Notes on contributors $\quad$ xi

1 Small firms and innovation policy in Japan:

an introduction

CORNELIA STORZ

PART I

Shift in policy changes 11

2 How do we formulate policies? The problem of defining policies and their evaluation

LAMBERT T. KOCH

3 Japanese science and technology policy in transition: from catch-up orientation to frontrunner orientation

MARTIN HEMMERT

4 Innovation policy for SME in Japan: the case of technology transfer centres

KLAUS RUTH

5 Cognitive models and economic policy: the case of Japan CORNELIA STORZ

\section{PART II}

The shift in entrepreneurial behaviour in SMEs

6 Restructuring the Japanese national biotechnology innovation system: prospects and pitfalls

REIKO KISHIDA AND LEONARD H. LYNN

7 Supplier system and innovation policy in Japan 



\section{Figures}

3.1 Assessment of the impact of factors related to external knowledge on the technology acquisition of pharmaceutical and semiconductor firms

3.2 R\&D intensity in five leading countries 43

3.3 Intensity of public R\&D spending in five leading countries 43

3.4 Number of researchers employed on limited-term contracts in Japanese government laboratories

3.5 Number of collaborative research projects between national universities and the business sector in Japan

3.6 Number of newly founded venture businesses originating from universities and government laboratories

6.1 Network structure in US and Japanese biotechnology industries

6.2 Startup and closure rates in Japan and the United States

6.3 Startup rates based on common definition, 1988-1994 



\section{Tables}

3.1 Number and size of publicly financed $R \& D$ institutes in Japan

6.1 Japanese policies to facilitate the creation of new ventures, 1994-2000

6.2 Organizations filing patent families of human DNA sequences, by organization type and priority country, 1980-1999

6.3 Japanese policies to improve flow of technology from universities to industry, 1995-2000

6.4 Share of world exports of advanced technology products in 1992 



\section{Contributors}

Martin Hemmert is Associate Professor of International Business at Korea University Business School, Seoul. His previous teaching and research affiliations include the University of Duisburg-Essen, Germany, the German Institute for Japanese Studies (DIJ), Tokyo and Hitotsubashi University, Tokyo. He has published numerous papers in journals such as Research Policy, Management International Review and Industrial and Corporate Change, and has also published five books, including Erfolgsfaktoren der Technologiegewinnung (Duncker \& Humblot, 2002) and Technology and Innovation in Japan (Routledge, 1998).

Takumi Hirai is Senior Researcher at the Institute for Advanced Industry Development, Osaka Prefectural Government, Osaka, Japan. He is the member of Japan Academy of Small Business Studies and Japan Section of the Regional Science Association International, and writes numerous research reports on the local economy and industry of Osaka. He has also published in leading Japanese journals about small business issues such as Sankaiken Ronsh $\hat{u}$ (The Economic and Business Review, Institute for Advanced Industry Development).

Reiko Kishida is currently a Research Associate with the Department of Marketing and Policy Studies at Case Western Reserve University and with the Center for Regional Research at HOSEI University. She has conducted research on entrepreneurship, innovation, and business community and family business, and these have been published in Asian Business \& Management, Family Business Review and Academy of Management Proceedings.

Lambert T. Koch holds the Chair of Entrepreneurship and Economic Development at the University of Wuppertal in Germany, and is the Director of the Wuppertal Institute of Innovation and Entrepreneurship Studies. His research work includes entrepreneurship, evolutionary economic policy and international economics. He is involved in consulting on entrepreneurship, is a political advisor 
and has a management function in entrepreneurship and regional development projects.

Leonard H. Lynn is Professor at Case Western Reserve University. Author of two books and more than fifty academic articles, Lynn was a Fulbright research scholar at Tokyo University and a Visiting Professor at Hitotsubashi University. He is a former president of the Association of Japanese Business Studies, member of the American Advisory Committee of the Japan Foundation and the editorial boards of several journals, and a recipient of the International Association for the Management of Technology Research Excellence Award.

Takashi Murakoso is professor at the Department of Management Information, Faculty of Management, Fukuyama Heisei University, Japan and a board member of Japan Academy of Small Business Studies. His research focuses on small business in industrial agglomeration. He is the author of 'Venture Innovation of Small Business' (Chusho Kigyo no Bencha Inobeshon, published by Minerva, Shobo), and the co-author of 'Global Economy and Small Business' (in Japanese: Gurobaru Economi to Chusho Kigyo, published by Sekai Shisosha).

Klaus Ruth is Senior Research Associate with a sociology background at the University of Bremen and CEO of innovatop, a Munich-based centre for innovation research. His recent projects addressed inter- and intra-organizational cooperation during product innovation in Japanese engineering industries (1999/2000) and compared technology dissemination in Japan and the United States (2001/2002). His most current research activities focus on the role of immaterial resources in inter-organizational innovation networks.

Cornelia Storz is Professor of Japanese Economy at the Department of Economics at the University of Marburg, Germany and author and editor of numerous publications on the Japanese economy, focusing on institutional change and innovation systems. She is member of the Advisory Council for Japan/Korea of the German Asssociation of Asian Studies, and treasurer of the European Association for Japanese Studies (since 2005).

Hiroshi Ueno is Professor at the Faculty of Regional Promotion, Nara Prefectural University, Japan. He recently carried out a research on Japanese small business, the development of overseas production in Asia and small business networking. He has written numerous books including 'Japanese Small Business Today' (in Japanese: Gendai Nihon no Chusho Kigyo, published from Jisosha) and co-authored 'Inter-Business Relationship in Japan' (Nihon no Kigyokan Kankei, published by Chuo Keizai Sha). 


\title{
1 Small firms and innovation policy in Japan
}

\author{
An introduction ${ }^{1}$
}

Cornelia Storz

The Japanese innovation system is said to be outdated. The increase of international patents, international scientific citations or the positive technology trade balance all do not alter the fact that the Japanese innovation system has distinct weaknesses: it is weak in giving birth to radical innovations, and is strong only in giving birth to more incremental innovations. This weakness is perceived as problematic since it may hinder welfare in the long run: firms become routine entrepreneurs, unable to read the competitive environment, and simply unable to produce innovative ideas. Indeed, Japan lost markets of leading-edge technologies to the USA in the 1990s, such as biotechnology or information and communication technology. In leading international rankings, Japan is placed low, compared to other Organisation for Economic Co-operation and Development (OECD) members in the last years. One of the reports, which was especially sobering for Japan, was the Global Information Technology Report of the World Economic Forum of 2004, which placed Japan at no. 20, far behind the leading OECD members. Obviously, the estimation of the Japanese innovation system is not too high. The international pressure on Japan to generate original knowledge of its own and to take responsibility for the international community in the production of knowledge and technical progress gives additional incentives to reform the established innovation system.

It has been argued that the reason for the weakness of the Japanese innovation system lies in its institutional structure, which is adapted to the needs of a catch-up economy. Even if one admits that single companies bring out successful innovations in niche markets, the Japanese innovation system in general does not seem to be suitable for radical, risky innovations. On the micro level, the integral cooperation of research departments with production or marketing departments, the low degree of internationalization in research laboratories, the education towards generalists or the close and long-term relationships between buyers and suppliers are often identified as reasons for lacking the readiness to be more innovative. 


\section{Cornelia Storz}

On the macro level, the closed labour market, the underdeveloped capital market, an industrial policy neglecting the importance of more competition, and the low openness of and mobility between institutions are seen as central reasons for its distinct weaknesses (e.g. Anchordoguy 2000; Goto 2000). Formerly competitive advantages have obviously developed into competitive disadvantages since new technologies require other institutional settings, based on openness, competition and mobility.

All the critics are right in the point that these characteristics are decisive for the Japanese system, but they underestimate one important factor: the role of small and medium enterprises (SMEs) in the innovation process. In contrast to the USA, where a lot of the new industries' success in the 1990s can be traced back to an innovation system which gives SMEs a stronger role, in Japan, the institutional framework with its weak competition policy, its underdeveloped labour and capital market, and especially the weak institutional ties between universities and SMEs (whether start-ups or cooperations) were not suited for the generation of innovative ventures. Indeed, most of the mentioned elements of the catchup-state do not foster the increase of SMEs: education at universities is designed for generalists in large firms, but not for young start-up entrepreneurs; basic research takes place, but is not transferred into enterprises, and especially not into SMEs; the capital market is dominated by banks and venture capital is still scarce; the labour market gives no incentives for mobility and the exchange of knowledge. The political concepts and policy tools - tax credits and subsidies, research infrastructure, the intellectual property system, competition policy - showed a preference for cooperation, diffusion and risk-adversity, but not for the promotion of entrepreneurship until the 1990s. As for SMEs, Japanese SMEs can be characterized by their lasting integration into enterprise groups: almost every second SME in Japan is a supplier, the majority of them even work as exclusive suppliers, hardly diversifying their customers or generating products of their own. They are the core of the Japanese 'networkeconomy' with a distinct long-term orientation. Given this background it is not astonishing, that a Japanese 'Silicon Valley' is not in sight yet (Okada 1999; Hall 2002; Kawashima 2002).

The specific orientation of the Japanese innovation system can be assessed, in a pointed way, as being tragic: we learnt from institutional theory that single institutions are always interlinked and mutually complementary, both resulting in path dependence. For a true and successful change in one institution, it is therefore necessary to provide compatibility with the overall system of existing formal and informal rules. As this is tremendously difficult to accomplish, every single reform could even hamper the effectiveness of the whole system. This is the reason why 
system change is typically rigid and slow: the stability of existing institutions may lead to a low success in institutional transfers and 'best practice'-rules (Berkowitz et al. 2003). Certain authors surely recognize the openness of development - North (1997) already conceded that there are 'windows of opportunity' which make change possible - but especially in applied research, a certain determinism has gained a foothold, and a scepticism towards institutional change and the ability to implement successful reforms preponderates: Eggertsson (1998), for example, heads one of his works with the title 'Limits to Institutional Reforms', and other critical writers analyse the reasons for the reduced options for designed policy planning (Zysman 1994; Yarbrough and Yarbrough 1998). The problems of the transformation process in Eastern Europe were used as an illustrative example of how restricted the options for political reforms can be, and what role the complementarities of formal and informal institutions play (cf. Panther 1998; Schröder 1999). ${ }^{2}$ Several younger publications explain the restrictions on change in Japan and East Asia as resulting from complementarities between formal and informal institutions (compare e.g. Aoki and Hayami 2001; Pascha 2002; Storz 2002). The more the institutional settings differ, the more difficult the transfer will be:

But to recognize the superiority of one organizational mode of capitalism is not to say that it is an easy task to import, copy or assimilate its rationale and its institutions, by the very fact of their being specific to a society.

(Boyer and Hollingsworth 1997: 93)

In homogeneous groups, institutional change may take place even more slowly (Eisenberg 1999). If one classifies Japan as a relatively homogeneous culture, ${ }^{3}$ the persistence of established institutions can be considered as especially strong here. Indeed, younger works on Japan support the thesis of institutional path dependence, in relation to monetary or fiscal policy. As for the Japanese innovation system, complementarities can be found between research and marketing departments, the human resource system, the education of young, mouldable generalists, the diffusion orientation of property rights and the credit-based and risk-averse financial system. A change of the whole Japanese innovation system will require reforms in all sub elements - universities, enterprises, politics, capital and labour market. As a consequence, a change of one institution, whether formal or informal, necessitates the change of all institutions in which it is embedded: since the human resource department does not accept mobility, there is no incentive for individuals to change firms or to start an enterprise of their own. On the other hand, as re-employment is sanctioned by the decline in earnings, there are no mobile individuals and no incentives 


\section{Cornelia Storz}

for human resource departments to change established practices. Another example for mutual reciprocity is property rights. Changing the law would only make sense if legal decisions were governed by the idea that innovators indeed had rights which need to be protected, but this is obviously not the case. In other words, the problem of reforming the Japanese innovation system lies in its path dependencies, called knowledge regimes, trajectories, dominant designs or techno-economical paradigms in other contributions. These path dependencies work as a specific selection environment, which only includes or excludes the possibilities that suit the already existing institutional setting.

With the negative experience in developing and transforming countries, a certain tradition of perceiving chances for reform and leeway for action as utterly restricted, has been established. In this understanding, path dependencies of given institutional settings are often understood as a system to which actors have to adapt. Therefore, suitable formal (and informal) institutions become an important prerequisite for the development of nations. The influence of history and the resulting persisting difficulties of the transformation process in Eastern Europe give indeed enough reason to convince critics that the potential for political reforms is not as high as was assumed, and that it is wise to make the limits of planned design evident.

The authors in this volume support the thesis that the challenges for the Japanese innovation system are high because of path dependencies. But then they leave the widely spread scepticism and suggest another approach: they identify a high willingness to learn, which differs, depending on the field, but is nevertheless high, which can be demonstrated as well in the political as in the entrepreneurial area, and they stress the rationality of slowness of change which results from the complementarities in innovation systems. In cases where the results do not correspond with the expectations, the authors ask whether the expectations were appropriate: if change had taken place radically, single reforms could have been uncoordinated, which would have been even more problematic. Also they could have unleashed opposition since people have to invest in learning new rules, which presupposes an understanding of the necessity of reforms.

Which change, which learning took place in Japan at the interface of SMEs and innovation policy? ${ }^{4}$ On a political level, new targets were set in relevant political areas in order to make the Japanese innovation system fit for more radical innovations. This meant the establishment of new policy concepts, new policy tools and of new institutions that superseded the previous diffusion-oriented innovation system, which mainly targeted large firms. As far as the level of targets is concerned, this change can be described as a paradigm change ${ }^{5}$ : Japanese policy-makers today are 
moved by new underlying ideas, impelled by the incentive to leave Japan's position as a catch-up state and give up previous practices, such as the indiscriminate distribution of funds and the diffusion-oriented intellectual property system. They are eager to build up a more frame- and competitionoriented political framework, to professionalize and open up national research and technology institutes and to foster mobility between the single elements of the Japanese innovation system. In this new political concept, SMEs play a central role in the realization of innovation and economic growth.

Taking this approach, the authors want to diverge from the view that institutions and their complementarities are a given fact, but stress that it is more useful to understand institutions as entities that can be creatively designed, presupposing that there is a societal consensus on the need for reforms, and for appropriate incentives to lead the reforms into the right direction. This requires an understanding that reforms are needed, an open discourse about the necessity of change, a broad societal communication and the individual conviction that a need for action is given. From this viewpoint the preconditions for change are not suitable institutions to which actors have to adapt, but the insight that a change of institution may lead to increased benefits. If one takes this approach, new leeway for reforms and change emerges. Yet, without a consensus and the understanding that reforms are appropriate, no change is to be expected.

In order to answer the question to which degree and how institutional change takes place in the Japanese innovation system, the volume is divided into two main parts: the first part (Part I) analyses the shift in policy changes, the second part (Part II) the shift in entrepreneurial behaviour in SMEs in selected industries. Since a separation between the micro and the macro levels is necessary for the clearness of argumentation on the one hand, but both levels are closely interconnected on the other hand, the authors assembled here focus on one level in their argument, but try to consider the other as well.

Part I starts with general theoretical considerations on the options of political reforms. In his contribution, Lambert Koch (Chapter 2) shows that every policy-making process starts with cognition and communication: which state of affairs is perceived as a problem, and which state of affairs is recognized as a problem. This prephase of the political process is important, because it explains when and under what conditions political decisions can be really enforced. In cases where the problem is not perceived as a general problem which should be solved by the society, some groups will try to push through 'their' problem in later phases of policy making. Therefore political reforms require a sufficient societal 
consensus that the new policy is indeed beneficial. The following contributions take up this issue of policy formulation and discuss the change of the Japanese innovation system, partly in a comparative perspective with the USA. The contribution by Martin Hemmert (Chapter 3) discusses the policy shift in innovation policy in the 1990s. The shift took place in order to address the perceived weaknesses of the Japanese innovation system since, following the idea of Koch, the necessity to reform was recognized: the low volume of public R\&D spending, the previous focus on large firms (e.g. in research consortia), the traditional diffusion orientation and the low degree of openness (e.g. mobility on the labour market for researchers; internationality of research) on one side, and the clear success of the American system in new industries on the other side were obviously strong incentives for real adjustments. An important tool of the new political aim is the 'Science and Technology Basic Law' whose rigidity of enforcement is indeed striking: despite a harsh macroeconomic environment, the aim to increase R\&D (especially basic R\&D) spending was not given up. As a result, the intensity of public R\&D spending rose, a clear exception in the global trend of declining or stagnating R\&D intensities. One reason that is identified in the broad consensus in the Japanese society is that a change of the Japanese innovation system is necessary, which finds its expression from the fact that, in contrast to other law initiatives, the 'Science and Technology Basic Law' was enacted due to the initiative of a multiparty group of Diet members, which is highly unusual in Japan. The subsequent contribution by Klaus Ruth (Chapter 4) analyses a successful tool of the Japanese innovation policy, which was learnt the 'other way around', namely by the USA from Japan. The author analyses the policy tool of Japanese technology and research centres (kôsetsushi) in the national and regional innovation system (called industrial culture by him), the reasons for their previous success and their adaptation process in the American innovation system. This contribution is of special political interest because, first, the Japanese technology centres have worked quite successfully in Japan so that there should be an incentive to learn from Japan, and second, it gives a good illustration of mutual learning: the so-called MEP programme (Manufacturing Extension Partnership) can be interpreted as a successful institutional transfer from one cultural context into a very different one. In a broader sense, Ruth's contribution shows that the idea of path dependence and complementarity is helpful for understanding the adaptation processes, but that the difficulties of the transfer should not be overestimated as they can be overcome by entrepreneurial alertness.

While Hemmert and Ruth focus on policy changes in the Japanese innovation policy, the contribution by Cornelia Storz (Chapter 5) focuses on the new role of SMEs as innovators in the Japanese small firms policy. 
The perception of SMEs had been far from attributing them an important role in innovation in the past; in contrast, they were even seen as a problem for the welfare of the Japanese economy - coined in the specific Japanese expression of 'SME as a problem' (chûshô kigyô mondai). This explains why traditional innovation policy, as described before by Hemmert, had been focused on large firms: SMEs were just not perceived as being suitable candidates for policy tools conducive to innovation. Here again, the importance of cognitive models as described by Koch becomes visible. With the 1990s the perception of SMEs changed in Japan: the previous 'problem' became a 'problem-solver'. The relative slowness in the implementation of reforms is interpreted as being rational: it is argued that, in contrast to innovation policy and locally based SME policy, the need for action on the national level was only seen superficially, so that in the phase of policy formulation, the idea of 'weak' SMEs could be pushed through again. This stance is rational because first, the Japanese supplier system is relatively stable (comp. Ueno/Murakoso/Hirai in this volume), so that special policies directed towards smaller and weaker enterprises still make sense; second, a radical change may cause numerous liquidations and by this a macroeconomic instability; and third, a radical reform of small firms policy may be misguided if Japan's comparative strengths lie especially in the integrated assembling industry, and not in independent, radical innovations generating venture businesses. Storz therefore identifies a certain change, but not as radical as Hemmert did for innovation policy, resulting from different convictions towards reforms.

In Part II, the innovative potential of Japanese SMEs is discussed. The two contributions in this part focus on two industries with absolutely different strengths and weaknesses: the biotechnology industry, where Japan is said to have lost its competitiveness, and the assembling industry, where Japan is leading worldwide. The function and role of SMEs in the two industries can be described as being opposite. The authors of this part support the thesis that the Japanese innovation system possesses specific characteristics which are different from the American system, but they come to interesting conclusions concerning the assessment of the political and entrepreneurial leeway for action. Reiko Kishida and Leonard Lynn (Chapter 6) analyse SMEs in the biotechnology industry in Japan. The background to this contribution is that, up to the 1980 s, one believed that Japan would dominate the biotechnology industry, just as it headed the assembling industries before. However, in the 1990s it seemed that the American model, supporting university research and new business ventures, was more conducive to strength in biotechnology. Kishida and Lynn first qualify the position of Japan, as it is only weak in comparison to the USA, but not unusually weak in comparison to other OECD countries, 


\section{Cornelia Storz}

and second recommend a concentration on industries where Japan has natural comparative advantages, namely industries in which a complementarity to the existing innovation trajectory is given. A radical rebuilding of the Japanese innovation system would be misguided from this point of view. The authors acknowledge the concept of path dependence and the characteristics of the Japanese innovation system (including exclusive labour markets), but are not so sceptical about the inherent strengths of the Japanese innovation system, since they accentuate the varieties and learning options existing in established paths. The contribution of Hiroshi Ueno, Takashi Murakoso and Takumi Hirai (Chapter 7) discusses the leading role of SMEs in the assembling industry. They analyse the changes taking place in the Japanese supplier system which necessitate a policy shift from a policy which aimed at adjusting the small size of enterprises to larger entities by promoting cooperation and cartels, to an entrepreneurship policy which takes the specific comparative advantages of SMEs and the possible innovative potential into consideration. The disintegration of the traditional vertical enterprise groups 'automatically' led to a greater independence for smaller firms and to the necessity of strengthening their innovation potential. The question is how the Japanese industrial organization is suited for such radical changes, or whether it would not be more helpful for its competitive strength to only revise the system. They show that especially on the local level new forms of learning are taking place, for example, research-intensive cooperation between government and SMEs, which is, in the Japanese context, highly innovative.

Debating changes in innovation policy in Japan and the attempts to secure a stronger and more innovative role for SMEs, the authors of this volume come to the conclusion that institutional barriers to change indeed exist - in their weight dependent on the functional subject - but overall they are positive in their estimation of Japan's competitiveness. The volume thus has three important results: first, the harsh assessment of the Japanese innovation system seems to be misguided; second, suggestions for radical change have to be encountered carefully; and third, learning potentials in given paths should not be underestimated. Therefore the problem is not that institutions are a given fact, but that a certain combination of explaining factors may explain certain developments, as the superiority of certain institutions, whereas opposite developments exist as well. It is important to identify these approaches since they only affirm already existing prejudices, and it will then not be possible to understand other modes of development. We hope that this volume contributes to a better understanding of how policy changes take place and how new policies and new roles assigned for SMEs result in innovation in Japan. 


\section{Notes}

1 The editor of the book led a research project on technology dissemination policy in Japan and the USA which was financed by the German Federal Ministry of Education and Research. Technology transfer centres and the transfer of their concept to the USA were the main focus of the project. The project was further supported by the University of Applied Science of Bremen.

2 Leipold (1997: 64) writes that because of the necessity of reform policy to take effect on all levels, there are no prospects for quick success of reforms in Russia.

3 Important foreign culture influences, which lead to disruptures in Japan, are not denied with this statement (cf. Storz 2002).

4 Innovation policy and SME policy takes place mainly in a framework and rulesoriented policy (e.g. property rights (esp. patents), enforcement of competition) and in a more regulative approach, aiming especially at adjusting market failures (e.g. infrastructure, public subsidies, regulation). The authors in this volume refer to different areas. It should be mentioned that the Japanese policy shift is not to be understood as a singular development, but has to be understood against the background of an international shift to entrepreneurship policy (comp. e.g. OECD 2000).

5 According to Hall (1993), the new setting of targets can be described as a paradigm change when it is accompanied by new instruments and new political objectives. A paradigm change means a radical break with the setting of instruments, with the instruments themselves, and with the hierarchy of political objectives.

\section{Bibliography}

Anchordoguy, M. (2000) 'Japan's Software Industry: A Failure of Institutions', Research Policy, Vol. 29: 391-408.

Aoki, M. and Hayami, Y. (2001) 'Introduction: Communities and Markets in Economic Development', in M. Aoki and Y. Masahiko (eds) Communities and Markets in Economic Development, Oxford: Oxford University Press, 15-24.

Berkowitz, D., Pistor, K. and Richard, J.-F. (2003) 'Economic Development, Legality, and the Transplant Effect, European Economic Review, Vol. 47, No. 1: 165-195.

Boyer, R. and Hollingsworth, R. (1997) 'From National Embeddedness to Spatial and Institutional Nestedness', in R. Boyer and R. Hollingsworth (eds) Contemporary Capitalism. The Embeddedness of Institutions, Cambridge: Cambridge University Press (Cambridge Studies in Comparative Politics), 433-484.

Eggertsson, T. (1998) 'Limits to Institutional Reforms', Scandinavian Journal of Economics, Vol. 100, No. 1: 335-357.

Eisenberg, A. (1999): 'Die Lösungen sozialer Dilemmata und der Wandel informeller Institutionen', Diskussionsbeitrag Nr. 04-99, Jena, Max-Planck-Institut zur Erforschung von Wirtschaftssystemen.

Goto, A. (2000) 'Japan's National Innovation System: Current Status and Problems', Oxford Review of Economic Policy, Vol. 16, No. 2: 103-113.

Hall, B.H. (2002) 'The Assessment: Technology Policy', Oxford Review of Economic Policy, Vol. 18, No. 1: 1-9.

Hall, P.A. (1993) 'Policy Paradigms, Social Learning, and the State', Comparative Politics, Vol. 25, No. 3: 275-296.

Kawashima, M. (2002) 'Waga kuni ni okeru kokunai gijutsu iten seisaku to shokadai', Ritsumeikan Keieigaku, Vol. 41, No. 4: 93-114. 
Leipold, H. (1997) 'Der Zusammenhang zwischen gewachsener und gesetzter Ordnung: Einige Lehren aus den postsozialistischen Reformerfahrungen', in D. Cassel (ed.) Institutionelle Probleme der Systemtransformation, Berlin: Duncker \& Humblot, 43-68.

North, D.C. (1997) 'The Contribution of the New Institutional Economics to an Understanding of the Transition Problem', UNU World Institute for Development Economics Research (UNU/WIDER), Working Paper, WIDER Annual Lectures 1, Helsinki.

OECD (2000) Small and Medium Enterpise Outlook, 2000 Edition, Paris: OECD.

Okada, Y. (ed.) (1999) Japan's Industrial Technology Development. The Role of Cooperative Learning and Institutions, Tokyo: Springer.

Panther, S. (1998) 'Historisches Erbe und Transformation', in G. Wegner and J. Wieland (eds) Formelle und informelle Institutionen: Genese, Interaktion und Wandel, Marburg: Metropolis, 211-252.

Pascha, W. (2002) 'Wirtschaftspolitische Reformen in Japan - Kultur als Hemmschuh?', in Duisburger Arbeitspapiere Ostasienwissenschaften, No. 44, Institut für Ostasienwissenschaften: Universität Duisburg-Essen.

Schröder, R. (1999) Konfliktbewältigung, soziokulturelles Erbe und wirtschaftlicher Fortschritt. Zu den unterschiedlichen Entwicklungserfolgen der Länder Ostasiens, Afrikas und Lateinamerikas, Tübingen: Mohr Siebeck.

Storz, C. (2002) 'Zum Wandel der japanischen Unternehmensorganisation Innovationsfähigkeit zwischen Diskontinuität und Stabilität', ORDO - Jahrbuch für die Ordnung von Wirtschaft und Gesellschaft, 53: 299-328.

Yarbrough, B.V. and Yarbrough, R.M. (1998) 'Unification and Secession: Group Size and "Escape from Lock-in", Kyklos, Vol. 51, No. 2: 171-195.

Zysman, J. (1994) 'How Institutions Create Historically Rooted Trajectories of Growth', Industrial and Corporate Change, Vol. 3, No. 1: 243-283. 


\section{Part I}

\section{Shift in policy changes}





\title{
2 How do we formulate policies?
}

\section{The problem of defining policies and their evaluation}

\author{
Lambert T. Koch
}

\section{Initial thoughts}

The aim of this chapter is to understand and analyze policy, economic policy in particular, as an evolutionary process. Agents in this process are by no means only those who are in the public eye perceived as responsible parties for policy and decision-making. Every policy has its roots beyond the official political structures, in areas where there is 'private' dissatisfaction, where there is a need for action, where this kind of perception is shared with others, where potential policy content is defined and, finally, where critical masses, which can generate pressure for policy action, are created.

The view of the policy-making process proposed here, goes beyond traditional approaches by emphasizing the relevance of cognition and communication. It moves away from the implicit idea currently prevailing, even in well-informed circles, that there are 'born' state tasks, 'right' packages of measures to implement 'objective' aims and scientific methods to find out what 'good' policies are. The basic credo of an evolutionary theory of economic policy is to see policy as a product of communicated, related perceptions (cf. Hodgson 2001: 279ff., for a more general perspective). These perceptions - which influence evaluations of policy conditions, formulation of objectives and packages of measures - are themselves transformed by the results of running political processes.

This doubly recursive structure leads to innovations, giving the phenomenon its evolutionary character. ${ }^{1}$ With each change in perception, the scenario of incentives to implement creative and rational adjustments also changes - on the one hand on the part of the political decisionmakers, on the other hand on the part of those affected by policy. If, for example, measures to fight mass unemployment in a country are perceived as being increasingly ineffective, over time opposition to this policy will grow. The result is increased motivation on the part of politicians, afraid 


\section{Lambert T. Koch}

of losing the next election to create new solutions to the problems and to make sure these are implemented in spite of various obstacles. From the perspective of politics this implies not only a continuous political innovation process but also a policy for innovation in the economy and in favour of those who are considered to be promoters of innovation and employment. Hence a policy that regards the special requirements of small and medium enterprises (SMEs), clearly a primary source of innovation, has to be considered as most important.

Accordingly and in turn, processes of innovation are not only relevant to politicians and politics; they are also essential to strategic management and strategic processes within enterprises. Again, the cognitive abilities and imprint of those acting strategically on behalf of an economic entity are especially liable for the success and innovativeness of their respective institution.

Today, the media play a decisive role in the assessment of initial situations as well as in the evaluation of corresponding (new) approaches to solving problems (cf. Luhmann 2000). They accelerate the process of finding areas of dissatisfaction among citizens, they strengthen interest groups, increase the pressure for action on the decision-makers, thus representing both an instrument and potential threat to these people, they supply alternative interpretations of political answers and thereby increase the possibility to react between impulses from the political basis on the one hand and those of action-takers on the other hand. With a view to the overall theme of this chapter, the interesting point here is how, in the process of a worldwide media-supported intensification of information and communication, political paradigms which have dominated for many years can be rendered obsolete and apparently effortlessly replaced by new ones. It would seem as if the relative sluggishness of informal and formal institutions is reduced in this process.

These preliminary thoughts should make clear that the evolutionary policy approach to be presented in part in the following chapter is in many ways inter-disciplinary. For example, it takes up criticism that was already expressed as far back as Albert in his time: he proposed that older ideas of economic policy-making had a tendency towards being instrumentally technocratic and that this tendency should be accompanied by exaggerated ideas of feasibility (cf. Albert 1977). Therefore this chapter will deal with a methodological foundation, called for by Albert and others, with the consequence of endogenising and to a certain extent of 'depriving' democratically legitimized (economic) policy of its power. This is demonstrated in the course of the argumentation, when the process of economic policy-making is analysed from a relativistic perspective, which is constitutive for the evolutionary economics thought. This also allows to integrate older lines of argument into this process, such as von Hayek's 
knowledge debate (cf. von Hayek 1983) or Simon's rationality discussion (cf. Simon 1955) as well as public choice theory and institutional economics at a later stage.

\section{On the basic assumptions of economic policy from a constructivism perspective}

Those who recognize the individual actor as the basic unit and point of departure for all economic action in the sense of methodological individualism, will not be able to avoid first dealing with the conditions of human perception and action in any analysis of economic policy phenomena. ${ }^{2}$ This 'relative nature' mainly takes concrete form in the epistemological restrictions of the make-up of the human perceptive apparatus. It is the brain that provides the action-taker, and thus also all those participating in the process of economic policy-making, with access to an outside world, however this world may be characterized. How the latter functions and what consequences it has is the theme of modern cognitive science. ${ }^{3}$

In tune with mainstream ideas, initially, a departure from the idea of a passive, externally determined perception of the environment can be recognized. Today, it is normally considered as proven that our brain, which processes environmental stimuli, links these external impulses with already existing cognitive structures in an actively constructive way. ${ }^{4}$ Every piece of incoming information that is absorbed receives its specific identity in our brain and mechanisms such as perception, inference, attribution and memory, in particular, act as mental operations. ${ }^{5}$ Cognitive psychology provided sound theoretical and empirical proof of these contexts as early as the 1960s and 1970s (cf. Neisser 1976) and this later provided strong support for the development of an approach which was to become known as cognitive constructivism. The following ideas in this chapter are based on this approach, which is present in almost all areas of contemporary psychology (for an overview cf. Nüse 1995). In this epistemological model, it is important to understand cognition also as discovery and invention, without having to commit oneself to a decision as to which parts of human perception actually provide information about the existence of an outside, subject-independent world. Without negating the idea of a 'neutral' environment, there is an unavoidable aura of uncertainty surrounding any statements made about it (cf. Vinden and Astington 2000).

The main general consequences which result from the integration of these contexts into an analysis of economic policy can be outlined in three points: in the first place, the idea of 'information' as the basic variable of planning in economic policy needs to be rethought. Here, the basic significance of information within this process is not being questioned, 
however a modification of the way information is understood is required. Modern cognitive sciences clearly prove that information about facts does not exist independently of individuals and thus cannot simply be passed on to others. Information in the actual sense of the word is created at the moment of reception of external signals in the apparatus of human perception. Thus, in the context of economic policy, the prevailing conditions of this genesis or transformation of information need to be investigated more intensively. Information transformation and transfer can be taken as phenomena which belong together and it is of particular importance to realize that each piece of transferred information gains a new identity in the act of being transferred. The main question to be looked at here is which factors, either intended or non-intended, influence the process of gaining meaning.

Then it should be pointed out that, second, these aspects throw a different light on the problem of forecasting, both at a scientific and an economic policy level. In information transformation the way our perceptive apparatus functions seems to hinder any use of transformation rules. Research into perceptive physiology has proved that the brain works in a kind of temporal rhythm, always combining several physiological events into one perception, then to be replaced autonomously or spontaneously by another. Here the content of a later perception can be changed, even if there has been no change in the sensory data (for an extensive description see Oeser 1987; Pöppel 1988). All of a sudden, completely new interpretations of situations can be created, which may then lead to very unexpected and new reactions. ${ }^{6}$ This means ceteris paribus, that it is for purely cognitive reasons that the possibilities of forecasting economic, social and political cycles decrease with increasing complexity of information networking in a society and between societies (globalization), especially as there are basic difficulties in connection with the attempt to observe and evaluate internal personal processes (cf. Little 1972; Nisbett and Ross 1980; Witt 1992).

Third, another consequence of integrating perception and cognition theories into the formation of a theory on economic policy originates from the central idea that no economic subject thinks, plans and acts against the background of an objective reality, but rather always within the framework of its own subjective reality which only experiences a partial comparison with other individual 'realities' via an act of communication. On the one hand 'cognitive maps' play a role here, a concept which will be dealt with in more detail later. On the other hand, the function of social interaction as a reality shaper comes into play. Living together in a society and economic policy is therefore conceivable only if, at least in certain areas, common relevant realities are created by way of communication as described by Berger and Luckmann (1979). This means that, from a cognitive-evolutionary perspective, social communication has a much 
more important function than merely the exchange of information, if we understand the term 'information' here in the traditional, more technical sense (cf. Habermas 1984). Acceptance of new information and its diffusion into society is thus an effect of society-specific communication structures and habits. In turn, the (political) reaction to such information and the dynamics of political decision-making according to it depend on these rules of communication. Societies like the Japanese, as it is analysed in this book, are orientated towards consensus and are therefore in need of thorough communication. Before any action taking is possible, promoters of change are likely to rely on slow or piece-meal decision processes (Introduction in this book) in order to achieve the necessary social acceptance of new information and thus of new developments or circumstances. ${ }^{7}$

For an initial summary the following should be kept in mind: an evolutionary theory of economic policy that attempts to understand real policy formulations on the basis of the previously occurring construction process of this 'econo-political reality', should differentiate between two levels of thought. On an individual level the creation of individual information is in the foreground, that is, subjective boundary conditions of the genesis of very specific construct. On a collective level, on the other hand, it has to be found out whether individual impulses spread out in the social environment and how they can thus make a contribution to the formulation and evaluation of economic policy.

\section{On the evolution of content in economic policy}

Following the ideas presented in the last section, this section will first separately address the two levels of identifying econo-political reality. Here, to a certain extent analogously with evolutionary biology, logic of variation or selection will be identified. On the individual level the question is why, of all incoming sensory stimuli, some are always selected from a complex variety and, as initial perception, influence the individual's own subsequent perceptions, so that an unmistakeable path-dependent reality is created for each individual. On the collective level, on the other hand, the interesting aspect is how certain interpretations prevail - at least temporarily - when alternative realities meet, and how they gain influence on the political communication process.

\section{Variation/selection processes on the individual level}

As an aid for the investigation into the individual level, the concept of 'cognitive maps' will be addressed here. This concept, the development of which is linked to Piaget's work (1987), combines the above-mentioned concepts with a series of sub-phenomena in information processing which have not yet been addressed. For example, an important point is that 
cognitive maps are highly selective, meaning that pieces of knowledge are linked within them under the same label in the form of terms for characteristics, prototypes, limiting cases and examples. ${ }^{8}$ Parallel to this socalled, tacit knowledge is arranged knowledge, which is constantly being developed and applied, thus changing in action and at the same time influencing the human ability to act without the agent himself or an external observer being able to systematically describe its structure (for an application-based overview see, for example, Hirschfeld et al. 1994). In any cognition and memory process, cognitive maps, which help master the complex range of sensory stimuli, play a central role: they form the framework, so to say, into which newly constructed information is inserted, to then be complemented by already organized pieces of knowledge (cf. Eysenck 1984: 324). Thus a referential network is created within which experiences are condensed into patterns, which themselves then shape experiences. All evaluations, expectations, plans and decisions made by agents are based on this interdependent linkage of present and past cognitions (cf. Koch 1996). All economic subjects, whatever role they may be playing at any moment in the process of economic policy, are affected by this subjective pre-structuring of perception. Politicians, bureaucrats or voters, members of whatever social class, the old or the young: in their reception of information, events and complex situations all are subject to the biological restriction of only being able to perceive what their brains offer them on the basis of their personal (stored) 'history'.

In contrast to the concept of 'bounded rationality', the concept of 'cognitive maps ${ }^{10}$ thus emphasizes not so much the lack of quantity in information gathering as the unavoidability of path-dependent quality changes in the reception of information. In addition it has been shown that the process of variation and selection taking place in the perceptive apparatus can only be indirectly influenced by perceptive content. This happens when the focused reception of knowledge and the effort to gain experience in a certain area change the basic content which is selectively relevant in the construction process. A relevant example here would be reading a book on technology and innovation policy and possible economic implications.

A further decisive sub-phenomenon in the process of cognition-led action is the creation of intentionality. Going backwards from the already structured econo-political situation, one point of reference is the idea of the econo-political problem whose roots are in the perception of contradictions in the subjective area. If there are such considerable contradictions to the previous subjective 'reality' in an individual perceptive situation in the face of certain 'information conditions', these cognitive dissonances can at the same time awaken the wish to reduce them. How strong the stimulus is, depends on the estimation of the expected costs and benefits of corresponding activities. ${ }^{11}$ The costs can 
be, for example, to analytically structure and then to communicate the initially subjectively defined problem (e.g. in discussions or publications), they can express themselves in altered choice behaviour and they can (this option involves the highest costs) imply triggering off activity in citizens initiatives, parties or government authorities. 'Information conditions' in which cognitive dissonance occurs can on the one hand be newly created. However, they can also remain unchanged and the ambiguity solely results from a recombination of established consciousness content which is produced by the apparatus of perception (cf. Pöppel 1988). While the latter possibility can occur at any time, the reception of new target parameters (e.g. ideas or values) or new knowledge about actual parameters (causal contexts and restrictions) must be added for the former - for example, by reading the above-mentioned book.

As already indicated, the discussion so far implies an altered image of the agents in the political process. Initially, we have the politician in mind as the economic policy-maker, but the assumption of the ubiquitous influence of cognitive maps emphasizes that any idea of an exogenous controller having a complete catalogue of assumptions about the behaviour of agents in a system, is doomed to failure. His perception and his resulting behaviour are rather inseparably and reflexively coupled with the specific social context which he is a part of. Every economic politician is himself 'just' an endogenous variable in the model of economic policy (cf. Witt 1992: 119ff.). In the process of changing cognition, knowledge components and evaluations, his own cognitive maps are just as inconsistent as those of any other individual agent, so that in principle no 'objective' decision-making field can exist in the area of economic policy (cf. Scherer et al. 1988: 803ff.; Eggertsson 1997: 1189).

Regarding the group of voters, there are important conclusions to be drawn from the point of view of cognitive science, which are complementary to corresponding reflections in political economics: in the case of democratic votes on agents and programmes in economic policy, for example, it must seem obsolete to look for voting procedures which could represent an 'objective' portrayal of voters' preferences. Also the idea of the 'voters' mandate', which is often diagnosed is nothing more than a point-in-time-based open structure which changes its importance in a continuous process of reflexive interpretation of reality. ${ }^{12}$ Each elected person interprets the 'voters' mandate' just as contextually as the voter evaluates the information available to him concerning a social situation. ${ }^{13}$ Voters and the elected will change their ideas of target and performance mutually dependent on each other in the course of a legislative period and will thus also alter their interpretation of problem situations, leading to a co-evolution of relevant decision-making fields. This clearly shows why an evolutionary understanding of economic policy is supported here and, 
at the same time, leads to the analysis of the collective level of the process of economic policy-making.

\section{Variation/selection processes on a collective level}

Here, the question needs to be dealt with as to which kinds of subjectively perceived discontent (problem variation) - for example, if faced with an expected under-supply of certain public goods - actually end up becoming a problem of economic policy (problem selection). To explain this, the constitutive function of interaction and communication for societies needs to be examined (cf. Blume and Durlauf 2001). When individuals take up contact with each other, they 'automatically' alter the reality for the person they are interacting with. They observe reactions to their own actions and, if necessary, conceptualize recurrent new experiences together with previous knowledge as cause-effect relationships in new variations or cognitive maps. The fact that in this situation each individual acts according to his own, subjective, schematically coded expectations, aims and purposes is also termed 'double contingency'. As we can assume that within social communities the subjective realities of interactive partners are at least partly synreferential in advance, agents can also always work towards orienting the cognitive area of others towards a certain object (cf. Rusch 1994: 63). This point represents an important interface where it is decided whether individually perceived problems ever become intersubjective or societal problems at a certain point in time.

Here the mobilization resources of individual economic subjects play a decisive role and there is a wide range of possibilities: first, it depends on the strength of the intrinsic potential, that is, on the degree of subjectivelyperceived dissatisfaction and on the will to mobilize. Second, there must be sufficient mobilization abilities such as the correct selection of communication partners and the necessary argumentation skills. Here the social position taken on by the mobiliser is important, as well as the economic and/or political resources and power potential available to him and the experience already made with him in similar situations in the past. When the spark of problem perception jumps from the individual level to the collective level, a problem subsequently gains a new piece of identity with each further communication step, that is, its quality by no means remains constant during the diffusion process, nor is there any guarantee that every person concerned will interpret a communicated problem in a similar way. Here the complexity of the subject matter and the quality of the communication process play an essential role. 'The more successful orientation interactions there are and the more reliable they are, the stronger will the agents be convinced of the common and equal nature of reality' (cf. Rusch 1994: 71). In other words, depending on the situation, 
there can be a homogenization of how people interpret reality and problems. Whether a problem which is perceived and discussed in parts of society actually becomes an issue in economic policy depends, in essence, on this homogenization process. The more homogenous the perception of a certain economic target/performance discrepancy and the larger and more powerful the dissatisfied group, the higher the probability, all else being equal, that the problem will be admitted to the political level. In spite of this, no generally valid if-then criteria can be derived for this step. Historical constellations play a role which needs to be evaluated according to what kind of macroeconomic situation a society is in, what other problems are on the issues list and how urgent they are, and thus what problem perception and problem treatment capacities are still available at that point in time (cf. Meier and Slembeck 1994: 75). An additional, very important point to consider is what institutionally dictated mechanisms facilitate or how they impede the problem being admitted to the political level (e.g. constitutional requirements for referendum petitions) - a question which will not be dealt with further here. But even if a certain degree of homogeneity is necessary as a kind of minimum 'critical value' for admitting a problem to the level of economic policy, the relativity of this context must be considered. The reason is that in increasingly intransparent, pluralistic and multicultural societies, it will become generally more difficult to install homogenous, powerful interpretations of problems which are at the same time stable in time and content.

With the acceleration of technological progress and the global diffusion of knowledge (decreasing 'knowledge half-life'), as well as the internationalization of the economic and inter-jurisdictional competition that goes with it (cf. Vanberg 2000), the relevant problem areas and at the same time the interpretation of individual problem areas are fanning out more and more. However, the more heterogeneous the prevailing and competing realities are, the more difficult it is, all else being equal, to make any qualified statement on the course of problem admittance processes and thus projections about future developments in the process of economic policy as a whole. As a result of this development, one thing is becoming more and more important: to what extent are initially alien problem areas and interpretations of problems communicated to the other groups in a society in order to create a pool of relevant information in common knowledge (intended reduction of ambiguity)? From the perspective proposed here, such a pool seems to be a condition sine qua non for constructive socio-political discussion on the solution of problems which come up. To a certain extent it combats a 'de-rationalization' of the process of economic policy-making. In accordance with this, the economic policymaking process would be 'rational' in a sense that what is being communicated about it is also what every individual concerned understands as 


\section{Lambert T. Koch}

being what the sender wants to express; therefore, the more intensively a theme-based process of mutual orientation gets going, the higher the probability that a problem recognized by many will later be treated 'correctly' or 'rationally' - in the view of many.

Now, a closer look will be taken at the mechanisms and patterns which play a role in the process of problem diffusion in economic policy. This includes, above all, the observation that cost-benefit relations which economic agents are confronted with, if they want to spread an individual view of a problem, are highly dependent on the established communication structures within a society. These form the 'resonance space' in which problem interpretations have to prove themselves (cf. Siegenthaler 1994: 177ff.). Here, communication structures should be understood as the total number of valid possibilities and limits of communication between economic subjects in a society. In the modern 'information economy', the various media are of particular importance (cf. Löffelholz and Altmeppen 1994). They do not simply function as 'neutral' communication channels (information transfer); they rather play a decisive controlling role in problem origination processes by spreading new possibilities for interpretation (information transformation). The abstract object of public opinion as an obstacle or selector for individual models and interpretations is, to a great extent, a product of the media. A careful evaluation of public opinion can show individuals or groups of agents what costs of mobilization and thus what level of material and personal resources are to be expected to ensure that a problem actually becomes an issue in economic policy (cf. Kuran 1995). Here, it can be shown that the problems by no means always originate in the same way. Ideally, there are two basic patterns. ${ }^{14}$

The first one, the bottom up formation of opinion, represents the 'ideal democratic situation': a problem is perceived relatively homogeneously by a group of individuals, and potential supporters - that is, interest groups, governments and parliamentarians - have to be 'triggered into action' by the basis. The extensive overlapping of individual cognitive maps, which is necessary in advance of this, means that this type seldom occurs in its purest form, especially considering the fact that there are many structural obstacles which can have an effect. Of particular importance is the fact that, as a rule, the so-called agenda setters are indispensable, that is, those who take a problem and make it a political issue, whereby the mobilization of effective media is potentially very 'expensive' in this case.

Therefore, second, a large part of the formation of opinion in society is a more top-down situation, that is, it is triggered by influential agents. For politicians and representatives of powerful interest groups - for example trade union functionaries - the access to relevant publicity channels and the focused influence on public opinion that goes with it, mostly incurs 
relatively low transaction costs. ${ }^{15}$ 'They have capacity available to them to ensure a media-friendly processing of issues and therefore enjoy good access to the mass media' (Meier and Mettler 1988: 41). Thus it is relatively easy for them to produce certain problems or interpretations of problems in a focused way, that is, to choose the right moment in time, in order to instrumentalize them in the process of economic policy-making. This can be observed in the discussion about a potential involvement of the German army in a possible war in the gulf region at the moment.

Now, an important role is played by the question as to what events or constellations kick off a problem process and in which economic, social and political context. If there is latent discontent, which has been predominant in a larger social group for a long time, the course of problem diffusion will be different than if only a small peripheral societal group sees need for econo-political action on a certain issue. Based on a categorization in Bennett (1980: 113ff.), various categories of initiation of econo-political problems can be differentiated according to the number of people affected and the extent to which they are affected (cf. Meier and Slembeck 1994: 68ff.).

In this context, one can speak of an interest group problem if only a minority in society is affected, but this minority organizes itself formally on the basis of the high willingness to pay, shown by the individuals concerned. On the basis of the German coal problem in the Ruhr area, the cognitive determinants which are relevant here become clear: normally this concerns groups of economic subjects whose individual realities have a high level of synreferentiality in advance, as they have economic (industry, profession etc.), social (class, ethnicity etc.) and/or geographical (estate community etc.) features in common. This means that the costly setting up of functioning communication structures and the spread of common interpretations of reality are rendered superfluous. In case of structural problems, however, there are a large number of affected agents, but the individual is affected to a lesser degree. Even if the motivation to form a formal organization is weaker for this reason, this type of problem triggering is still just as significant as the former one. To go back to the introduction of the euro, for example, the political significance associated with it becomes clear. In the run-up to the Bundestag elections in 1998, the election campaign strategists of the largest German parties saw an above-average level of uncertainty concerning this issue. From a cognitive-evolutionary point of view, the reason for this was that in the course of the currency debate, each potential voter had an opinion, but these opinions were based on completely different backgrounds concerning knowledge, experience and interest. As a result, it seemed dangerous to commit to a certain strategy at too early a stage, as public opinion was extremely unstable under the given circumstances. Only the latter of the 


\section{Lambert T. Koch}

ideal types of elite and crisis problems, which are less frequent in reality, will be addressed here as this is a particularly interesting phenomenon for the context under discussion. A chaotic situation is characteristic, after which a coincidental individual event can very quickly completely change the societal assessment of the situation and thus also the relevance of possible previously existing problems (interest group, structure or elite problems) (cf. Kuran 1995). For example, taking a look at public reaction to a media-effective accident at a chemical production plant, extremely intense 'avalanche-like' protest can be observed in certain cases - especially if there have been no similar accidents in the recent past. It may even happen that all chemical production plants in a country become time bombs in public opinion. The decisive consideration here is that the suddenly altered assessment of the situation can lead to huge pressure on political agents. A social problem is 'born', which results in a political necessity to immediately formulate and implement new aims for a certain area which has been at most a peripheral issue for a long time as regards social interest. It is obvious what kind of economic consequences such coincidental individual events can have, for example, for a whole industry. From a cognitive-evolutionary point of view, the interesting aspect to such an example is that in certain cases the homogenization of cognitive maps can take place very quickly and unpredictably. When a large majority has swung towards a certain view of reality, decisions can be taken which would never have had a chance of implementation in the past. This is also an aspect which again makes the significance of the factors 'coincidence', evolutionary self-dynamics and path dependency very clear for the results of the process of economic policy.

\section{On the evaluation of econo-political action}

So far the genesis and formulation of economic policy have been emphasized and there are methodological reasons for this, which stress the separation of the origin of problems and their treatment. However, in reality, both phases in the policy-making process overlap. As policy is already 'underway' at any point in time of observation, the variation/ selection processes on the individual and collective levels are also influenced by the perception of previous steering efforts. This is just one reason why a prejudice-free evaluation of current measures never takes place.

In this context it would not be right to claim that evolutionary processes of policy formulation have evolutionistic characteristics. This would mean, assuming a positive selection which would regularly bring policy onto the right path, that it would prove itself most suitable 'overall' as opposed to other alternatives. However, the fact is that in an evolutionary world, society's evaluation of centralized steering efforts must always be 
seen as competition in itself (cf. Breton 1998). In this competitive situation, evaluations can dominate for a certain period, maybe because the political decision-makers provide a ready-made evaluation to stabilize their power. Here it is possible that a selection of 'independent' expert consultants, evaluators or research institutes has an influence on the result of the analytical task. Furthermore, the way the problem develops plays a role here. If it is a crisis situation, there is often temporary dominance of one or a small number of motives. This results in the fact that packages of measures, which were previously rejected, suddenly seem to become suitable, for example, due to a series of undesired side and remote effects.

For example, after 11 September, 2001, safety policy measures in domestic and foreign policy were judged to be 'good' solutions by the broader population, who, only a few weeks earlier would have criticized such measures as causing unacceptable damage to their freedom as State citizens. Similarly, in Japan and other countries, economic crises which led to bankruptcy and mass redundancy resulted in a call for supply-side policy measures, regulatory reforms and an intensification of innovation and entrepreneurship (e.g. Boltho and Corbett 2000; Matsuba 2001). Here it is obvious that the enhanced status of one ideology reduces the status of competing models.

This means that economic policy and politics in general are - to a certain extent - subject to the laws of Schumpeterian competition, that motivates the creation of the new and rejection of what seems to be proven. Here, there are wave movements of different lengths, analogue to economic phenomena. Considering this, the replacement of one paradigm by another must appear as a comparatively long-term phenomenon. It took years for all executive bodies in Germany to move away from Keynesian demand-side policy. Political growth cycles are, on the other hand, shortterm wave movements. Determined by legislative periods, policy tendencies in this area change on a regular basis, for example, after elections have been won, savings policies are replaced by generous spending gifts in order to win support before the next vote (e.g. Frey 1983).

The shortest and at the same time most irregular fluctuations in policy take place, of course, in the almost omnipresent political competition. This even happens when a problem has long been recognized by politics and its treatment is already in full swing. Here too, current power constellations play an important role. Individuals and groups will continuously attempt to change the perception of a problem on the part of the decision-makers to their own benefit. Here, there are many different formal and informal options of problem treatment on various decision levels, depending on the specific structure of the political system. For example, it is well known that preventive measures taken against the State's abuse of power in the more recent constitutional democracies 
('checks and balances'), result in many veto and influence possibilities, which do not exist in other systems. However, there are also considerable differences between the various forms of democracy. For example, the British Westminster model or its New Zealand offshoot enable a determined head of government or an ideologically homogenous 'policy conspiracy' to act much faster on the basis of their own interpretation of a problem than is possible in corporatist systems (cf. Wallis 1997).

It should not be forgotten that, regardless of to what extent they can influence and affect the situation, agents will attempt up to the last to use all their power, resources and powers of persuasion in order to ensure the success of their own interpretation of a problem and normally also the implementation of their own solution model. This continuous competition between alternative interpretations means that the observer is constantly being offered numerous - prima facie unsystematic or even seemingly contradictory - partial interpretations of the process of economic policy. Such apparent 'irrationalities' can be observed in particular when very different reality models are almost forcibly combined into one perspective in the problem treatment phase. The reason is that certain aims are formulated and certain measures are chosen from this political reality, solely due to the fact that this 'artificial' current perspective spreads very definite causalities - even if the latter often seem very unsuitable to the external observer (cf. Luhmann 1989).

In the background there is an important basic assumption which motivates the political process. This assumption aims at overcoming societal conflicts which hinder action by taking the wide variety of individual realities into consideration. ${ }^{16}$ So it is no surprise from a theoretical point of view that in this hither and thither of competing ideas about econo-political cause-effect contexts, chains of action are created which are difficult to comprehend taken at face value. Furthermore, a cognitive-evolutionary approach lends credibility to the assumption that the idea which could be labelled systematic 'muddling through' (cf. Lindblom 1959: 79ff.) is not a contradiction in itself. It should be much more the rule in economic policy - at least in a democratic market economy system, which is conceived as an open and pluralist society. ${ }^{17}$ This is because, with the institutionally secured admittance of variety, there is an unavoidable necessity of making compromises on the public level of action, implying a loss of logical consistency of the sub-arguments. Thus, the newer a field of policy is to a specific society, the less (formal) institutions exist to govern the processes that directly affect it. All the same this means that lobbyist interests powerful enough to affect policy, are more likely to succeed as there are no or only a few institutions that might prevent their influence-taking. In the case of Japanese SME-policy, in which a new body of rules and regulations is still emerging, these considerations are especially applicable. According 
to the reasoning mentioned earlier, this inhibits the danger of counteracting the original logic or innovation-political intensions, respectively. ${ }^{18}$

However, questions as to the number of compromises made on the steering level that a political system can cope with, would lead deeper into a normative discussion. Or the question could be posed: what relation must there be between stabilizing formal institutions that have a selfbinding nature as the result of a consistent regulatory policy on the one hand, and a flexible approach to pluralistic impulses on the other hand (e.g. Dixit 2000; Rodrik 2000; Metcalfe 2001)? What value has the natural inertia of certain ideologies, which, as informal institutions, slow down some current influences? How should the ever increasing penetration of global impulses be encountered in national policy processes? Can too much be asked of the basic social and political ability to deal with change (cf. Marquard 1986)?

These questions will remain unanswered here. The principle aim of this chapter was to awaken an understanding for the political process as a phenomenon that can be seen under the aspect of cognitive and communications science. The cause and effect connections described, should be considered independently of which measures and influences for stabilization or destabilization of certain tendencies can be observed in this process.

\section{Résumé}

With these thoughts in mind a short summary can be made. The point of departure of the argumentation in this chapter was the dissolution of the common knowledge assumption which is implicitly taken for granted in many papers dealing with the theory of economic policy-making. An evolutionary theory of economic policy bases its analysis on the genesis of a more or less well-defined field of occurrences and conditions. In other words, such a theory focuses on the perception, processing and reciprocal social construction of phenomena regarded as relevant to the political economic sphere. Central to the understanding of the actual content and assessment of economic policy-making and its transformation over time seems to be the mental deconstruction of the process of problem origination and policy formulation.

Subsequently, it becomes clear why both the process of problem origination as well as the process of problem treatment in economic policy, often seem to be systematically 'unsystematic' to the observer. As problem origination and problem treatment are always accompanied by complex competition for influence and power between different interpretations of reality, what is left over as the final result of this process on a collective level can still only be an ambiguous and partially contradictory compromise. This results from the collision of many different ways of 
thinking, reality models and ideologies whose foundations, even if they seem incommensurable, are set in relation to each other. It is the motivation of the decision-makers in economic policy to reduce ambiguity on all levels - at least in a democratic system - in order to become or remain able to act. The extent to which the left-over residue of ambiguity or cognitive heterogeneity is present in the phase of problem treatment, depends not least on the informal and formal givens of the socio-political system of a country. In an individual case analysis, the quality of the installed communication structures and the structure of the democratic involvement and decision-making rules would need to be investigated here.

Furthermore, it should be kept in mind that the appearance of such problem interpretations, born out of the societal communication process and the solution patterns which follow, is in no way long-lasting; it rather shifts according to the extent to which certain events, discoveries or power shifts help other or new realities to become temporary 'competitive successes'. Therefore, a positive theory of economic policy must also thematize influential factors of the variability of its categories. It should understand the societal communication process as an all-encompassing medium in which interests concerning economic policy, models and ideologies are not only transported and strengthened, but also put in their place. The agents, sometimes in a double role of decision-maker and party affected by the resulting policy can be understood as evaluators - either as creators of majorities or as grave diggers - for certain approaches. However, with the relativistic basic positions proposed here, it would not be possible in any way to claim that they had objective decision-making competencies. They are always endogenous variables in a continuous political communication process.

For analysing contemporary developments in Japan, these thoughts should be kept in mind. It is proposed here that SME- and innovationpolicy, as largely new phenomena to a culture characterized by a strong, yet old-fashioned institutional structure, are likely to face powerful resistance from many parts of society and pressure groups stuck to the traditional perspective of the economy and policy-making. On the other hand, if the need to reinforce efforts in support of SMEs and innovation is understood as common consent in the consensus-oriented society of Japan, it will be endorsed on a fruitful and very broad basis.

\section{Notes}

1 The mechanisms that underlie endogenous change of these cognitive models are analysed in detail in the third section of this chapter (pp. 17-24).

2 Cf. Albert 1977: 205, who demands the inclusion of epistemological aspects in a theory of econo-political action 'which should be taken seriously from a realistic point of view'. 
3 The expression 'cognitive sciences' includes all disciplines which deal with the phenomena perception and cognition, including neuro-biology, chemistry, physiology and psychology, other fields of biology and psychology as well as some areas of philosophy.

4 Cf. Singer 2002, who describes three stages in the knowledge development of the human brain. In a first purely genetic step, the brain's primal knowledge structure as an outcome of the process of human evolution, is constructed. In the second stage, which lasts until puberty, the physical microstructure of the brain is reshaped by experience and the gaining of knowledge. The third step is commonly known as learning and is nearly without effect to the physical brain.

5 Perception is the absorption of stimuli by sensory cells and organs, inference is the formation of implicit conclusions and attribution is the sub-conscious allocation of cause by the brain.

6 In this context Hesse's reflections on 'cognitive creativity' as a basic variable in the theory of action and economics as well as the consequences of its integration for the explanation of innovation are particularly significant; cf. Hesse 1990.

7 Please cf. also the considerations on this topic at the end of Chapter 4.

8 Cf. Rees and Frith 1999, for a deeper insight into the neurobiological process of perception and selection-mechanisms in the human brain.

9 In a similar context to the one discussed here, Frey and Eichenberger 1991: 75, under the point 'reference point effects', refer to the example of the fear of inflation some Germans have. It seems to actually make a difference in the evaluation of econo-political scenarios whether agents still have (unpleasant) memories of inflation they experienced themselves or not. People with experience of certain events and developments will sub-consciously evaluate situations differently than individuals without the same history.

10 These are sometimes called 'scripts', or 'frames'. In all cases these are special types of complex structural organizations (the terms are also partly synonymous). For example 'frames', which will be dealt with later, normally describe organized knowledge structures that order conventionally determined knowledge of laws and standards which plays a role in social situations. Cf. Dijk 1997.

11 Cognitive assimilation and accommodation processes play a role in connection with the motivation to reduce cognitive dissonance or ambiguity. Cf. Meier and Slembeck 1994: 54ff.

12 In this context it can be of interest to analyse the mechanisms of reflexive reality modeling, also in advance of elections and votes. Spontaneous actions and institutionalized procedures ensure that the actual decisions have been made long before the formal election or vote takes place. In spite of this, this cognitiveevolutionary aspect of preparation for votes is often undervalued in expert literature on the subject, an exception being Slembeck, 1997.

13 Kuran 1987: 189ff. analyzes in detail the extent to which private preferences for example are in a continuous change process depending on private knowledge and public discussion and the 'preference distortions' which result.

14 Cf. Meier and Mettler 1988: 40ff. also Cf. Waterman 2002: 38f., for a brief overview of economic reasoning concerning these approaches.

$15 \mathrm{Cf}$. Mueller 1989. The general idea is that the transaction costs of turning social or political problems into issues (in the widest sense) are basically communication costs, using the example of patent law production; in Hutter 1989: 187f. examples for politically motivated 'problem generation' (top-down) can be found, for example, in Scharpf 1991.

16 However this does not exclude the possibility that political oppositions produce ambiguity on purpose to hinder the success of the actions of decision-makers or to manipulate society's evaluation of the results of actions. 
17 A reference can be made here to Popper's plea for a social technique of 'piecemeal social engineering', which he explains on the basis of the characteristics of such a society concept. Cf. Popper 1995.

18 A case-study on political influence regarding innovation policy is provided by Koch and Kautonen (forthcoming 2005).

\section{Bibliography}

Albert, H. (1977) 'Individuelles Handeln und soziale Steuerung: Die ökonomische Tradition und ihr Erkenntnisprogramm', in: H. Lenk (ed.) Handlungstheorien interdisziplinär, Bd. 4, Munich: Fink, 177-226.

Bennett, W.L. (1980) Public Opinion in American Politics, New York: Harcourt Brace Jovanovich.

Berger, P.L. and Luckmann, T. (1979) The Social Construction of Reality: A Treatise in the Sociology of Knowledge, Harmondsworth: Penguin.

Blume, L.E. and Durlauf, S.N. (2001) 'The Interactions-Based Approach to Socioeconomic Behaviour', in: S.N. Durlauf and H.P. Young (eds) Social Dynamics, Cambridge (MA) and London: MIT Press, 15-44.

Boltho, A. and Corbett, J. (2000) 'The Assessment: Japan's Stagnation - Can Policy Revive the Economy?', Oxford Review of Economic Policy, 16, 1-17.

Breton, A. (1998) Competitive Governments: An Economic Theory of Politics and Public Finance, Cambridge: Cambridge University Press.

Ciompi, L. (1988) The Psyche and Schizophrenia: The Bond between Affect and Logic, Cambridge, MA: Harvard University Press.

Dijk, T.A. van (1997) Discourse Studies: A Multidisciplinary Introduction, Thousand Oaks, CA: Sage Publications, Inc.

Dixit, A.K. (2000) The Making of Economic Policy : A Transaction-Cost Perspective, Cambridge, MA: MIT Press.

Eggertsson, Thráinn (1997) 'The Old Theory of Economic Policy and the New Institutionalism', World Development, 25, 8, 1187-1203.

Eysenck, M.W. (1984) A Handbook of Cognitive Psychology, London: Erlbaum.

Frey, B.S. (1983) Democratic Economic Policy: A Theoretical Introduction, Oxford: Blackwell.

Frey, B.S. and Eichenberger, R. (1991) 'Anomalies in Political Economy', Public Choice, 68, 71-89.

- (1994) 'Economic Incentives Transform Psychological Anomalies', Journal of Economic Behaviour and Organization, 23, 215-234.

Goffman, E. (1986) Frame Analysis: An Essay on the Organization of Experience, Boston, MA: Northeastern University Press.

Habermas, J. (1984) The Theory of Communicative Action, London: Heinemann Education.

Hayek, F.A. von (1983) Knowledge, Evolution, and Society, London: Adam Smith Institute.

Hesse, G. (1990) 'Evolutorische Ökonomik oder Kreativität in der Theorie', in: U. Witt (ed.) Studien zur evolutorischen Ökonomik I, Berlin: Duncker \& Humbolt, 49-73.

Hirschfeld, L., Lawrennce, A. and Gelman, S.A. (eds) (1994) Mapping the Mind, New York: Cambridge University Press.

Hodgson, G.M. (2001) How Economics Forgot History, The Problem of Historical Specificity in Social Science, London and New York: Routledge. 
Hutter, M. (1989) Die Produktion von Recht: Eine selbstreferentielle Theorie der Wirtschaft, angewandt auf den Fall des Arzneimittelpatentrechts, Tübingen: Mohr.

Koch, L.T. (1996) Evolutorische Wirtschaftspolitik: Eine elementare Analyse mit entwicklungspolitischen Beispielen, Tübingen: Mohr.

Koch, L.T. and Kautonen, T. (2005) 'Cooperation in Regional New Venture Networks: Experiences from Germany', International Journal of Entrepreneurial Behavior and Research (IJEBR), 13, 2, 127-144.

Kuran, T. (1987) 'Chameleon Voters and Public Choice', Public Choice, 53, 53-78. (1995) Private Truths, Public Lies: The Social Consequences of Preference Falsification, Cambridge, MA: Harvard University Press.

Lindblom, C.E. (1959) 'The Science of Muddling Through', Public Administration Review, 19, 79-98.

Lindenberg, S. (1993) 'Framing, Empirical Evidence, and Applications', in: P. Herder-Dorneich, K.-E. Schenk and D. Schmidtchen (eds) Jahrbuch für Neue Politische Ökonomie 12: Neue Politische Ökonomie von Normen und Institutionen, Tübingen: Mohr.

Little, B.R. (1972) 'Psychological Man as Scientist, Humanist and Specialist', Journal of experimental Research in Personality, 6, 95-118.

Löffelholz, M. and Altmeppen, K.-D. (1994) 'Kommunikation in der Informationsgesellschaft', in: K. Merten, S.J. Schmidt and S. Weischenberg (eds) Die Wirklichkeit der Medien: Einführung in die Kommunikationswissenschaft, Opladen: Westdeutscher Verlag, 570-591.

Luhmann, N. (1989) 'Politische Steuerung', in: H.-H. Hartwich (ed.) Macht und Ohnmacht politischer Institutionen, Opladen: Westdeutscher Verlag, 12-16.

— (2000) The Reality of the Mass Media, Cambridge: Polity Press.

Marquard, O. (1986) Apologie des Zufälligen: Philosophische Studien, Stuttgart: Reclam.

Matsuba, M. (2001) The Contemporary Japanese Economy, Tokyo: Springer.

Meier, A. and Mettler, D. (1988) Wirtschaftspolitik: Kampf um Einfluss und Sinngebung, Stuttgart: Haupt.

Meier, A. and Slembeck, T. (1994) Wirtschaftspolitik: Ein kognitiv-evolutionärer Ansatz, Munich and Vienna: Oldenbourg.

Metcalfe, J.S. (2001) 'Institutions and Progress', Industrial and Corporate Change, Oxford University Press, Vol. 10, 561-586.

Mueller, D.C. (1989) Public Choice II, Cambridge: Cambridge University Press.

Neisser, U. (1976) Cognition and Reality, San Francisco: W. H. Freeman.

Nisbett, R.E. and L. Ross (1980) Human Inference, Englewood Cliffs.

Nüse, R. (1995) Über die Erfindung/en des radikalen Konstruktivismus: Kritische Gegenargumente aus psychologischer Sicht, Weinheim: Dt. Studien-Verl.

Oeser, E. (1987) Psychozoikum, Berlin: Parey.

Piaget, J. (1987) Piaget's Construction of the Child's Reality, Cambridge: Cambridge University Press.

Pöppel, E. (1988) Mindwork: Time and Conscious Experience, Boston, MA: Harcourt. Popper, K.R. (1995) The Open Society and its Enemies, London, New York: Routledge.

Rees, G. and Frith, C.D. (1999) 'How Do We Select Perceptions and Actions? Human Brain Imaging Studies', in: G.W. Humphreys, J. Duncan and A. Treisman (eds) Attention, Space and Action, Studies in Cognitive Neuroscience, Oxford: Oxford University Press, 72-88. 


\section{Lambert T. Koch}

Rodrik, D. (2000) 'Institutions for High-Quality Growth: What They are and How to Acquire Them', Studies in Comparative International Development, 35, 3-31.

Ross, L. (1977) 'The Intuitive Psychologist and his Shortcomings', in: L. Berkowitz (ed.) Advances in Experimental Social Psychology, vol. 10, New York: Academic Press, 173-220.

Rusch, G. (1994) 'Kommunikation und Verstehen', in: K. Merten, S.J. Schmidt and S. Weischenberg (eds) Die Wirklichkeit der Medien: Einführung in die Kommunikationswissenschaft, Opladen: Westdeutscher Verlag, 60-78.

Scharpf, F.W. (1991) Crisis and Choice in European Social Democracy, Ithaca, NY: Cornell University Press.

Scherer, K.R., Vogel, C. and Immelmann, K. (1988) 'Psychobiologie und Politik', in: K. Immelmann, K.R. Scherer, C. Vogel and P. Schmoock (eds) Psychobiologie, Grundlagen des Verhaltens, Stuttgart und New York: Free Press, 803-832.

Searle, J.R. (1995) The Construction of Social Reality, London: Free Press.

Siegenthaler, H. (1994) 'Wege zum Wohlstand: Das Beispiel der USA, der Schweiz und Brasiliens', in: W. Fischer (ed.) Lebensstandard und Wirtschaftssysteme, Frankfurt a. M.: F. Knapp, 173-212.

Simon, H.A. (1955) ‘A Behavioral Model of Rational Choice', The Quarterly Journal of Economics, 69, 99-118.

Singer, W. (2002) 'Neurobiologische Anmerkungen zum Konstruktivismus-Diskurs', in: Der Beobachter im Gehirn, Essays zur Hirnforschung, Frankfurt: Suhrkamp, 87-111.

Slembeck, T. (1997) 'The Formation of Economic Policy: A Cognitive-Evolutionary Approach to Policy-Making', Constitutional Political Economy, 8, 225-254.

Tversky, A. and Kahneman, D. (1981) 'The Framing of Decisions and the Psychology of Choice', Science, 211, 453-458.

(1982) 'Causal Schemas in Judgements under Uncertainty', in: D. Kahneman, P. Slovic and A. Tversky (eds) Judgement under Uncertainties, Cambridge: Cambridge University Press, 117-128.

Vanberg, V. (2000) 'Globalization, Democracy, and Citizens' Sovereignty: Can Competition Among Governments Enhance Democracy?', Constitutional Political Economy, 11, 87-112.

Vinden, P.G. and Astington, J.W. (2000) 'Culture and Understanding Other Minds', in: S. Baron-Cohen, H. Tager-Flusberg and D. J. Cohen 2000 (eds) Understanding Other Minds, Perspectives From Developmental Cognitive Neuroscience, 2nd edn., Oxford: Oxford University Press, 503-519.

Wallis, J. (1997) 'Conspiracy and the Policy Process: A Case Study of the New Zealand Experiment', Journal of Public Policy, 17, 1-30.

Waterman, A.M.C. (2002) "New political Economies" Then and Now, Economic Theory and the Mutation of Political Doctrine', American Journal of Economics and Sociology, 61, 1, 13-51.

Weick, K.E. (1986) 'Organizations as Cognitive Maps: Charting Ways to Success and Failure', in: H.P. Sims and D. Gioia (eds) The Thinking Organization, Dynamics of Organizational Social Cognition, San Francisco, CA: Jossey-Bass.

Witt, U. (1992) 'The Endogenous Public Choice Theorist', Public Choice, 73, $117-129$. 


\title{
3 Japanese science and technology policy in transition
}

\author{
From catch-up orientation to \\ frontrunner orientation
}

\author{
Martin Hemmert
}

\section{Introduction}

Japanese science and technology policy, like many aspects of the Japanese economy, has a strong reputation for being fundamentally different from the policies in other industrialized countries, or even for being unique. In particular, there is a widespread conviction that the Japanese government and bureaucracy are strongly engaged in fostering collaborative R\&D projects with leading manufacturing firms in order to enhance the international competitiveness of high-tech industries (Callon 1995; Goto 1997; Ray 1998; Sakakibara and Cho 2002). This view, however, is only based on the observation of particular projects which represent only a small part of the overall scope of science and technology policy. The common perception that Japanese science and technology policy is primarily engaged in organizing industrial $R \& D$ consortia, therefore does not necessarily match the reality.

This chapter aims at attaining a more balanced and realistic view of Japanese science and technology policy. In order to gain a comprehensive overall picture, a broad understanding of science and technology policy is applied. All programmes and measures by which the government influences a country's science and technology system and the technological competitiveness of its companies are considered.

First, Japanese science and technology policy, as it evolved during the previous decades until the early 1990 s, will be analysed. It is shown that it was strongly oriented towards the diffusion of existing knowledge rather than the generation of new knowledge, and therefore could be qualified as a catch-up oriented policy which was designed to support an innovation system still lagging behind the world's leading nations in most fields of science and technology.

Thereafter, the transition of the Japanese science and technology policy from catch-up orientation towards frontrunner orientation since the 1990s will be discussed. It is shown that in recent years, science and technology 


\section{Martin Hemmert}

policy makers have been undertaking serious efforts to adjust their policy to the needs of the Japanese innovation system, as Japan has become one of the technologically leading nations of the world. Finally, some conclusions from a Western perspective are outlined.

\section{Japanese science and technology policy in previous decades: supporting the technological catch-up}

When analysing Japanese science and technology policy, a first overview can be given by a comparison of the structure of Japan's national R\&D spending with leading Western countries (OECD 2004; Sōmushō Tōkeikyoku 2004 and earlier editions). Japan's total national R\&D intensity (proportion of GDP spent on R\&D activities) has been rising continuously throughout the last decades and already surpassed that of the major Western countries, such as the United States, Germany, France or the United Kingdom, in the 1980s. This observation strongly supports the notion that Japan has become one of the technologically leading countries worldwide.

The structure of Japan's national R\&D expenditures differed considerably from other countries' spending, however. The part of total R\&D spent by the government is clearly lowest in Japan among the group of leading countries. It stood almost invariably at about 20 per cent of the national R\&D spending throughout the last few decades. In the Western countries, in contrast, governmental spending accounted for between 30 and 50 per cent of the total R\&D. As a result, notwithstanding Japan's high total R\&D intensity, the proportion of GDP which falls to governmental R\&D expenditures, was lower than in the United States and the leading European countries. Only in recent years has it surpassed the United Kingdom, where governmental R\&D spending has been subject to far-reaching cuts.

The difference between Japan and the Western countries is even more pronounced when looking at the part of business sector R\&D spending, which is financed by the government (OECD 2004; Sōmushō Tōkeikyoku 2004 and earlier editions). This part is much lower in Japan than in all Western countries, indicating relatively low governmental subsidies for private $R \& D$ activities. In the last decades, only 1-2 per cent of business R\&D was financed by the government in Japan, whereas the corresponding proportion was much higher in the United States and Europe and stood somewhere between 10 and 20 per cent in most countries. In other words, while a substantial part of private $R \& D$ activities were funded by the government in Western countries, governmental funding of business $R \& D$ was on a very low level in Japan.

This difference between Japan and the other countries is partially a result of the low importance of defence-related public R\&D spending in 
Japan. In some of the Western countries, particularly in the United States, a substantial part of private R\&D activities, which are funded by the government, is incorporated in contract R\&D in technological fields related to defence. Even when taking this aspect into account, however, the very low direct governmental aid for business R\&D in Japan is eye-catching. Moreover, even if one includes R\&D-related tax breaks, the relative contribution of public funding to private $R \& D$ activities still remains very low (Goto and Wakasugi 1988).

Altogether, aggregated statistics of national R\&D spending indicate that though Japan's overall $R \& D$ intensity reached a very high level throughout the last decades, the role of governmental R\&D has generally been lower, and public subsidies for private $R \& D$ activities were particularly small. These findings contradict the widespread belief that governmental funding of collaborative R\&D efforts in the manufacturing sector is more important in Japan than in other countries.

A more detailed look at the structure of the relatively small governmental funds which were spent for the support of private $R \& D$ efforts directly shows that a major part was actually used for the financing of collaborative R\&D projects. In Japan the support for this kind of projects was channelled within the frame of the Act on Technological Research Associations in Mining and Manufacturing (Kōkōgyō gijutsu kenkyū kumiai-hō), which was enacted in 1961. Under this act, private firms' limited-term R\&D collaborations can be supported by the government. A closer examination of the more than 100 research associations which were founded under this Act until 1990 (Kōkōgyō Gijutsu Kenkyū Kumiai Kondankai 1991), shows that in most cases, more than half of the total $\mathrm{R} \& \mathrm{D}$ expenditures were financed by the government. Accordingly, most of the associations apparently were founded in order to gain access to $\mathrm{R} \& \mathrm{D}$ subsidies. This view is also supported by the observation that no joint R\&D laboratories were established in the overwhelming majority of cases. Instead, R\&D activities were divided between the participating firms (Goto 1997).

An important feature of the Japanese R\&D consortia, which were built in this context, is their semi-private character. There was no right or guarantee for a company to become a member of a research association only because it was willing to participate. In reality, the ministries guiding the associations often tend to pick the technologically strongest firms within an industry, in order to enhance the diffusion of knowledge between these firms and to improve their competitiveness as a whole. The most prominent cases of publicly supported research consortia in Japan were the Very Large Scale Integration (VLSI) and the Fifth Generation Computer Systems projects which were organized under the guidance of the Ministry of International Trade and Industry (MITI) (Callon 1995; 
Odagiri et al. 1997). As a result of the dominance of such projects, governmental $\mathrm{R} \& \mathrm{D}$ subsidies were primarily granted to the largest firms in each industry, whereas small and medium-sized enterprises (SMEs) have been effectively precluded from access to governmental funding of their R\&D activities.

In sum, the direct support for business sector R\&D by the Japanese government was (a) comparatively small in its total amount, (b) primarily diffusion-oriented and (c) predominantly directed at large firms. At least concerning the last aspect, there is a strong difference to the approach in some Western countries. In Germany, the United Kingdom and on EU level, there are also explicit, institutionalized programmes for the support of collaborative $R \& D$. In contrast to Japan, however, these programmes are not dominated by large firms. Some of them are, on the opposite, primarily aimed at the enhancement of the technological capabilities of SMEs (Callon 1995; Ray 1998; AiF 2002).

Another important field of science and technology policy is the setup and the funding of governmental research institutions. The maintenance of such publicly financed $R \& D$ infrastructure is regarded as necessary in fields like basic research, where the incentives for enterprises to conduct $\mathrm{R} \& \mathrm{D}$ activities of their own, are insufficient. The companies' technological competitiveness is strengthened through access to the knowledge governmental R\&D laboratories and universities possess.

Japanese R\&D statistics distinguish between three types of publicly financed R\&D organizations: (1) central government research institutions which are subordinated to specific federal ministries, (2) other public research institutions which are mainly positioned on the prefectural level and (3) so-called 'special corporations' (tokushu hōjin). The data in Table 3.1, which show the situation in 2001, also reflect the structure of governmental $\mathrm{R} \& \mathrm{D}$ institutions throughout the previous decades quite accurately since there has been relatively little change in their number and size. The special corporations are fewest in number, but largest in average size and therefore account for a substantial part of public R\&D infrastructure in Japan. They include such renowned organizations as the Institute of Physical and Chemical Research (RIKEN). These institutions have a relatively good reputation which is rooted in their comparatively high organizational flexibility. The rigid rules of employment and internal governance of the public sector do not fully apply to them, although they are predominantly financed by the government.

On average the central government $\mathrm{R} \& \mathrm{D}$ laboratories are much smaller than the special corporations, but many of them still have a considerable size. They mostly aim at conducting basic research in specific technological fields. Due to their bureaucratic governance, however, their productivity is assessed as being relatively low (Kusunoki 1998). The efficiency 
Table 3.1 Number and size of publicly financed R\&D institutes in Japan

\begin{tabular}{lccc}
\hline & $\begin{array}{l}\text { Number of } \\
\text { institutes }\end{array}$ & $\begin{array}{l}\text { Number of } \\
\text { employees }\end{array}$ & $\begin{array}{l}\text { Average number } \\
\text { of employees } \\
\text { per institute }\end{array}$ \\
\hline $\begin{array}{l}\text { Central } \\
\text { government } \\
\text { research } \\
\text { institutions }\end{array}$ & 71 & 30.694 & 432.3 \\
$\begin{array}{l}\text { Public research } \\
\text { institutions }\end{array}$ & 549 & 31.066 & 56.6 \\
$\begin{array}{c}\text { Special } \\
\text { corporations }\end{array}$ & 12 & 16.321 & 1360.1 \\
\begin{tabular}{l} 
Total \\
\hline
\end{tabular} & 632 & 78.081 & 123.5 \\
\hline
\end{tabular}

Source: Sōmushō Tōkeikyoku (2002).

and effectiveness of their research efforts appear to be hampered by internal and external communication barriers which stem from their hierarchical structure and from the life-long employment of their whole research staff.

The institutes at prefectural level are much more numerous but also much smaller in size. Many of them seem to function as technology transfer offices at the local level rather than organizations which conduct generic research activities of their own.

Due to the very diverse institutional structure of governmental research institutions which are located in different countries, it is not easy to make international comparisons in this field. The total number of employees in public research institutions in Germany, however, was slightly higher than in Japan at the beginning of the 1990s (Hemmert 1996). This is remarkable, considering the much larger size of the Japanese economy in relation to the German economy. It indicates that, at least when compared with Germany, the investment of the Japanese government in public R\&D infrastructure is not particularly high. Furthermore, an international comparison of R\&D expenditures per researcher in government laboratories in the early 1990s (Barker 1998) showed that the expenditure per capita is slightly higher in Japan than in Germany, but much lower than in the United States, France or the United Kingdom. This also suggests that the level of governmental funding of R\&D institutions is relatively low in Japan.

Another potentially important source of technological knowledge for the business sector is the results of R\&D activities conducted by universities. The institutional conditions for these activities are strongly determined by the government. This particularly applies to Japan where 
the Ministry of Education, Science, Sports and Culture (MESC) has a strong influence on the financing and organization, not only of the public universities, but also of the private universities, which are partially funded by the government as well.

An international comparison of average $R \& D$ expenditures per researcher at universities (Barker 1998) shows that the differences between Japan and the leading Western countries are even more pronounced here than in government laboratories. The average per capita expenditure of Japanese universities amounts to only one-third of their US counterparts' spending and is also much lower than in Germany, France or the United Kingdom. This indicates a relatively low level of governmental spending for R\&D activities at universities. Moreover, R\&D funds tend to be distributed evenly and thinly among university departments and chairs. As a result, each chair with its limited staff and funds often lacks the critical mass to conduct cutting-edge research.

The efficiency of R\&D activities at Japanese universities is further hampered by an internal structure which is often described as hierarchical and inflexible. Professors are regularly employed for most of their professional life by the universities from which they graduated, and often there is little or no cooperation between different universities and departments. Moreover, the degree of internationalization is very low. Foreigners accounted for less than 1 per cent of the faculty staff at Japanese national universities in the 1990s (Barker 1996). The involvement in international collaborative research projects was also relatively low.

As a result of their often inadequate funding and their internal governance problems, both universities and government laboratories were not regarded as competent partners for knowledge generation by many firms in Japan. In Figure 3.1, the average assessment of factors related to external knowledge for the technology acquisition of German and Japanese pharmaceutical and semiconductor firms, which were given by the firms' R\&D managers in 1999, are depicted. Both the technological level of and the conditions for cooperating with university and non-university research institutions were evaluated as significantly better by German R\&D managers than by their Japanese colleagues.

Finally, the organization and attitude of the bureaucracy which administrates the science and technology policy may also be taken into account when comparing Japan with other industrialized countries. One important aspect in this area is patent policy and administration. The patent system generally pursues two goals which are potentially controversial: the enhancement of innovative activity by protecting intellectual property rights and the diffusion of technological knowledge by publishing patents.

A comparative evaluation of the Japanese patent administration at the beginning of the 1990s (Ernst et al. 1993) revealed a clear priority of the 


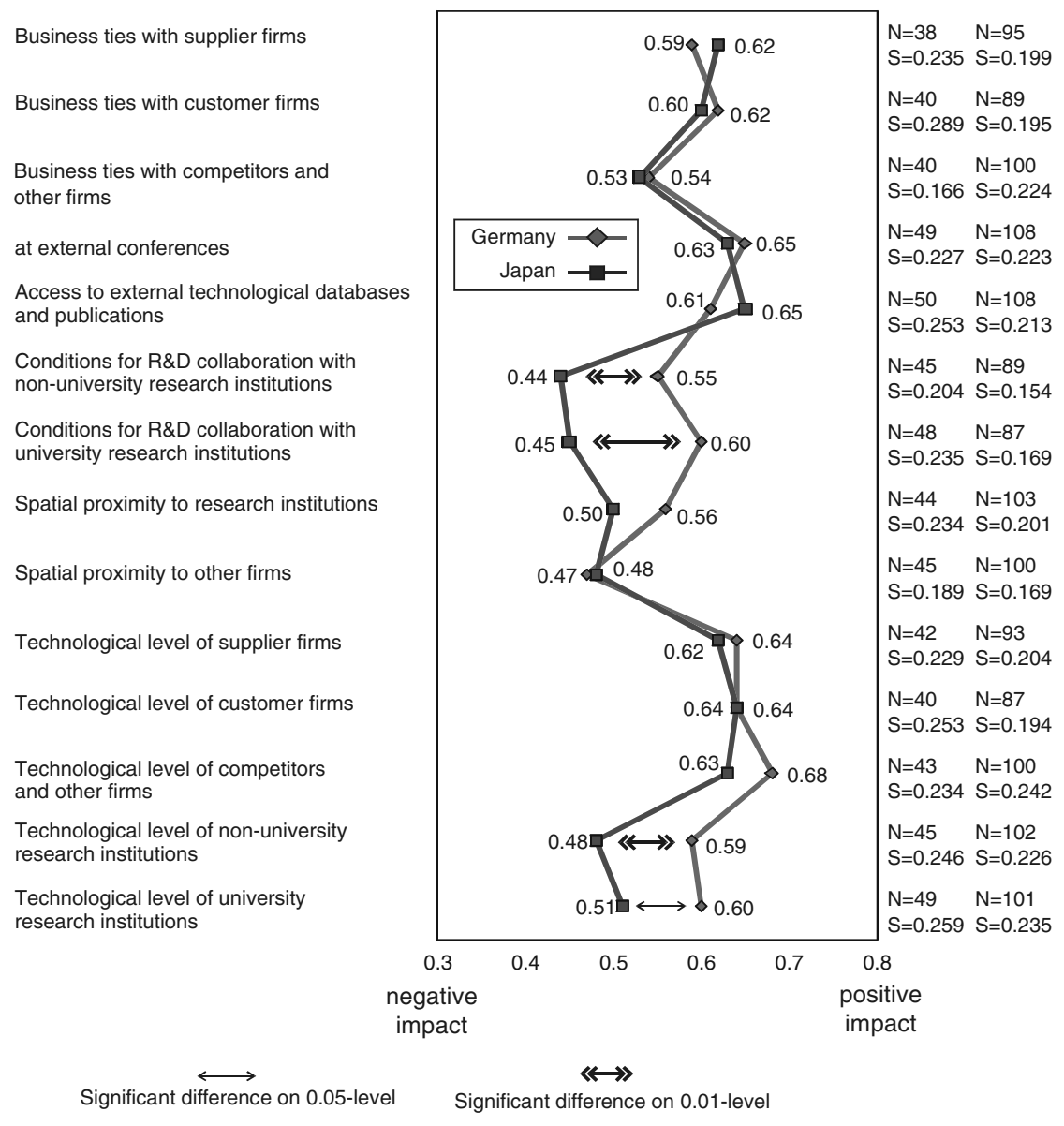

Figure 3.1 Assessment of the impact of factors related to external knowledge on the technology acquisition of pharmaceutical and semiconductor firms.

Source: Author's composition.

diffusion of knowledge. First, the technological coverage of patents was interpreted more narrowly than in other countries, thereby giving imitators good opportunities to invent around existing patents. Second, a patent application was costlier in Japan than in other countries. Third, a slow administrative process and the opportunity for outsiders to file opposition to patents before they were actually granted, further weakened the position of inventors vis-à-vis potential imitators. A further peculiarity of the Japanese patent system, which potentially lowers the value of patents, is the disclosure of all patents 18 months after their filing, even if they have not been granted yet (Okada and Asaba 1997). 
Another feature which is typical for the Japanese bureaucracy is the setup of numerous councils (shingikai) which are meant to give bureaucrats access to expert knowledge from universities, research institutions and the business sector (Hemmert 1996). The frequent use of such councils apparently fosters the diffusion of knowledge between different organizations and parts of the innovation system.

As a final aspect, the competence structure for science and technology policy on the central government level was relatively fragmented in Japan until recently. In other leading countries, this policy field is highly concentrated in one administrative body like the Department of Defence (DoD) in the United States or the Federal Ministry of Education and Research (BMBF) in Germany. In contrast, Japanese science and technology policy used to be administered by a large number of Ministries and Agencies which included at least three main actors: the Science and Technology Agency (STA), MESC and MITI. Whereas each of these Ministries was initially responsible for different fields of policy, all of them were strongly engaged in common themes related to science and technology. As a result, many of their programmes overlapped and were competing with each other.

The preceding comparative review of Japanese science and technology policy has shown that, at least until the early 1990s, there were significant differences to other major countries in many respects. The main findings may be summarized in the following points:

1 the volume of governmental subsidies for business R\&D was small;

2 the promotion of business R\&D focused on large firms;

3 the investment in governmental and university research organizations was low;

4 the governance of public research institutions and universities was bureaucratic and inflexible;

5 there was little interdisciplinary and international knowledge transfer in the science system;

6 the governmental science and technology policy programmes were dispersed between several ministries;

7 there was no strong focus on particular fields of science and technology;

8 science and technology policy was highly diffusion oriented (and not innovation oriented).

This overview clearly exhibits the need for a reorientation in science and technology policy in order to increase the competitiveness of the Japanese innovation system. In many respects, the Japanese science and technology policy appears to have been designed for a 'catch-up' and not 
for a 'frontrunner' innovation system. Instruments for supporting $R \& D$ activities and innovations by SMEs were given a particularly low priority. Whereas this catch-up oriented policy may have fitted the needs of the country's innovation system quite well in the decades after the Second World War, it seems to have become increasingly outdated since the 1980s, when considering the fact that Japan has become one of the technologically leading countries worldwide.

Subsequently, the various restructurization measures regarding these issues, which are being implemented since the mid-1990s, will be analysed. It is shown that Japanese science and technology policy has been changing substantially towards giving the generation of cutting-edge innovations in general and SMEs' R\&D activities in particular stronger support.

\section{The recent transition of Japanese science and technology policy}

\section{The science and technology basic law and plans}

On November 15, 1995, the Science and Technology Basic Law (Kagaku Gijutsu Kihon-Hō) was enacted by the Japanese diet. Among other issues, this law required the government to elaborate a five-year plan for the further development of the nation's science and technology system. As a consequence, the Japanese cabinet approved the first Science and Technology Basic Plan (Kagaku Gijutsu Kihon Keikaku) on June 2, 1996.

When it was released to the public, the plan received high attention, primarily because it intended a doubling of the government's science and technology budget until 2000, compared to 1992. Along with this issue, however, it also called for a reform of the Japanese science and technology system in a broader sense. The following aspects were particularly emphasized:

- more government aid for the work of young researchers;

- more joint industry-university-government R\&D;

- more international exchange in science and technology;

- more R\&D spending.

A second Basic Plan was approved by the cabinet on March 30, 2001 (Monbu Kagakushō 2002a). This plan calls for

- a further increase of the total R\&D intensity to 3.5 per cent of GDP and of governmental R\&D expenditures to 1 per cent of GDP;

- a higher efficiency of R\&D spending with a focus on life sciences, IT, environmental research, nanotechnology and material sciences; 
- a strengthening of the interface between $\mathrm{R} \& \mathrm{D}$, education, the science base and society;

- a more active role in international science and technology cooperation;

- an internationalization of the domestic research system.

These programmes apparently address most of the weaknesses of the Japanese science and technology system, which were identified earlier. This suggests that they mark a major turning point in Japanese science and technology policy. A comparison of the Basic Law and Plans with their predecessors, the eleventh and eighteenth recommendations of the Council for Science and Technology from 1984 and 1992, shows, however, that basically the same programmatic goals had been set before (Hemmert and Oberländer 1998). This indicates that there is a high degree of continuity in the governmental agenda for science and technology.

The truly new aspect of the recent programmes for science and technology policy, particularly the Basic Law, probably lies more in the preceding policy process that finally resulted in their enactment than in their actual contents. The Science and Technology Basic Law was enacted due to the initiative of a multiparty group of diet members with very diverse backgrounds under the leadership of a former MITI bureaucrat (NSF Tokyo Office 1996). This is highly unusual in Japan where legislation is normally put forward by the government bureaucracy and therefore the incident strongly suggests the formation of a broad consensus among Japanese policy makers that structural reforms in the science and technology system had become an urgent task for preserving and enhancing the nation's international competitiveness.

In sum, whereas the agenda of Japanese science and technology policy has not changed a great deal in recent years, there are signs of an increased readiness and seriousness to implement the proposed policies. Subsequently, the concrete measures which have been taken since the mid-1990s in order to address the need for structural reforms, will be discussed.

\section{Increases in $R \& D$ spending}

As a starting point for an analysis of the recent development in Japanese science and technology policy, some aggregated statistical data are reviewed (Figure 3.2). The R\&D intensity in Japan, which had already been considerably higher than that of the other leading countries before, started to rise again from the mid-1990s, after some years of stagnation. In all Western countries, in contrast, it declined in the last decade, although a partial recovery occurred in the United States and in Germany in the last few years. This indicates that the steady increase of 


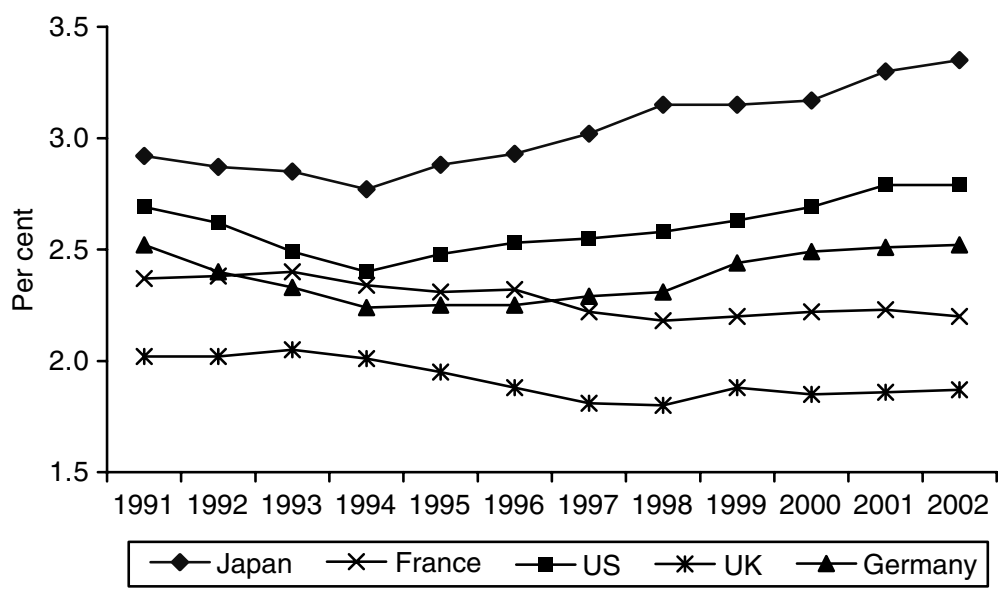

Figure 3.2 R\&D intensity in five leading countries.

Source: Monbu Kagakushō (2004).

Note

$\mathrm{R} \& \mathrm{D}$ intensity $=\mathrm{R} \& \mathrm{D}$ expenditures/GDP.

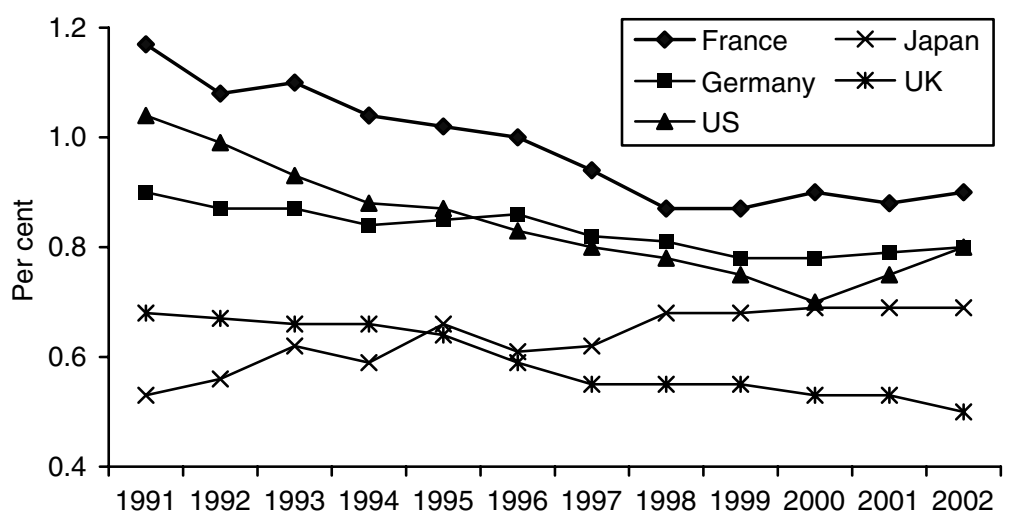

Figure 3.3 Intensity of public R\&D spending in five leading countries.

Source: Monbu Kagakushō (2004).

Note

Intensity of public R\&D spending = public R\&D spending/GDP.

$\mathrm{R} \& \mathrm{D}$ intensity in Japan is a rather exceptional trend among the leading industrialized countries.

The difference between Japan and the leading Western countries becomes even more pronounced, however, when the comparison is focused on public R\&D spending (Figure 3.3). In the United States, as 
well as in the Western European countries, the intensity of public R\&D spending declined steadily and substantially throughout the 1990s. In Japan, in contrast, a considerable increase can be observed. The intensity of public R\&D spending in Japan is still quite distant from the 1 per cent goal, which was set in the most recent Basic Plan. In recent years, however, none of the Western countries have even come close to this level either.

Altogether, Japanese $R \& D$ intensity in general and the intensity of public R\&D spending in particular increased throughout the 1990s and thereby Japan is a clear exception to a global trend of declining, or at best stagnating, $R \& D$ intensities. Thus, aggregated $R \& D$ data indicate that the goal of a (relative) increase in R\&D spending, set by Japanese policymakers, was clearly fulfilled despite a harsh macroeconomic environment in Japan. Moreover, Japan is the only leading country where such an increase has been achieved recently, although the other countries were also struggling for an increase in R\&D spending, due to intensifying international competition in many industries.

\section{Government support for business $R \& D$}

A feature which was identified as being typical for Japan above is the very low level of direct financial support for private R\&D activities by the government. Concerning this aspect, a slight increase could be observed in the 1990s. However, as recently as 2004, the proportion of total private $\mathrm{R} \& \mathrm{D}$ spending, financed by the government, amounted to only 1.4 per cent (Sōmushō Tōkeikyoku 2004), indicating that the overall importance of net transfers of R\&D budgets from the public to the private sector is still very low. ${ }^{1}$

The remaining question is whether a qualitative change in the focus of government support for R\&D activities in the business sector has taken place. On the one hand, the support system for R\&D consortia, primarily formed by large manufacturing firms (Technological Research Associations in Mining and Manufacturing), that had been dominating this policy field for decades, is still in effect. According to a recent report by the National Institute of Advanced Industrial Science and Technology (AIST), 26 out of 113 limited-term research associations, administered by MITI since the 1960s, are still active (AIST 2002).

On the other hand, however, a new system which is directed specifically at supporting SMEs' R\&D activities (and in particular venture businesses) was established by the Japanese government in 1998. Under the so-called Small Business Innovation Research (SBIR) system, 11 billion yen were budgeted in the fiscal year 1999, the first year of its operation. Since then, the amount of resources allocated to this system has been increasing. 
For the fiscal year 2004, its budget was increased to 28 billion yen (Monbu Kagakushō 2004). This is equivalent to about 17 per cent of the overall governmental funding of private R\&D activities. Moreover, a system of special tax breaks for start-up companies was also introduced in 2002 (Odagiri 2004).

In summary, whereas the absolute amount of direct governmental support for SMEs is still modest in Japan; its relative importance is rapidly increasing. The fact that a system for the support of R\&D activities in such firms has been established in Japan is remarkable in itself. The recent development indicates that the one-sided focus on the support of large firms, which had been dominating Japanese science and technology policy, has changed to a more balanced approach which supports SMEs' R\&D activities as well as large firms', within the frame of a relatively small total budget for R\&D subsidies.

\section{Reorganization of governmental research institutions}

The governance of public research institutions in Japan, which has remained almost unchanged for decades with its triangular structure of (1) a few 'special corporations', (2) some governmental institutes which are attached to the central government bureaucracy and (3) a large number of smaller institutes on the prefectural level, has been undergoing major reorganization in recent years. The 'special corporations' as well as the majority of the central government laboratories have been reorganized to become 'independent administrative bodies' (dokuritsu gyōsei hōjin) since 2003, with the aim of giving them and their staff a greater administrative flexibility (NISTEP/MRI 2004a).

Furthermore, there have been efforts under way since the 1980s to build more flexible, project based research organizations in addition to the traditional government laboratories. Exploratory Research for Advanced Technology (ERATO) is probably the most prominent case among these new types of research organizations. It widely received very positive evaluations (Barker 1998; Kusunoki 1998).

Another more recent approach to increase the flexibility of these laboratories is the introduction of limited-term contracts for R\&D personnel. The possibility of employing researchers in government laboratories on limited terms was opened up by the Japanese government in 1997. Two such types of new contracts were provided: one for very renowned senior researchers, (shōhei-gata) and one for promising young researchers (wakate kyōiku-gata). Remarkably, the new contract types are primarily directed at attracting top researchers to government laboratories, and not at the possibility of laying them off in case of unsatisfactory performance. 


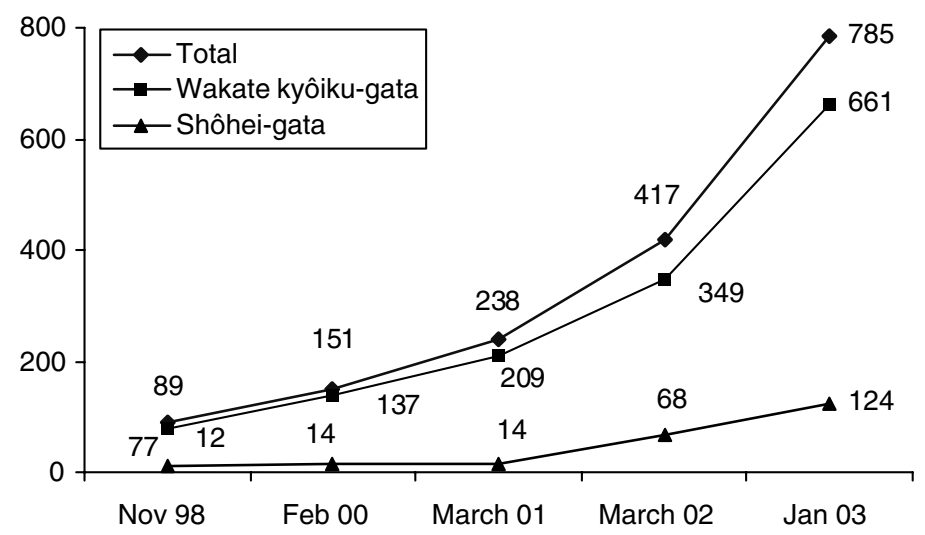

Figure 3.4 Number of researchers employed on limited-term contracts in Japanese government laboratories.

Source: Monbu Kagakushō (2004 and earlier editions).

The statistics on the number of researchers, who have been hired by government laboratories on limited-term contracts (Figure 3.4), clearly indicate that the proliferation of these new contract types is rapidly increasing. A recent analysis of the relative importance of the new contract system revealed that in January 2004, 5.6 per cent of the research staff in government laboratories was working under one of the new contract types, suggesting that the overall importance of the new contract system is still limited. In the age group between 26 and 30 years, however, the researchers with limited-term contracts already amounted to 16.8 per cent of the total staff (NISTEP/MRI 2004a).

Simultaneously, the law for the employment of university teachers was amended in 1998 in order to allow limited-term contracts for lecturers and professors as well. At the universities, the new employment system is gaining momentum faster than in the government laboratories, with the number of university teachers, who are employed on limited terms, jumping from 624 in October 2000 to 5248 in October 2002 (Monbu Kagakushō 2004). This compares with a total number of about 150,000 university teachers in Japan. Currently national universities account for more than half of the limited-term employment.

In sum, despite its still low share of total employment in government laboratories and national universities, the use of limited-term contracts for researchers and professors is rapidly gaining significance in Japan. This indicates a serious commitment to increase flexibility in the governance of public research institutions and universities by science and technology policy makers. 


\section{Knowledge transfer from universities and government laboratories to firms}

Another field of the Japanese innovation system where the need for major reforms has been indicated, is collaborative $R \& D$ between research institutions, universities and business firms which enhances technology transfer from the public to the private sector. According to some recent statistics (Figure 3.5), the number of collaborative research projects between national universities and the private sector has been rapidly increasing in the last few years.

These statistics have to be interpreted with some caution because of the possibility that some collaborative projects which already existed before, may have only been officially reported recently, due to the government administration's more positive attitude towards such activities. Therefore, the real increase in collaborative R\&D activity is probably lower. Nevertheless, the data strongly suggest that collaborative R\&D and technology transfer from the public to the private sector have gained importance in Japan. This view is also supported by the results of a questionnaire survey of about 1,000 Japanese venture businesses in 1998. According to this survey, 10.9 per cent of the firms were engaged in collaborative R\&D projects with government laboratories, and 19.7 per cent in projects with national universities (Sakakibara et al. 1999). This suggests that collaborative $\mathrm{R} \& \mathrm{D}$ between government laboratories, universities and companies is about to become a normal phenomenon.

This development has been supported by an increasing number of side-business allowances for professors (Monbu Kagakushō 2002a) which indicate a relaxation of the administrative practice on this issue. Moreover, 36 technology licensing offices (TLOs) have been set up in

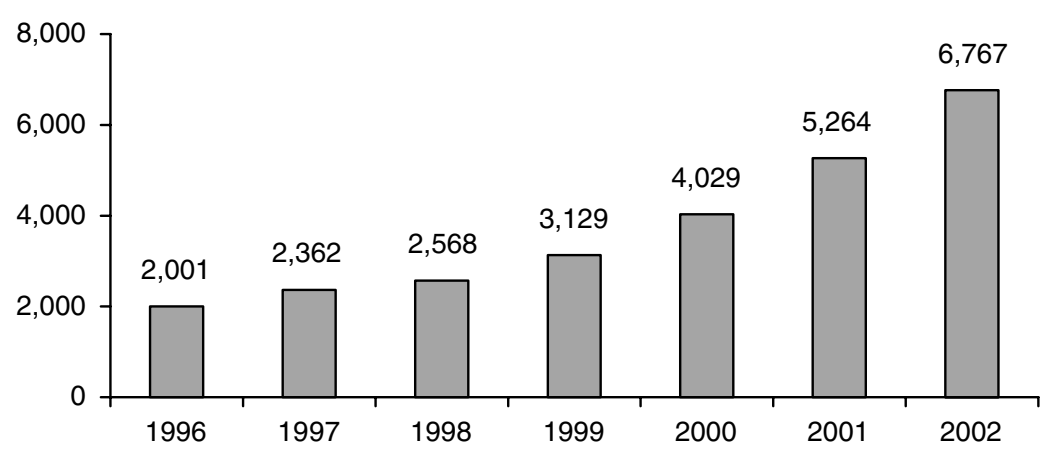

Figure 3.5 Number of collaborative research projects between national universities and the business sector in Japan.

Source: Monbu Kagakushō (2004). 


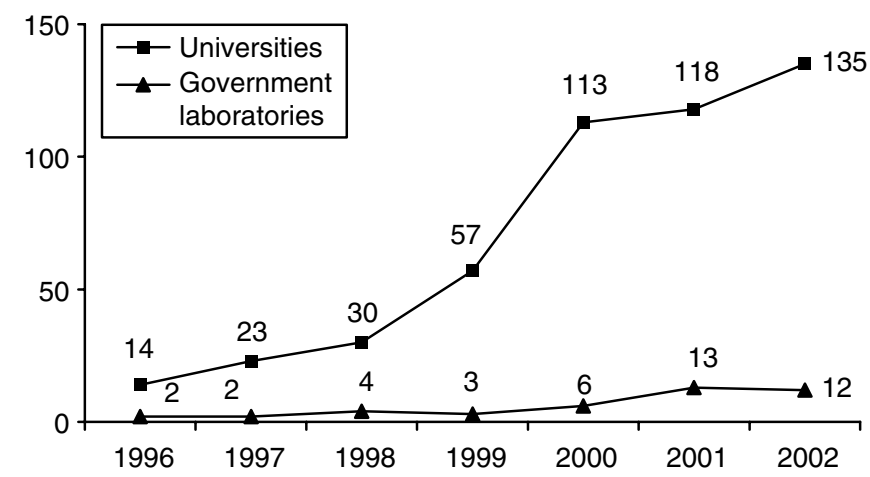

Figure 3.6 Number of newly founded venture businesses originating from universities and government laboratories.

Source: NISTEP/MRI (2004b).

universities to enhance the transfer of technology from universities to the business sector (Monbu Kagakushō 2004).

Figure 3.6 shows the development of the number of new venture businesses, originating from universities and government laboratories each year. Whereas such academia-rooted venture businesses were almost inexistent only a decade ago, the number of start-ups from universities has been rapidly increasing during the last years. Compared with the overall size of the Japanese economy, their number is still miniscule. However, the recent increase is a sign that the combination of various policies, such as special support programmes for venture businesses and the enhancement of research collaboration between universities and companies, is bearing some fruit.

\section{Internationalization}

The level of internationalization in Japanese science and technology, which was indicated as being relatively low, is also certainly increasing. The number of Japanese researchers who are sent abroad and foreign researchers who are invited to Japan on the base of government-sponsored fellowships, rises every year (Monbu Kagakushō 2002a). The number of foreign university teachers in Japan amounted to 5,038 in 2000 and thereby accounted for 3.3 per cent of the total staff. The corresponding numbers were 3,554 and 2.6 per cent in 1994 (Monbu Kagakushō 2002b and earlier editions). In a more recent analysis, the number of regularly employed foreigners was estimated to amount to about 1 per cent of the total staff in government laboratories and about 3 per cent at universities 
(NISTEP/MRI 2004a). These data indicate an increasing internationalization of the Japanese science system on the one hand. On the other hand, the pace of this development is modest at best, resulting in a level of internationalization which is still low, compared to other leading countries.

\section{Strengthening intellectual property rights}

The practice of the Japanese patent administration in the last decades was described earlier as being primarily diffusion oriented and less innovation oriented. Concerning this issue, however, a certain reorientation already occurred in the mid-1990s. The right to oppose patents before they are granted has been removed, and the filing of patents has been made easier and thereby less costly for applicants (Tokkyochō Sōmubu Sōmuka 1995). More recently, the Japanese patent office has explicitly taken the stance of a pro-patent legislation and administration. Additional measures have been taken to strengthen the innovators' position in the patent system (Tokkyochō 2000, 2004):

- a strengthening of the administrative stance of inventors filing patent violation claims against imitators;

- a rise of the administrative fines for violators of the patent law;

- an increase of administrative resources for the settlement of patent disputes;

- a further reduction of the administrative burden on patent applications and a waiver of patent fees for up to 3 years for SMEs.

Furthermore, the patent administration emphasizes that it is working on a reduction of processing time for pending patent applications. The average time required between a patent application and a 'first action' of the patent administration, however, recently increased from 19 months in 1999 to 22 months in 2001 to 25 months in 2003 (Tokkyochō 2004 and earlier editions). In the United States, the corresponding average waiting time was 14.4 months in 2001 and 18.4 months in 2003 (US Patent and Trademark Office 2004). These data indicate that whereas the processing times for patent applications appear to have been lengthening globally in recent years, there is still room for improvement, as regards the efficiency of the Japanese patent administration.

In 2002, the Basic Law on Intellectual Property (chiteki zaisan kihon$h \bar{o}$ ) was passed by the Japanese diet. Whereas only a few concrete measures, such as the setup of an Intellectual Property Policy Headquarters in the cabinet, are prescribed by this Law, it strongly symbolizes an increased commitment by Japanese policy makers to care for the protection of intellectual property. Only recently, the establishment of a special court 
for patent litigation within the Tokyo High Court was discussed. This would improve the practical prospects for inventors who want to pursue patent violations (Odagiri 2004).

Altogether, the recent track record strongly indicates that the Japanese patent legislation and administration are working towards strengthening the inventors' position and thereby changed their earlier stance, which was primarily diffusion oriented.

\section{Reorganization of the government bureaucracy}

A final issue, which can be expected to have a major impact on the Japanese science and technology policy, is the merger of the Ministry of Education, Science, Sports and Culture (MESC) with the Science and Technology Agency (STA) to the new Ministry of Education, Culture, Sports, Science and Technology (Monbu Kagakushō or MEXT), which took effect in January 2001 as part of a major reorganization of federal ministries and government agencies (Monbu Kagakushō 2001). Whereas this administrative merger was not conducted in the specific context of science and technology policy, but in the wave of a total reorganization of the Japanese government bureaucracy, it definitely marks the end of most of the administrative fragmentation, which was outlined earlier as a feature of this policy field in Japan. The new ministry can be expected to become as dominant here as the corresponding administrative bodies in the major Western countries. While it remains to be seen how smooth the post-merger realignment of science and technology policy on the lower administrative level will be, at least the foundation for reducing the inefficiencies and doubling of efforts, which were created by the former administrative fragmentation, has been laid.

\section{Overall evaluation}

The previous discussion has shown that whereas the programmes for Japanese science and technology policy, which have been put forward since the 1990s, are not entirely new, the relevant actors have evidently become more serious about their implementation than before. Governmental R\&D spending, as well as R\&D spending in general, is substantially increasing. The direct governmental support for companies' $R \& D$ activities, although still remaining on a low level, is gradually shifting from a one-sided focus on large firms to the support of SMEs and venture businesses. Considerable efforts have been made to increase the flexibility of government laboratories and universities. As a consequence, the number of collaborative $R \& D$ projects between academia and industry is increasing, leading the way for a more effective knowledge transfer from 
the former to the latter. The internationalization of Japanese science and technology is also rising, albeit at a very modest pace. In the patent administration, a considerable shift towards a strengthening of the inventors' position vis-à-vis imitators took place. Finally, the recent merger of two major ministries bears the potential for a substantial increase in the efficiency of science and technology policy administration.

In sum, the whole range of problems, which were outlined before as hurdles for a better performance of the Japanese science and technology system, has been seriously addressed, albeit with different intensities and success in different areas. The continuous increase of governmental R\&D spending is particularly impressive when considering the serious financial strains of the Japanese government budget since the 1990s. Moreover, as regards policies to foster $\mathrm{R} \& \mathrm{D}$ activities in the business sector, a remarkable shift of attention from large firms to SMEs, and particularly start-up firms, has taken place. This policy shift has already resulted in a visible increase in the number of venture businesses, although a gap to some of the other leading countries, particularly the United States, still remains (Odagiri 2004).

A recent study of Japanese biotechnology venture businesses (Odagiri and Nakamura 2004) showed, however, that considerable problems still remain for innovative small firms in the business environment. About half of the surveyed firms quoted 'procurement of capital' and 'recruiting of research staff' as major start-up hurdles. Despite all the recent changes, $R \& D$ resources are still highly concentrated on large firms in Japan.

In the overall context of the Japanese innovation system, progress appears to be comparatively slowest in the fields of the employment system for researchers and the internationalization of the science and technology system. Both observations are no surprise, since unlimited employment for highly qualified workers has been a backbone of the Japanese employment system for decades and the degree of internationalization in the Japanese economy is generally lower than that of Western countries. Long-term employment practices, as well as cultural and language barriers, appear to be among the problems which are most difficult to deal with when pursuing institutional change.

There can be no doubt, however, that, due to a major reorientation of Japanese science and technology policy, the Japanese innovation system in general has, to a considerable degree, been transformed from a 'catchup' system towards a 'frontrunner' system. Accordingly, a substantial improvement of performance within the Japanese science and technology system has already ${ }^{2}$ occurred, and this development may well continue in the future, unless the institutional transformation is stopped. Time was when Japan was famous as an imitator and not as a producer and supplier of scientific and technological knowledge. 


\section{Conclusion}

From a Western perspective, two major conclusions can be drawn from the analysis of the transition of Japanese science and technology policy. First, the international technological competitiveness of Japanese companies, which has been lagging behind in the last decade due to weaknesses in the domestic innovation system, can be expected to improve again in the coming years. The institutional environment, which firms are embedded in, is certainly not the only, but a very important determining factor of their technological competitiveness. ${ }^{3}$ Moreover, a significant time lag may occur between institutional changes in upstream science and technology system and the outcome of these changes in terms of competitive performance of enterprises on the market. In other words, the benefits of the transition of the Japanese science and technology system, which has already taken place, may only be seen to their full extent on the market in the course of time. Therefore, Western firms should not underestimate the future technological competitiveness of their Japanese rivals.

Second, Japan now appears as a potentially more attractive partner for international collaboration in science and technology than in the past. This applies to collaborative research between universities and research institutions as well as to companies' R\&D activities. One reason for this is the improvement in the Japanese science and technology system which translates into higher competencies of Japanese R\&D laboratories and better conditions for conducting R\&D activities of one's own in Japan. Another reason is the strong interest in international exchange, shown by many Japanese individuals and organizations. Since the internationalization of the science and technology system is still relatively low, there is a widespread interest in Japan to intensify international collaboration in this field. Moreover, due to the increased competencies of Japanese R\&D organizations in many technological fields, the danger of being milked by Japanese partners one-sidedly in the course of collaborative R\&D should not be as immediate nowadays as perceived by many Westerners in former decades.

\section{Notes}

1 This proportion becomes even lower when excluding the governmental transfers to the 'special corporations' which are treated as part of the private sector in the statistics, but are predominantly financed by the government. The part of R\&D spending of private firms (in a narrow sense), which is publicly financed, amounted to only 1.1 per cent in 2004, almost unchanged, compared to the early $1990 \mathrm{~s}$ (Sōmushō Tōkeikyoku 2004 and earlier editions).

2 As can be seen from the detailed discussion of performance indicators in the most recent White Paper for Science and Technology, Japan's position has been improving persistently in the last years regarding a wide range of indicators which include 
the production and citation of scientific papers, patent applications and grants, and the international trade of technology (Monbu Kagakushō 2004).

3 For a detailed empirical analysis of the importance of various institutional factors for the technology acquisition performance of high-tech firms, cf. Hemmert (2004).

\section{Bibliography}

$\mathrm{AiF}$ - Arbeitsgemeinschaft industrieller Forschungsvereinigungen (2002) Jahresbericht 2001, Köln: AiF.

AIST - Sangyō Gijutsu Sōgō Kenkyūsho (2002) Sangyō gijutsu sōgō kenkyūsho nenpō. Heisei 12-nendo (Annual Report of the National Institute of Advanced Industrial Science and Technology, 2000 Edition), Tokyo: Sangyō Gijutsu Sōgō Kenkyūsho.

Barker, B. (1996) Japan: A Science Profile. London: British Council.

(1998) 'Internationalizing Japanese Science', in M. Hemmert and C. Oberländer (eds) Technology and Innovation in Japan. Policy and Management for the Twentyfirst Century. London and New York: Routledge, 70-86.

Callon, S. (1995) Divided Sun. MITI and the Breakdown of Japanese High-Tech Industrial Policy, 1975-1993. Stanford, CA: Stanford University Press.

Ernst, A., Hild, R., Hilpert, H.G. and Martsch, S. (1993) Technologieschutz in Japan - Strategien für Unternehmenskooperatione, Munich: Ifo Institut für Wirtschaftsforschung.

Goto, A. (1997) 'Co-operative Research in Japanese Manufacturing Industries', in A. Goto and H. Odagiri (eds) Innovation in Japan, Oxford: Oxford University Press, 256-274.

Goto, A. and Wakasugi, R. (1988) 'Technology Policy', in R. Komiya, M. Okuno and K. Suzumura (eds) Industrial Policy of Japan, Tokyo, San Diego, CA and London: Academic Press, 183-204.

Hemmert, M. (1996) 'Lernen von Japan? Strukturen und aktuelle Entwicklungen in der japanischen Forschungs- und Technologiepolitik', Wissenschaftsmanagement, Vol. 3: 132-137.

- (2004) 'The Influence of Institutional Factors on the Technology Acquisition Performance of High-tech Firms: Survey Results from Germany and Japan', Research Policy, Vol. 33: 1019-1039.

Hemmert, M. and Oberländer, C. (1998) 'The Japanese System of Technology and Innovation: Preparing for the Twenty-first Century', in M. Hemmert and C. Oberländer (eds) Technology and Innovation in Japan. Policy and Management for the Twenty-first Century, London and New York: Routledge, 3-19.

Kōkōgyō Gijutsu Kenkyū Kumiai Kondankai (1991) Kōkōgyō gijutsu kenkyū kumiai 30-nen no ayumi (The development of Technological Research Associations in Mining and Manufacturing over 30 years), Tokyo: Nihon Kōgyō Gijutsu Gijutsu Shinkō Kyōkai.

Kusunoki, K. (1998) 'Organizational Innovation in Japanese Basic Research: From Bureaucracy to Dynamic Network', in M. Hemmert and C. Oberländer (eds) Technology and Innovation in Japan. Policy and Management for the Twenty-first Century, London and New York: Routledge, 87-114.

Monbu Kagakushō (2001) Heisei 13-nenpan kagaku gijutsu hakusho (White Paper on Science and Technology 2001), Tokyo: Zaimushō Insatsukyoku. 


\section{Martin Hemmert}

Monbu Kagakushō (2002a) Heisei 14-nenpan kagaku gijutsu hakusho (White Paper on Science and Technology 2002), Tokyo: Zaimushō Insatsukyoku.

(2002b) Heisei 14-nenpan monbu kagaku tōkei yōran (Overview of Education and Science Statistics 2002), Tokyo: Zaimushō Insatsukyoku.

— (2004) Heisei 16-nenpan kagaku gijutsu hakusho (White Paper on Science and Technology 2004), Tokyo: Zaimushō Insatsukyoku.

NISTEP/MRI (2004a) Dai 1-ki oyobi dai 2-ki kagaku gijutsu kihon keikaku ni oite teiryō mokuhyō ni meiji sareta shisaku no tassei jōkyō, heisei 15-nendo chōsa hōkokusho (Fulfillment situation of quantitative goals in the 1st and 2nd Science and Technology Basic Plan, research report 2003), NISTEP Report No. 76, Tokyo: Kagaku Gijutsu Seisaku Kenkyūsho/Mitsubishi Sōgō Kenkyūsho.

- (2004b) Shūyō na sangakukan renkei, chiiki inobēshon shinkō no tassei seika oyobi mondaiten, heisei 15-nendo chōsa hōkokusho (Achievements and problems regarding the promotion of industry-university-government collaboration and regional innovation, research report 2003), NISTEP Report No. 78, Tokyo: Kagaku Gijutsu Seisaku Kenkyūsho/Mitsubishi Sōgō Kenkyūsho.

NSF Tokyo Office (1996) Japan's Basic Law for Science and Technology, Report Memorandum No. 96-11, Tokyo: NSF Tokyo Office.

Odagiri, H. (2004) Advance of Science-Based Industries and the Changing Innovation System of Japan, COE/RES Discussion Paper Series, No. 64, Graduate School of Economics, Hitotsubashi University.

Odagiri, H. and Nakamura, Y. (2004) Nihon no baio benchā kigyō, sono igi to jittai (Japanese biotechnology venture firms, their role and their situation), NISTEP Discussion Paper No. 22, Tokyo: Kagaku Gijutsu Seisaku Kenkyūsho.

Odagiri, H., Nakamura, Y. and Shibuya, M. (1997) 'Research Consortia as a Vehicle for Basic Research: The Case of a Fifth Generation Computer Project in Japan', Research Policy, Vol. 26: 191-207.

OECD - Organisation for Economic Co-operation and Development (2004) Main Science and Technology Indicators 2004/2, Paris: OECD.

Okada, Y. and Asaba, S. (1997) 'The Patent System and R\&D in Japan', in A. Goto and H. Odagiri (eds) Innovation in Japan, Oxford: Oxford University Press, 229-255.

Ray, T. (1998) 'Collaborative research in Japan and the West: A Case Study of Britain's response to MITI's Fifth Generation Computer Initiative', in M. Hemmert and C. Oberländer (eds) Technology and Innovation in Japan. Policy and Management for the Twenty-first Century, London and New York: Routledge, 151-169.

Sakakibara, K., Kondō, K., Maeda, N., Tanaka, S., Koga, T. and Ayano, H. (1999) Nihon no benchā kigyō to kigyōsha ni kan suru chōsa kenkyū (A survey about venture firms and entrepreneurs in Japan), NISTEP Report No. 61, Tokyo: Kagaku Gijutsu Seisaku Kenkyūsho.

Sakakibara, M. and Cho, D.-S. (2002) 'Cooperative R\&D in Japan and Korea: A Comparison of Industrial Policy’, Research Policy, Vol. 31: 673-692.

Sōmushō Tōkeikyoku (2002) Heisei 13-nen kagaku gijutsu kenkyū chōsa hōkoku (Report on the Survey of Research and Development 2001), Tokyo: Nihon Tōkei Kyōkai.

- (2004) Heisei 16-nen kagaku gijutsu kenkyū chōsa hōkoku (Report on the Survey of Research and Development 2004), Tokyo: Nihon Tōkei Kyōkai. 
Tokkyochō (2000) Tokkyo gyōsei nenji hōkokusho - 1999-nenpan (Annual Report of the Patent Administration - 1999 Edition), Tokyo: Tokkyochō.

- (2004) Tokkyo gyōsei nenji hōkokusho - 2004-nenpan (Annual Report of the Patent Administration - 2004 Edition), Tokyo: Tokkyochō.

Tokkyochō Sōmubu Sōmuka (1995) Heisei 6-nen kaisei kōgyō shoyūken-hō no kaisetsu (Commentary of the Industrial Property Right Law - amended in 1994), Tokyo: Hatsumei Kyōkai.

US Patent and Trademark Office (2004) 2003 Performance and Accountability Report, Washington, DC: US Patent and Trademark Office. 


\title{
4 Innovation policy for SME in Japan \\ The case of technology transfer centres
}

\author{
Klaus Ruth
}

\section{Introduction}

Innovation is often considered to be the 'elixir of life' for production and competitiveness. It is increasingly considered a phenomenon that requires active intervention and steering. Almost every country runs some innovation-related programmes targeted at stimulating or increasing the performance level of innovation. These policy measures start at various levels: companies, intra-organizational networks, regional or national level.

Alongside general policies, there are programmes dedicated to special groups or innovators. Small and medium-sized enterprises (SMEs) are one such group that is gaining public interest. Especially in the field of manufacturing, these small and medium companies play an important role in the competitiveness of many (or most) industrialized countries. They comprise the bulk of manufacturing establishments, generate a large portion of employment in industry, and since they are often integrated into the supply chains, they play an important role in the production of quality goods. Thus, they contribute to maintain global competitiveness. However, these small companies often suffer from shortages in capital, financial and human resources as well as in managerial and technological knowledge. These deficiencies often force them to work below the standards and market requirements. For decades, policy makers have been aware of the problems and also seem willing to implement policy means targeted at supporting the SMEs. In many countries this has led to the establishment of technology transfer centres, which preferably offer their services to small and medium-sized companies. Two of these countries Japan and the United States - are the subjects of this chapter's analysis.

When considering changes in global competition (not only goods and labour markets, but also production sites), we can observe a general tendency towards an increase of knowledge-based or knowledge-driven production. The shift of production and innovation into new technological fields like biotechnology might serve as an example for these new 
developments, which delineate an enormous challenge to the traditional patterns of SME operation in production and innovation. It is commonly assumed that the SMEs' innovation style is more small-scale and incremental rather than radical or 'game changing', but there are some objections to this view e.g. by Rothwell $(1983,1992)$. He suggests that in innovation neither large nor small companies have any significant advantages over each other. Advantages tend to come from the input, capabilities and competences that individuals bring to the organization, rather than from tangible resources. Therefore, it is not the material resource scarcity of the very small enterprises that is the crucial factor for their disadvantages, but rather the skill, knowledge and competence that their people embody, that is, their intangible resources. The findings presented in this chapter will help to evaluate the role of tangible and intangible resources for the creation of innovation competence in SMEs, by considering the different institutional settings, differences in the innovation policies etc., which in the terminology of the underlying research approach of this chapter is equivalent to saying: differences in their industrial cultures.

Through the industrial culture approach, this section of the book picks up the thread of the introduction to this volume, which indicates the problem of path dependencies and the problem of embeddedness and mutual interaction of institutions, which impede cross-cultural learning processes. If the assumption that the institutions of an economy are complementary on a systems level is true, the crucial point when changing single institutions is the adaptation of these improvements to the system in order to maintain the overall coherence. This is precisely what the comparison in this chapter is looking at: how the United States borrowed and adapted components of a successful innovation system to meet their specific needs. Obviously, answering this question, at the same time helps to assess how and under which circumstances Germany can borrow from the US and Japanese experiences with technology transfer centres for SMEs.

Eventually, this chapter addresses the issue of weak institutional ties between universities and SMEs in Japan, raised in the introduction. Though public research and development centres are at the heart of the analysis rather than universities, these nevertheless contribute to the implementation of a triple helix structure (Leydesdorff 2000) of state, industry and university collaboration in Japan - and thus may help to overcome the traditional weaknesses. ${ }^{1}$

\section{Research questions and empirical cases: relevance and scope}

Without major doubts, it can be assumed that SMEs have become more important since production systems worldwide were transformed from 
Fordist into post-Fordist or from mass production towards flexibly specialized production (Piore and Sabel 1984; Womack et al. 1992; Cook 1999; Boyer and Freyssenet 2000). The new forms of social organization in production, accompanying these transformations were characterized by

- an increase of outsourcing,

- a restructuring of supply chains,

- generally, a disassembly of larger companies into smaller units.

These trends affected SMEs insofar as that through outsourcing and an increased integration of suppliers into the production and innovation processes, they became more important, but were not always able to meet these new requirements (Szarka 1990; Storz 2000).

Nowadays it seems even more difficult for SMEs to keep pace with the developments and derived challenges: in a technological respect, it requires a lot of competencies and accumulated skills and know-how to meet the needs for highly sophisticated technology in advanced production systems. On the other hand, SMEs 'traditionally' are short of managerial knowledge, know-how in organization and of course, financial resources (SMEA 2001).

In the case of Japan, these factors, eventually, make up the framework for innovation and technology policy. While the task of transferring technological knowledge to the deficient SMEs was done extremely well by technology transfer centres during the last decades, since the mid-1990s these centres and thus this model of support find themselves in a crisis, because the requirements of contemporary production and innovation have changed and have increasingly become more ambitious. In the case of post-war Japan, this development is synonymous with the incremental shift from a catching-up towards a knowledge-creating economy (Kodama 1995). During the former stage, the major obstacle to economic success (especially of SMEs) was the availability of production and innovation knowledge, in the latter phase, how to generate (technological) knowledge becomes crucial for economic success.

These changes can be observed in many countries (and some evidence has been gathered in this book). Thus it can be assumed that there is a paradigm shift taking place, a shift from diffusion-oriented policy towards $a$ policy of innovation support and innovation enabling. The main outcome of this policy change is a new structure of interorganizational cooperation and an improvement of the performance level of SMEs, the supply chains, as well as regional and national production and innovation systems.

Supporting SMEs through policy measures is a common practice in many countries. However, it is subject to dispute whether the measures preferred in the past are still appropriate or if a new orientation is needed, 
and if the latter is accepted, which shall be the new goals and new means for an SME support policy. Since there are well known examples to be found in countries such as Japan and the United States, a research project comparing both countries was established in $1999 .{ }^{2}$ During a three-year period, three waves of empirical investigation in the US and Japan were conducted. The major goal was to trace the changes in the SME support policies in both countries. The objects of research were technology transfer centres in both countries which offer their services preferably (or exclusively) to SMEs; in the United States, these nationwide centres were run with the assistance of the Manufacturing Extension Partnership (MEP) programme administered by the National Institute of Standards and Technology (NIST) and funded by the Department of Commerce. The kôsetsushi $i^{3}$ acting as technology transfer centres all over Japan are taking a similar approach to their US 'counterpart', and common for both country cases is that the transfer centres are in transitory phases, which is mainly induced by the challenges of globalization to which even the SMEs feel themselves increasingly exposed. These transitions were the core subject of the research conducted. Details on the strategies to cope with the changing situations will be given in subsequent sections of this report.

\section{Some short remarks on sampling}

The research concept basically complied with the principles of cross validation; therefore the research design strived for methodological and investigator triangulation (cf. Denzin 1989; Denzin and Lincoln 1994). The core empirical research was based upon semi-structured interviews, which were conducted in the respective native languages and carried out in mixed teams (whenever possible). Additionally, participant observation was taken into account. The average duration of the interviews was about two hours.

The fieldwork in Japan was made up of three sequential steps. On the first go, which was meant to open up the field and to provide some first cases, 12 experts of universities and ministries were interviewed and six kôsetsushi centres were visited. The second round produced a second Japanese sub-sample, covering five kôsetsushi centres and one subsidiary (in each case, interviews with the directors and one or two advisors, and in three cases, additional accompanying advisors to client companies), 14 client companies (interviews with presidents/owners or general managers), interviews with researchers (2) and experts from the prefecture administrations (2) and SMEA/METI (2).

Furthermore, the results of an empirical survey conducted during 1999/2000 by the author on Japanese SMEs and their cooperation with each other and with universities/research institutes were useful as 
additional empirical backing. Finally, in a third stage the Japanese research partners of both projects conducted a follow-up in 2002 with selected kôsetsushi and some particular SMEs, and integrated the results into this report.

The sample taken in the United States is comprised of four MEP centres (in each case, interviews with the directors and one or two advisors), two MEP locations (field offices), two client companies (interviews with the general managers), two consultants collaborating with MEP centres, one SME support centre not funded by the MEP programme and interviews with researchers (four) and independent consultants (two). ${ }^{4}$

Since an international comparative research approach is truly challenging and brings up some serious methodological questions as well as questions concerning the contents, some considerations regarding the underlying research framework concept will be discussed before the comparative analyses and evaluations can be developed. The institutions and actors, developed under the concept of industrial culture, were the basis of empirical research (Ruth 1996). If industrial culture is used as a framework for empirical research, methodological issues must be considered. Since these are of particular importance for comparing Japanese phenomena with similar patterns in the United States, the following section on the framework of research will address the difficulties with international comparisons.

\section{Theoretical framework}

Various theoretical and empirical approaches have pointed out the significance of SMEs for innovation and innovation systems (Whittaker 1997; Storz 2000; Shapira 2001; Lindman 2002). Particularly the research approaches focusing on regional economies and regional innovation networks emphasize the increasing importance of SMEs in emerging regional innovation systems (Heidenreich 1997; Braczyk et al. 1998; Cook 1999; Hassink 2000; Doloreux 2002; Kitagawa 2004). The common assumption of these concepts lies in the idea that SMEs' role in economy is changing from dependent actors in supplier chains towards pro-active players within innovation networks. Plenty of research has provided examples of successful regions, which heavily rely on SMEs as important actors of equal value, e.g. Silicon Valley, Baden-Württemberg or Tuscany (many examples given in Braczyk et al. 1998). But despite the success stories of certain regions' outstanding economic performance, founded upon SMEs, only a limited number of SMEs can keep up with the pace and scope of innovation nowadays. A considerable number of SMEs are characterized by structural deficiencies in comparison to large companies. Thus in many countries, governments have initiated policy support 
structures, which aim particularly at the small companies. At the same time many efforts have been made to support small companies at the regional and municipal level by developing local infrastructure and improving economic performance.

These efforts can be analyzed as a means of contributing to regional innovation systems or economic milieus (Camagni 1995), but they can also be interpreted in terms of innovation actor networks (Latour 1999) or institution-based and evolutionary innovation approaches. Following the evolutionary concept, companies (or organizations) are learning organizations, which develop their input factors, particularly knowledge (technology and processes etc.) by learning through their own or others' experiences. Since the endogenous learning and knowledge creation capabilities are limited, networking among companies and other innovators is a means of developing innovation capabilities. Through this interaction, the involved innovators can improve their competences, the networks can develop a higher level of expertise, and eventually through their cooperation, modify their (regional) innovative environments - or innovative milieu or their regional innovation system. These inter-organizational relationships can take various forms regarding power or resource distribution (Duschek 2004). Even though theory seems to favour heterarchic network relationships (discussed as the mode two of knowledge production in Gibbons et al. 1999; Nowotny et al. 2001), which are, besides others, characterized by trust and high levels of reciprocity and reliability, hierarchic networks are widespread and not at all negligible. Eventually, both network types contribute to and are simultaneously part of the regional innovation systems. From a knowledge production perspective, state policy, R\&D (universities and research institutes) and industry are the components of an institutional configuration labelled as the Triple Helix of innovation in university-state-industry interaction (Etzkowitz and Leydesdorff 1998; Leydesdorff and Etzkowitz 2001). Rather than assigning basic and applied science to different institutional spheres, the Triple Helix model emphasizes the increasing inter-relatedness of theoretical and applied problem solving, which more and more requires boundary crossing between the institutional actors. Thus, the formerly clearly distinguished university-state-industry actors are now crisscrossing: universities are acting like companies and companies are increasingly resembling universities (cf. Leonard 1998). As pointed out by Baber (2001), Japan used to have a more clear-cut separation of the three institutions, compared to many other societies. This affords an insight into why Japanese universities hardly conduct any applied research and why applied research and development is placed at state/public supported technology transfer centres. The conditions under which the Triple Helix is emerging in Japan is the question backing all analyses presented in the following sections. 


\section{Klaus Ruth}

The three sketched pillars of research in technological knowledge production and dissemination (resource based approach to SMEs' innovation capabilities, regional innovation approach and the Mode 2/Triple Helix concept towards knowledge production) are amalgamated in the industrial culture approach (Rauner and Ruth 1990) which guided the empirical research. Therefore the following paragraph will sketch the research concept that was developed with the purpose of conducting international comparisons on innovation subjects.

\section{Industrial culture}

The following paragraphs shall give some comparisons between Japan and the United States. It is therefore useful to give some brief explanations of the research concept on which these comparisons can be theoretically and methodologically based: the industrial culture approach (Rauner and Ruth 1990; Ruth and Rauner 1996). For the purpose of international comparisons, an industrial culture is understood as a dynamic object which takes shape on various interdependent levels: the macro or national level, the meso or regional level, institutional or organizational level and last, but not least, the micro or individual level. Thus, industrial culture is developed as a multi-layer model of an 'actor-driven institutionalist system approach' towards innovation. This approach was designed for overcoming the innovation systems approaches' fallacy of an 'institutionalist overdeterminination' of innovative actors, that is, the failure to consider actors and their actions as undetermined - though possibly bounded by various rationalities rather than determined by institutions. On the systems level, the industrial culture approach further develops the concepts of National Innovation Systems and their overemphasizing the forces of coherence being effective within national systems of innovation by reinforcing the 'forces of incoherence', thus centrifugal forces (which interfere with economic equilibrium). These conflicting forces form the basis of industrial cultures' dynamism towards change. A continuing challenge to systems stability is cross-cultural adoptions of single innovation factors that have attributed to improvements of national innovation systems elsewhere in the global economy. In progressing the argument, the effects of these 'perturbations' on the development of industrial cultures are further discussed later in this section in terms of cross-cultural learning or borrowing as it took place in the case of the kôsetsushi. The following interdependent dimensions have been developed and proved to be significant constituents of industrial cultures: social institutions (covering common cultural values and attitudes as well as industrial relations, technical styles and role models etc.), industrial organization (the structure and organization of industry or industrial sectors), general and vocational education and training, industrial 
(and R\&D) policy and last but not least, psychology. To sum it up, the research concept of industrial culture is devised as a multi-layered, actororiented approach, which means that (i) the relevant dimensions and their operational variables are located at various societal levels and (ii) that industrial culture is a coherent and dynamic system of mutually stabilizing dimensions, which as an integral complexity, serves as an action orienting framework for individuals, groups, organizations, networks or for regions and nations.

Since this chapter is committed to the concept of international comparison rather than 'point to point' comparisons, it makes the context factors themselves a subject of comparison, that is, the interaction or global coherence between 'text' (which are the variables like technology transfer) and 'context', that is, the structural, social and cultural background (Grootings 1986). The guiding image for this approach is Geertz' concept of 'thick descriptions', which tries to make the meaning behind the data/phenomena understandable, by working out the complex interdependency and intermingled overlay of phenomena (Geertz 1973). Thus, a comprehensive description of the contexts under which the technology transfer centres are acting is needed. As indicated in the heading of the following section, it is not only policy but also cultural and social aspects, which are addressed and utilized as the framing concept for comparative interpretations.

\section{Policy and culture contexts}

In accordance with the insights of the preceding paragraphs and with this chapter's goal to compare innovation policy in Japan and the United States it makes sense to consider the broader social, institutional and cultural contexts that interact with policy actions. Since an international comparison always requires the construction of contextual knowledge in order to conduct an appropriate comparison, it is necessary to provide information on the contexts which some readers might not have. Thus, short sketches of Japanese and US social, cultural and political peculiarities will be worked out.

\section{Japanese industrial organization, policy structure and industrial culture}

The most important structural characteristic of Japanese industry, and particularly of the manufacturing sector, is the large portion of SMEs. Evidently, this is true for almost all developed economies, but the Japanese manufacturing sector shows a comparatively high amount of very small enterprises (with 20 or less employees), which for decades 


\section{Klaus Ruth}

were the forerunners of a structure now labelled as supplier chains or supplier networks.

By the re-definition in the most recent amendment of the "New Small and Medium Enterprise Basic Law' (1999) SMEs in manufacturing and related industries (excluding wholesale, retail and service sectors) are classified as employing 300 or less regular employees or with an invested capital of 300 million yen or less (SMEA 2000). According to the 2000 census, the number of business establishments in the manufacturing sector in 1999 was 689,194 , of which 685,312 were small and medium-sized companies. The number of small-scale companies, a sub-set of the SME class, amounts to 584,365 establishments, which covers approximately 85 per cent of the SME category (JSBRI 2002).

These very small companies gained a doubtful reputation as the bottom of the Japanese manufacturing sub-contracting system during the post-war phase. Historically, small companies used to serve the local markets with food, craft goods and services. But after the Second World War, in accordance with Japan's accelerated 'catching up' industrialization, the small companies were gradually transformed into 'servants' in the supply chains which were rapidly spreading out in the manufacturing sector in the 1960s and 1970s (Storz 1997; Whittaker 1997). Though this seems to be an acceptable description of the situation in the past, it is no longer adequate for the 1990s. Most of the 'subcontracting studies' up to the 1990s perceive small companies as passively obedient to their parent companies. But since the burst of the bubble economy, most of the small and medium sized companies follow a new policy of reducing their dependency to one single major company. This striving for the reduction of financial risks is very widespread among SMEs and, since it implies a reduction of collaboration with major companies, it cuts off the formerly 'direct and automatic' access to technological know-how from the large (parent) companies. Though some SMEs were able to improve their position in innovation relationships under the new policy of SMEs to diversify their customer bases, an increasing number of small companies found it increasingly important to cooperate with other - preferably independent - sources of technological expertise. Regarding the $R \& D$ cooperation preferences, there are some pronounced differences between small and large enterprises' behaviour. While the majority of large manufacturing companies, which are engaged in $R \& D$, maintain cooperation with universities, the number of small and medium companies cooperating with universities is much smaller (only one-fifth of SMEs engaged in R\&D activities). About a fourth of SMEs doing $R \& D$ are not cooperating at all, while only 10 per cent of the large companies do not cooperate with other organizations. The interviews conducted with SME presidents disclose that for many of them the services 
provided by public or national research institutes do not match their needs. The preferred cooperation partners of SMEs are other SMEs operating in the same industry, and public research institutes (SMEA/JSBRI 2001).

Besides the voluntary networking among independent SMEs, the most vital means of support in technology development and improving innovation capabilities for SMEs are the public policy's various initiatives to provide technological support as well as HRD and business improvements to SMEs. The most important actors in these public support schemes are the Ministry of Economy, Trade and Industry (METI), particularly through its Small and Medium sized Enterprise Agency (SMEA), furthermore, the universities and public R\&D institutes and laboratories, and, above all, the public testing centres kôsetsushi. This chapter will focus its attention on the latter. ${ }^{5}$ The following analyses and interpretations focus first and foremost on the public testing centres, that is, their services and relationships to SMEs as well as their relationship to other innovation actors like universities and institutes and their contribution to a technology transfer infrastructure (Hassink 1997). This is mainly because the kôsetsushi are a Japan-wide network of regional support centres. Run under the auspices of the prefectures they offer a variety of services to SMEs in all prefectures of Japan. The services provided are especially tailored towards the needs of the SMEs, which in particular means considering regional and local peculiarities.

\section{The social and cultural organization of innovation in US manufacturing}

Still very often, the major insight of researchers analysing innovation or technology transfer in the United States is that 'America is a big country'. This statement is used for justification of at least two difficulties in doing research in the United States. First, it is undoubtedly very difficult to provide typical findings (not to mention statistical means). And second, in empirical investigations the sample is almost never big enough to meet the standards of representation and validation.

Keeping these general difficulties in mind, there are good reasons to conduct a highly selective investigation on innovation policy addressing SMEs in the US manufacturing sector.

Similarly to the Japanese case, the US economy also has a huge number of SMEs operating in the manufacturing sector. The number is 362,829 establishments (US Census Bureau 2001 \#709). It has to be considered that small and medium-sized companies in the United States are defined as those with fewer than 500 regular employees. Obviously this definition does not match the Japanese classification, but the difference can be 
ignored since this report is not applying statistical procedures. Actually the empirical findings in both countries show that the definitions are not strictly followed in the transfer centres' daily operations; and in both countries the majority of client companies lie within the cluster of 100 employees or fewer.

In a general view, the US SMEs share the problems of their Japanese 'partners'. The burning issue is the problem of under-capitalization and above all the lack of (advanced) technological expertise and access to cutting edge technological know-how. At first glance the technology transfer and innovation support policy in the United States is facing pretty much the same problems as the Japanese, and the implemented technology and innovation policy is - superficially observed - very similar: a nation-wide network of approximately 70 regionally embedded technology transfer centres run under the Manufacturing Extension Partnership (MEP) programme. Beside these centres, there is a variety of other organizations providing similar services such as the NASA Technology Transfer programme for SMEs, the Small Business Administration (SBA) and a number of decentralized state activities/initiatives such as the Thomas Edison Programme in Ohio.

\section{The kôsetsushi centres in Japan ${ }^{6}$}

All over Japan a network of approximately 170 public testing centres (kôsetsushi) is operating in the field of technology transfer, advice, enabling product innovation, networking and last but not least in providing testing facilities and services for small and medium-sized companies. ${ }^{7}$ The possible clients of these kôsetsushi preferably belong to the manufacturing industries. According to the 1999 Establishment and Enterprise Census of Japan, the Japanese manufacturing industry is comprised of 689,194 establishments of which 3,882 are considered large enterprises. This means that 99.4 per cent of all the enterprises in manufacturing are small and medium-sized companies (the approximate number is 685,000). Around 85 per cent of all enterprises can be assumed to be small-scale establishments with less than 20 employees (quoted by JSBRI 2002). There is a huge heterogeneity among these SMEs regarding their technological level, their market performance, their human resources structure etc., which makes it difficult to assess their competitive performance and thus the arising needs. But what remains without doubt is that there is a considerable number of small enterprises with structural deficiencies in the fields of technology, human resources or competitiveness.

Given that these deficiencies generate a 'demand' for services to compensate and improve the performance level of small and medium-sized companies, it is easy to understand that policy established a nation-wide system/structure for technological support of SMEs. The above-mentioned 
public testing centres form such a structure. But it has to be considered that many of these centres have a long history dating back to the early twentieth century. ${ }^{8}$ At that time, a considerable number of centres were founded, but many were first established as agricultural extension centres and later on transformed into industrial centres. During the decades of the last century a continuous flow of founding new establishments (sometimes they were the result of mergers) was taking place. From the early days, these centres were actually established and run by local prefectures or city governments and were only supervised by METI's (formerly MITI's) Small and Medium Enterprise Agency (SMEA). In general, the largest share of the kôsetsushi funding is provided by the prefectures, a little is sponsored by the METI and some income is attained through commissioned services. The accumulated budget of all kôsetsushi in FY 1994 was about, 750 million dollars (Bass 1998) and according to various interviewees' estimations surpassed the sum of 1,000 million dollars in FY 2003.

What remains to be stated - independent of assessing the financial resources spent to establish and maintain the kôsetsushi system all over Japan - is that during the last decades the kôsetsushi undoubtedly contributed to the increase of single SMEs' efficiency and, even more important, the kôsetsushi system supports the improvement of Japan's industrial organization as a whole - and thus boosts Japan's global competitiveness.

\section{The kôsetsushis' services}

Today in Japan every prefecture maintains at least one kôsetsushi and additionally there might be a limited number of subsidies, which generally are located in or nearby industrial clusters within the prefecture. This sums up to approximately 170 technology transfer centres over all prefectures in Japan. Being located at arms' length to the potential clients is the dedicated policy of the kôsetsushi.

The service portfolio provided by the kôsetsushi is uniform and can be understood as standardized, but regarding the contents tailored to the regional peculiarities. In detail the services cover the following:

- Technical assistance. The centres respond to requests by SMEs, contacting them via phone or personally (including factory site visits). These inquiries can range between a three-minute phone call and a consultation lasting several days. Generally the subjects are technical matters, but beside the traditional material, machinery, production process problems increasingly combined with technological, business and managerial advice is called for.

- Testing and use of equipment. This used to be - and still is - an important service provided by the centres. Manufacturers bring prototypes or manufactured parts for analysis of material or surface quality, for measuring of tolerances and the like. The kôsetsushi provide 
test protocols, which generally are accepted by the regional industry and often serve as quasi certification. Additionally, some kôsetsushi offer supervised use of machinery and equipment for testing of the SMEs' own products, and for manufacturing purposes (production test runs etc.).

- Cooperative research and development. The transfer centres offer the conduct of joint research and development projects with SMEs, either on a bilateral basis or as a network activity in which several companies as well as universities or other research institutes can be involved. These collaborations often are set up in the so-called 'exchange plazas' run by almost all kôsetsushi - though labelled with varying names. These institutes offer SMEs the opportunity to meet and explore opportunities for cooperative product development and the like.

- Networks of innovation. These networks and permanent working groups often start with discussions on technological, business and market issues (e.g. through expert guest lectures), and then proceed towards more practical issues like developing joint business plans, manufacturing partnerships or cooperative product innovation.

- Information and training. This is a service addressed to a broad audience of regional SMEs. Technical libraries and databases serve as information pools to be used either directly by the SMEs or through the kôsetsushi's personnel. The latter sometimes covers the service to conduct Internet inquiries in patent databases. The offered training courses address a wide range of topics - preferably IT-related courses, CAD etc. The courses are either held as full-day seminars or as evening courses; the latter can last several weeks.

The most popular services provided, are testing and technical assistance. Testing, a highly appreciated service, is principally offered free of charge. The client companies generally are satisfied with this service, but the quality and scope of testing facilities varies. Some kôsetsushi have specialized equipment (according to the region's traditional specialty), but in general there have been no significant purchases of equipment since the early 1990s. Thus, it is only a matter of years until technological progress makes the testing facilities outdated - if this is not already the case. Most of the directors and managers of the examined transfer centres are aware of this problem, but there are no signs for an improvement of the situation: first, the bubble burst and then the fiscal crises have emptied public budgets since the 1990s, while the 1999 revision of the Small and Medium Enterprise Basic Law re-directed a considerable share of available funding to support start-up companies and to maintain well-performing firms (SMEA 2001). 
The ranking list of services looks like this: as already mentioned, the most popular services are technical assistance and testing activities, followed by cooperative research and development. Finally, networking and information and training activities are not really unpopular services but the demand is not as strong as it is for technical assistance and testing. ${ }^{9}$ Rather than trying to explain theoretically how the services are used, I will give a brief example derived from the empirical survey. But beforehand some remarks on pricing policy need to be made. The strategy for charging for the services offered is very easy: only symbolic prices have to be paid, thus they are factually free of charge. This evidently is a strong incentive for very small enterprises to get in contact with the kôsetsushi and use their services. We will see that despite this positive incentive only a small portion of the regional SME population is a client of the kôsetsushi. On the other hand, the fact that no business revenues are produced, drives the kôsetsushi into a strong dependency on public funding.

\section{A typical example}

To give some impression of how SMEs use the kôsetsushi's services, a typical example shall be given: Nakamura Seisakushô ${ }^{10}$ is a small enterprise located in Niigata, employing 45 regular employees and a small number of part time employees (eight). The company produces crankshafts for motors, punching dies, and dies and moulds. A long history of cooperation, dating back almost to the founding of the company in 1992, exists with the kôsetsushi (which is within a 10 minute car ride). In the beginning, the most needed service was testing. The company was able to manufacture parts at a high level of accuracy but could not measure them and provide testing protocols. The Niigata kôsetsushi was well equipped with measuring devices and was able to deliver the service, and this turned out to be the starting point for an ongoing continuous and trustful collaboration. Today the company uses the full range of services provided by the kôsetsushi. Nakamura Seisakushô plays a leading role in one of the local product innovation networks. These networks are also found in other prefectures. The main purpose is to support those companies, which want to develop new products for new markets. This explains why these networks often begin with discussing new product perspectives either with personnel of the kôsetsushi or with invited experts from institutes, universities or successful entrepreneurs. In the case reported here, the network developed a very ambitious plan to launch a local automobile industry in Niigata (where there is none). During a period of six to seven years this plan was downscaled to the project of developing a small-sized unmanned vehicle, which can be used for transporting people (also elderly and handicapped) at fairs or other localities. 
The sketched innovation network assembles presidents of 11 companies that are in some cases direct competitors, but nevertheless it was possible to establish a high level of trust among the participating presidents. A 'cultural' explanation for establishing trustful and favourable communication and cooperation structures is the penchant for cooperative individualism, rather than Western 'rugged' individualism, an idea based on Yamazaki's 'contextual' approach (Yamazaki 1994). Evidently, there is no automatic cultural mechanism establishing an atmosphere of trust and a high level of communication and information sharing among the network actors, but through mutual preparedness to take trust building measures it can be easily achieved - and can be extended to further collaborations in other contexts.

Similar mechanisms are in effect between the kôsetsushi's advisors and the company presidents: once they have established a common communication basis, they can achieve a high trust level, which guarantees a long lasting cooperation.

\section{The kôsetsushi's competence building}

The kôsetsushi's personnel are dominantly comprised of technical staff, which is in accordance with their (still prevailing) mission of providing technological, rather than business and managerial, services. In five of six visited technology transfer centres (including one branch office) close to 80 per cent were university graduates (bachelors or masters) in engineering. Most of them were recruited directly from university. Two kôsetsushi had a considerable share of staff who were transferred permanently from the prefecture administration. An interviewee from the SMEA confirmed this as a general problem of the technology transfer centres in Japan, because these transferred employees were usually at the end of their careers and the chances of them developing into fully fledged advisors are low. This is mainly because the time required for getting acquainted with the matter and becoming accustomed to the specific problems of SMEs takes years, which is perceived as a negative incentive for the end-ofcareer transfer employees.

In contrast to these 'fossilized' structures, there were two technology transfer centres in the sample which employed an extraordinarily young staff of technical people, none of whom were transferred from prefecture administrative bodies. Settling into new jobs and familiarizing themselves with the specific subjects took the 'freshmen' a couple of years. This process, far from being incidental, was well structured by a system of 'work in tandem' which meant accompanying a senior advisor during his client meetings, etc. Eventually, the junior advisors were capable of doing the job appropriately. 
Interestingly, over time, strong personal relationships between the technical advisors and 'their' clients are emerging. These informal relationships guarantee a long lasting cooperation between the SMEs and the kôsetsushi, and a high level of mutual trust, which is important for further activities like launching innovation networks etc.

Summing up the findings it can be stated that, in general, the SMEs are highly satisfied with the scope and the depth of services; some companies wish to have more detailed and in-depth technical assistance. All of the companies appreciated the 'symbolic' pricing. But some of the visited companies formulated the wish for extended services, which go beyond the mainly technical assistance provided by the kôsetsushi. The clients could (1999/2000, 2001 and 2002) not fulfil these needs yet, when the interviews were conducted, but almost all of the directors of the kôsetsushi were aware of these expectable changes in the demands shifting from 'pure technology' towards integrated technical and business advice. Additionally, the shift from a provider of a huge variety of services towards a broker of information and services was clearly seen as an emerging issue.

Despite the kôsetsushis' great and widely appreciated achievements in improving the Japanese industrial organization and global competitiveness, one problem to be addressed is the fact that the centres can only reach between 5 and 10 per cent of the local SME population. The reasons given by the kôsetsushi's staff are lack of time of the SME presidents, lack of information about the kôsetsushi and its services etc. What was not mentioned, but addressed during company interviews with SMEs not cooperating with technology transfer centres, was the poor standing the kôsetsushi suffer from - at least in those parts of the SME population that are engaged in high technology areas like semi-conductor and IT industries or nanotechnologies. Companies operating in these fields usually are equipped with a high level of specialized knowledge accumulated over time, which goes beyond the more broad and general capabilities rather than the in-depth technological capabilities of the kôsetsushi's staff.

Among the interviewed directors and advisors of the kôsetsushi centres there was, in some respects, an atmosphere of fear. Around 2001, it was quite clear that some systems for evaluating the kôsetsushi would be implemented and the centres were not able to estimate the arising consequences of this 'innovation'. These being whether they will suffer severe cuts in their budgets (provided their evaluation is negative) or whether they will be forced to change their pricing policy to the detriment of the SMEs. The dominating attitude was reserved - only a few people saw the inherent chances of improving the operation and services of the kôsetsushi through the implementation of evaluation systems (first insights on the consequences of evaluating the kôsetsushi are presented in Shapira and Furukawa 2003). 


\section{Klaus Ruth}

\section{The MEP centres in the United States}

The American counterpart of Japan's kôsetsushi is the MEP programme, which operates in all federal states across the United States. This network affiliates approximately 70 manufacturing extension centres and around 400 field offices located all over the United States. The centres and field offices work directly with the local small and medium-sized manufacturers. Picking up the thread of the above sketched structural and industrialcultural peculiarities characterizing the US manufacturing sector we can state a lot of similarities between Japan and the United States. There is a large number of SMEs in the US manufacturing industry: approximately 350,000 enterprises are the back bone of industrial production. Though increasingly important for the national production and global competitiveness as suppliers for large companies, there is a widening productivity gap between large and small companies. Thus, there is a similar scenario of problems and deficiencies as in the case of Japanese SMEs. To close the gap and to improve the SMEs' performance, support via technology and know-how transfer is needed. These are the general tasks of the MEP centres (and field offices). Looking closer at the services offered by the MEP centres it turns out that by and large they offer the same service portfolio as the kôsetsushi in Japan. The most striking difference is the low importance of testing. The interviewees estimated that less than 5 per cent of the MEP activities are related to testing and measuring. Only those centres cooperating with other more technology based and better equipped programmes or with engineering departments of local universities carry out these testing services on a larger scale. The major fields of activities are the following:

- Integrated technical and business assistance. Labelled with lean enterprise and includes kanban and kaizen systems, business process restructuring/improvement, total productive maintenance etc. These services are offered as one-day workshops held at the MEP centre. An additional, more technical service is manufacturing cell and plant layout; it is always delivered on site. A further field of technical assistance was the so-called e-business-readiness, which was a prominent single service at the time the interviews were conducted.

- Quality assurance. The development, implementing and maintaining of quality systems and the preparation of SMEs for an ISO certification (ISO 9001 and ISO 14000) are the core of the quality assurance activities. These are delivered as workshops or courses held at the centres and attended by the clients, and as a more advanced in-company advisory service. 
- Human resources development and training. The assistance in this field ranges from collaborative job design and analyses for developing and offering training and development units.

- Cooperative applied research and development. This activity is very similar to the Japanese case. The subject of these joint activities is the search for new products and 'paving the way' for bringing them into the market. Cooperative R\&D is in most cases bilateral, sometimes a third party (mostly specialists in the respective subject field) is included.

- Networks of innovation. All MEP centres that were researched offered their clients the opportunity to join permanent working groups with the chance of further developing into innovation networks, which eventually might launch tangible innovation; currently there are no innovation networks.

It needs to be noted that in the face of the huge variety of services and given the limited internal human resources in the MEP centres, a considerable share of the services involves the inclusion of external experts, for example, consultants, universities and specialized providers. Thus an important role played by the MEP centres is that of an expertise broker.

The most prominent services provided, were quality assurance and lean manufacturing or lean enterprise. These services were part of a standardized package that was offered by all MEP centres - nevertheless it was adapted to the customer's specific needs and to the particular industrial contexts. In many cases, it led to a complete reorganization of business processes. These services are not limited to technical advice nor are they restricted to one dimension of the business processes. On the contrary, the advisors/consultants of the investigated MEP centres maintained pronounced holistic approaches. Certainly, they accepted the clients' initial (technical or quality) problem and worked on this, but whenever it turned out that solving the problem required a broader approach considering organizational and managerial issues, they tried to convince their clients to follow the more comprehensive business-restructuring path. Even if this might look like 'increasing turnover' from the MEP centres' point of view, it was reported that there were no cases where clients were dissatisfied with the service enlargements. On the contrary, these customers all belong to the pool of long-standing clients.

Depending on the particular situation (local industrial structure and local availability of technical facilities and know-how), there were some MEP centres, which had a comparatively large share (up to 40 per cent of turnover) of technical assistance. In these cases, the main focus was on the customization of automated machinery and design, developing and improving automated production processes. 


\section{Klaus Ruth}

Human resources development and training courses ranged behind the integrated technical, business and quality assistance. Interestingly, the training courses and seminars acted as entrance gates to collaboration with MEP centres.

Cooperative product innovation always ranged behind the abovementioned services - even though developing future-oriented products for emerging markets would be the best way to secure staying in business. The interviewees' responses unanimously indicate that these activities require a high level of mutual trust. At the same time this explains why the MEP centres have enormous difficulties establishing local or regional innovation networks. Since these activities are closely tied to competitiveness, hardly any SME feels challenged to participate and run the risk of losing competitive advantages.

In accordance with their mission statements, the MEP centres preferably serve SMEs, but if there is a large local company asking for service, the large company will also be served. There were two cases reported in which a large manufacturer, together with some of his suppliers, asked for technical and quality assistance from the MEP centre.

As already indicated, the number of client companies being served two or more times is very high. At the time the interviews were conducted, the share of new (first time) clients was around 25 per cent. The accumulated number of clients served by each MEP centre is, on an average 5-10 per cent of the regionally accessible SME population. Thus, there is a huge potential for more activity. One reason why it is difficult to get into business relations with these 'hidden reserves' is that the average company size of MEP centres' clients is above 100 employees. This is not accidental, but rather related to the pricing policy of the MEP centres. In clear contrast to the kôsetsushis' policy of symbolic prices, the MEP centres charge market prices comparable to those of commercial consulting companies. Thus the services of the MEP centres are hardly affordable to the very small enterprises with less than 20 employees - given their chronic scarcity of financial resources. This structural bias will be discussed and evaluated in the following chapter on comparative conclusions.

A look at the budgets of the MEP centres shows that most of the centres were build on various sources of public and private funding: the share of federal funding is about one-third, the remaining two-thirds originate from state support (through state programmes like Thomas Edison Centres in Ohio) and from clients' revenues. This mixed financing truly reduces the dependency on public funding and makes the MEP centres less vulnerable to federal budget cuts, such as the budget cut in FY 2004 from 105.9 million dollars down to 12.6 million dollars. It remains to be seen how far this development affects the operation of the MEP centres, but because of the financial structure sketched above, it seems likely that 
they will continue their work. If a 100 per cent publicly subsidized system, such as Japan's, was facing similar drastic cuts, it would break down.

\section{The MEP centres competence building}

The visited MEP centres and field offices all showed a similar qualification structure among their personnel. Unlike Japan, the staff was not predominantly comprised of engineers, but rather 50 per cent of the personnel were technical people - mostly bachelors of engineering. The remaining half was people with a business, economy or psychology background. Generally, only people with prior industry experience were recruited by the MEP centres.

As indicated earlier, there was a circle of freelancers and independent consultants around the MEP centres who collaborated on a project basis. It is noteworthy that all MEP centres which were surveyed employed coop students. It was a good opportunity, at least in some cases, to be employed at the MEP centre after returning to the university and finishing the studies.

In general, the interviewees emphasized that for job seekers, there were comparatively high incentives to work at an MEP centre, because the wages are good (it competes with salaries at middle-sized consulting enterprises) and MEP centre staff have a big advantage over employees of nation-wide operating consultants: there is only client visiting 'at arm's length', that is, no extensive travelling activities. These two factors contribute to low turnover and thus relatively stable personnel.

\section{Evaluation}

In pronounced contrast to the Japanese kôsetsushi system, the MEP programme has implemented an internal evaluation system, which is conducted by the NIST. Additionally, there are some external evaluations that are not conducted regularly (Shapira 2001). NIST's evaluation efforts target at quantifying the arising benefits for the SME. A one-page questionnaire is sent out asking for the quality of the service, the performance of the staff and for quantification of project-induced cost savings, job creation/retention and the like. Evidently, this is only a limited impact evaluation, which presumably serves the purposes of the programme administration. Though there is a considerable uncertainty regarding the reliability of data, it allows some assessment of the regional impacts of the MEP centres' work.

During the interviews here, one case was reported of a process-inherent evaluation conducted by the MEP centre staff targeted at evaluating the project performance. It is highly informal, not standardized and is carried out as self-supervision meetings, which are held during the project and right after finishing a project. These meetings include people directly 
involved with the SMEs and staff from the MEP centre. Once established, this 'informal self-evaluation' is of great value for the MEP staff in order to improve their concepts, processes and services.

\section{Comparative conclusions}

In the following, some detailed conclusions will be presented followed by a general conclusion tied up with a recommendation.

1 When comparing the funding structures of the Japanese kôsetsushiall of which are financed by their respective prefectures and local governments - with the funding of the MEP centres, it becomes clear that the Japanese way of single-source funding in combination with the marked policy to deliver cheap services and, therefore, not produce any business revenues, on the one hand makes the services affordable to all SME, but, on the other hand, creates a high dependency upon the sponsoring authority. It makes them vulnerable to policy changes like those in the wake of the latest revision of the Small and Medium Enterprise Basic Law in 1999, which launched a shift from broad SME support towards an 'elitist' support of the best performing SMEs. Despite the potential risks and dangers, the biggest advantage of the Japanese system is still the fact that services are almost free of charge and thus even the very small SMEs can afford the services. On the contrary, the US MEP centres are less dependent on federal funding and are thus more robust towards policy changes, because there are other public (state sponsored) sources available and business revenues are produced by charging market prices for the delivered services. The price paid for the emerging greater independency of MEP centres is the exclusion of very small SMEs as customers, because they cannot afford to pay the high prices charged. The positive side of the relatively high prices is a corresponding high appreciation of the delivered services, which contributes to a better reputation.

2 Both countries' technology transfer centres share a comparatively low rate of success when considering their access to the local and regional SME population. In neither case surveyed or found in literature is the ratio above 10 per cent. This clearly indicates that different pricing strategies generate neither advantages nor disadvantages. Though the US system of charging the SME clients market prices explains why very small SMEs are kept out, the reverse strategy of delivering services almost free of charge followed in Japan does not guarantee high demand. Explanations for why so few SMEs use the kôsetsushi's services range from lack of knowledge to the mismatching of needed services and services actually supplied. 
3 The kôsetsushi centres focus very narrowly on technical assistance while the MEP centres develop a broader integrated business-oriented service. Although a considerable number of SME clients appreciate the services of the kôsetsushi and consider them to be appropriate to their current needs, the Japanese kôsetsushis' technology transfer concept is falling short of the challenges raised by the transition from the supply-chain model that influenced the SME strongly towards the new role of self-supporting innovator. The former phase was primarily characterized by technological deficiencies of SMEs, which prevented their escape from supplier relationships. But if the transition towards innovators is to be fully realized, broader competencies are needed (marketing, organizational expertise, managerial resources etc.). The kôsetsushi centres still do not provide these services on a broad scale and thus are not as progressive as their US counterparts. The MEP centres offer a broad set of integrated business services, which makes them more sustainable.

4 The Japanese system of kôsetsushi centres is more successful in networking with local clients. A considerable variety of different network types exist: production networks, innovation networks, dissemination networks and strategic innovation policy networks. These networks were usually launched by the kôsetsushi utilizing their infrastructure (exchange plazas), but after a while, they run without major input from the kôsetsushi. A crucial success factor for networking is the Japanese communication culture and an easily maintained high trust level. In the US, the MEP centres' attempts to establish client networks have failed because of the clients' fear of losing competitive advantages, know-how, etc.

The question as to how far the technology transfer centres contribute to improving the regional economies has to be answered cautiously. In general, the contributions are difficult to measure. In the case of the MEP centres, which are strongly geared towards single companies, the impacts on the regional economy can only be understood as the result of these projects. The NIST's evaluation efforts try to measure these impacts in terms of jobs created. In Japan, it is the excellent local networking that bears some potential for regional development. Some of these networks explicitly intend to improve the regional economy through their activities.

5 The Japanese kôsetsushi have only very recently (since 2002) started to launch evaluation systems - mainly as a consequence of METI's Guideline for Technology Evaluation, which was established in 1997 and amended in 2001. So far, no comprehensive data on the quality of these evaluations is available. Compared with this, the US MEP programme established an evaluation system early on in the programme. 
As mentioned earlier, the main purpose is to quantify the success. This evaluation concept calls for further development and refinement and could be amalgamated with the informal in-process self-evaluation conducted by some MEP centres.

All in all, the research findings indicate that technology transfer centres, which provide a specialized service for small and medium-sized enterprises, are a useful institution. The major reasons for specialization are the SMEs' distinctive needs, which technology transfer centres that offer general services (not addressed to a specific target group) cannot adequately fulfil. Additionally, the common, non-specialized R\&D service providers like universities, R\&D laboratories and general technology transfer centres have very little incentive to specialize in the technological problems of SMEs, because they are not challenging for them, and in the case of universities, not suitable to build a career on.

The described sketch of problems is true for both countries inquired probably more for Japan than for the United States. Even when considering the different operation modes of MEP and kôsetsushi centres, we find that in both cases, benefits for the targeted customers are generated. The different approaches arise from different social, institutional and cultural contexts in which the respective centres are embedded. If this chapter draws the generalizing conclusion that the US MEP centres are more future-oriented in comparison to their Japanese counterparts, this indicates that the United States have a lead over Japan. But there are emerging signs that the Japanese system will be reformed and thus adapt to the changing needs of SMEs.

If the broadest conclusion of this chapter is that running a national technology transfer system for SMEs makes sense, then other countries which have not yet established such a system should do so. Even if measuring the contribution of such systems to regional economies or to regional innovation systems is a difficult task, it remains without major doubts that by improving the technical and business bases of SMEs, the supply chains of production improve and thus the regional, national and global competitiveness is increased. When accepting the general recommendation to establish a national technology transfer system for SMEs, the remaining questions are: how and what can we learn from the given examples? Which is the role model for learning - Japan or the United States? Which policy, institutional, social and cultural structures can be built upon?

If we want to answer these questions in Germany, we need to thoroughly re-think the prevailing policy, institutional, social and cultural contexts and develop ideas for how new structures, routines and institutions can be implemented in the German industrial culture. The idea of cross-cultural borrowing (van Buskirk and Takeuchi 1984) focuses on the creative adaptation and integration of management or business concepts 
into the existing structures by developing them further. This might be a useful approach. In Germany, there are technology transfer structures to build upon. On the one hand, the regionally focused Steinbeis centres have a clear SME orientation. On the other hand, the Fraunhofer Institutes have a technological rather than an SME focus, but could play a role in establishing a national network of technology transfer centres for SMEs.

In conclusion, more research and constructive concept development is needed to get a clear idea of what innovation policy for SMEs in Germany could look like.

\section{Notes}

1 This issue will be developed further in Chapter 3 of this volume.

2 Carried out between 1999 and 2002 at the University of Applied Science in Bremen, funded by the German Ministry of Education and Research (FKZ 1703899). The project was directed by Cornelia Storz who did the first part of empirical work. The second phase of research was conducted by the author in collaboration with Japanese and US research partners.

3 Kôsetsushi is an acronym derived of the Japanese words for public kô, establishment setsuritsu, and testing lab shikenjo.

4 The scheduled interviews with the MEP administration were cancelled because of the unexpected incidents of September 11, 2001.

5 The internationally well-recognized Technopolis programme is widely neglected in this article, because it has different goals and was not specifically geared towards the SME clients Abe, S. (1998) 'Regional Innovation Systems in Japan', in H.-J. Braczyk, P. Cooke and M. Heidenreich (eds), Regional Innovation Systems. The Role of Governances in a Globalized World (pp. 286-318), London: UCL Press.

6 The findings presented in the following portray a selection of the extensive empirical material. The presentation focuses only on those findings which above all contribute to the comparison with the US case of MEP centres.

7 Originally, an import from the United States by the end of the nineteenth century as agricultural centres, they were rapidly transformed to industrial centres after the war Shapira, P. (1992) 'Modernizing Small Manufacturers in Japan: The Role of Local Public Technology Centers', Technology Transfer, 40-57.

8 The oldest centre's founding is dated to 1873 .

9 Note that there is no quantitative measuring as in the United States where the charged prices can be taken for establishing a ranking.

10 The name is fictional, though the descriptions are not.

\section{Bibliography}

Abe, S. (1998) 'Regional Innovation Systems in Japan', in H.-J. Braczyk, P. Cooke and M. Heidenreich (eds), Regional Innovation Systems. The Role of Governances in a Globalized World (pp. 286-318), London: UCL Press.

Baber, Z. (2001) 'Globalization and Scientific Research: The Emerging Triple Helix of State-Industry-University Relations in Japan and Singapore', Bulletin of Science, Technology \& Society, 21: 401-408.

Bass, S.J. (1998) 'Japanese Research Parks: National Policy and Local Development', Regional Studies, 32: 391-403. 
Boyer, R. and Freyssenet, M. (2000) 'The World That Changed the Machine. A New Framework for the Analysis of the Automobile Industry', Sociologia del Trabajo, 41: 3-45.

Braczyk, H.-J., Cooke, P. and Heidenreich, M. (1998) Regional Innovation Systems. The Role of Governances in a Globalized World, London: UCL Press.

Camagni, R.P. (1995) 'The Concept of Innovative Milieu and its Relevance for Public Policies in European Lagging Regions', in K. Haynes, K. Button and P. Nijkamp (eds), Regional Dynamics (pp. 317-340), Cheltenham: Edward Elgar.

Cook, C.R. (1999) Production Networks Revisited: Causes and Consequences of Supplier and Customer Linkages in the Metal Manufacturing Sector, Cambridge, MA: Harvard University Press.

Denzin, N.K. (1989) The Research Act, Englewood Cliffs, NJ: Prentice Hall.

Denzin, N.K. and Lincoln, Y.S. (1994) Handbook of Qualitative Research, Thousand Oaks, CA: Sage.

Doloreux, D. (2002) 'What We Should Know About Regional Systems of Innovation', Technology in Society, 24: 243-263.

Duschek, S. (2004) 'Inter-firm Resources and Sustained Competitive Advantage', Management Revue. The International Review of Management Studies, 14: 53-73.

Etzkowitz, H. and Leydesdorff, L. (1998) 'The Triple Helix as a Model for Innovation Studies', Science and Public Policy, 25: 195-203.

Geertz, C. (1973) 'Thick Description: Towards an Interpretive Theory of Culture', in C. Geertz (ed.), The Interpretation of Cultures. Selected Essays (pp. 3-30), New York: Basic Books.

Gibbons, M., Limoges, C., Nowotny, H., Schwartzman, S., Scott, P. and Trow, M. (1999) The New Production of Knowledge. The Dynamics of Science and Research in Contemporary Societies, London: Sage.

Grootings, P. (1986) 'Technology and Work: A Topic for East-West Comparison?', in P. Grootings (ed.), Technology and Work (pp. 264-288), Croom Helm: London.

Hassink, R. (1997) 'Technology Transfer Infrastructures: Some Lessons from Experiences in Europe, the US and Japan', European Planning Studies, 5: 351-370. (2000) 'Regional Innovation Support Systems in South Korea and Japan Compared', Zeitschrift für Wirtschaftsgeographie, 44: 228-245.

Heidenreich, M. (1997) 'Regional Innovation Systems in a Global Market', Kölner Zeitschrift für Soziologie und Sozialpsychologie, 49: 500-527.

JSBRI (2002) White Paper on Small and Medium Enterprises in Japan. The Age of the Local Entrepreneur - Birth, Growth and Revitalization of the National Economy, Tokyo: Ministry of International Trade and Industry.

Kitagawa, F. (2004) Innovation Systems, University-Business Networks and Regionalization of the Knowledge Economy in Japan, Regionalization of Innovation Policy-Option and Experiences, Berlin: JDZB.

Kodama, F. (1995) Emerging Patterns of Innovation. Sources of Japan's Technological Edge, Boston, MA: Harvard Business School Press.

Latour, B. (1999) 'On Recalling ANT', in J. Law and J. Hassard (eds), Actor Network Theory and After (pp. 15-25), Oxford: Blackwell.

Leonard, D. (1998) Wellsprings of Knowledge. Building and Sustaining the Sources of Innovation, Boston, MA: Harvard Business Schools.

Leydesdorff, L. (2000) 'The Triple Helix: An Evolutionary Model of Innovations', Research Policy, 29: 243-255. 
Leydesdorff, L. and Etzkowitz, H. (2001) 'The Transformation of UniversityIndustry-Government Relations', Electronic Journal of Sociology, 5. Available online at: http://www.sociology.org/content/vol005.004/th.html?PHPSESSID= e3f3eb88a4309a8f15a4cf4daec52b47

Lindman, M.T. (2002) 'Open or Closed Strategy in Developing New Products? A Case Study of Industrial NPD in SMEs', European Journal of Innovation Management, 5: 224-236.

Nowotny, H., Scott, P. and Gibbons, M. (2001) Re-Thinking Science. Knowledge and the Public in an Age of Uncertainty, Cambridge: Polity Press.

Piore, M.J. and Sabel, C.F. (1984) The Second Industrial Divide. Possibilities for Prosperity, New York: Basic Books.

Rauner, F. and Ruth, K. (1990) 'Perspectives of Research in Industrial Culture', in W. Karwowski and H. Rahimi (eds), Ergonomics of Hybrid Automated Systems II (pp. 115-132), Amsterdam: Elsevier.

Rothwell, R. (1983) 'Innovation and Firm Size: A Case for Dynamic Complementary, or is Small Really Beautiful', Journal of General Management, 8: 5-25.

- (1992) 'Successful Industrial Innovation: Critical Factors for the 1990s', R\&D Management, 22: 221-239.

Ruth, K. (1996) 'Industrial Culture - An Action-Oriented View at Innovation and Production', in L. Rasmussen and F. Rauner (eds), Industrial Cultures and Production - Understanding Competitiveness (pp. 84-103), London: Springer.

Ruth, K. and Rauner, F. (1996) 'Industrial Culture and Production - Towards a New Research Approach', in L. Rasmussen and F. Rauner (eds), Industrial Cultures and Production - Understanding Competitiveness (pp. 3-17), London: Springer.

Shapira, P. (1992) 'Modernizing Small Manufacturers in Japan: The Role of Local Public Technology Centers', Technology Transfer, 17: 40-57.

— (2001) 'US Manufacturing Extension Partnerships: Technology Policy Reinvented?', Research Policy, 30: 977-992.

Shapira, P. and Furukawa, R. (2003) 'Evaluating a Large-scale Research and Development Program in Japan: Methods, Findings and Insights', International Journal of Technology Management, 26, No. 2/3/4: 166-190.

SMEA (2001) Outline of Japan's New SME Policies (p. 27), Tokyo.

SMEA/JSBRI (2001) White Paper on Small and Medium Enterprises in Japan. 2001. A Wake-Up Call to Small Business - Building a Self-Sustaining Enterprise, Tokyo.

Storz, C. (1997) Der mittelständische Unternehmer in Japan, Baden Baden: Nomos Verlag.

(2000) 'Venture Businesses in Japan. Protagonists of a New Economic Order?', in T. Hozumi and K. Wohlmuth (eds), Schumpeter and the Dynamics of Asian Development (pp. 109-137), Münster: LIT Verlag.

Szarka, J. (1990) 'Networking and Small Firms', International Small Business Journal, 8: 10-22.

van Buskirk, W. and Takeuchi, K. (1984) 'Absorbing Management Technologies. A Cross-cultural Approach', The Journal of Tokyo Keizai University, 137: 273-289.

Whittaker, D.H. (1997) Small Firms in the Japanese Economy, Cambridge: Cambridge University Press.

Womack, J.P., Jones, D.T. and Roos, D. (1992) Die zweite Revolution in der Autoindustrie. Konsequenzen aus der weltweiten Studie aus dem Massachusetts Institute of Technology. Frankfurt, New York: Campus Verlag.

Yamazaki, M. (1994) Individualism and the Japanese, Tokyo: Japan Echo Inc. 


\title{
5 Cognitive models and economic policy
}

\author{
The case of Japan ${ }^{1}$
}

\author{
Cornelia Storz
}

\section{Introduction}

In 1956, the Dutch Nobel Prize winner Tinbergen was still able to assert that the regulation of economic systems could be achieved by creating a specific concentration of economic knowledge. Correspondingly, rules for an optimum on political design based on a structural model of economics were continually developed. This optimism vanished as it was discovered that economic systems are too complex to be steered in a goal-directed way. The disappointing experiences of the Eastern European countries in their transition from a centrally planned economy to a market economy, the decline of economic growth in Germany before and especially after reunification and the severe depression in Japan in the 1990s coined the 'lost decade'. Flagrant accounting scandals despite new international accounting standards and the defection from international environmental standards are just some examples of the difficulties of implementing economic reforms. The assumption that basic structures of economic systems are known and that political target definitions can be based on efficiency criteria exclusively, is no longer valid today, although it often still appears in political practice, as the political conception toward transformation states has recently shown (Tinbergen 1956; Eggertsson 1997).

The theory of institutional economics in particular, draws attention to three important aspects which have been neglected hitherto: (1) incentives through institutional settings, (2) information shortages and (3) preferences of politicians. Without wanting to criticize these positions in detail, ${ }^{2}$ they, too, exclude essential aspects: they only look at the parts of the process of economic policy which come after the identification and admission of problems, namely target definition, programme formulation and evaluation, and neglect the role of cognitive models existing before the whole process of formulating economic policies starts. Thus, the origin and treatment of problems always depend on a specific perception of reality, which differs between societies. ${ }^{3}$ 
Influenced by cognitive psychology, economists are slowly acknowledging the importance of cognitive models in economic policy since they can act as a break even to reforms, an assumption which seems to be appropriate. Such an analysis normally takes place on a very abstract level. This contribution tries to give empirical evidence for the thesis that cognitive models indeed do influence political processes considerably. A selected field of Japanese economic policy, namely Japanese small and medium-sized enterprise (SME) policy, is used as an example since reform efforts in this field are especially drastic, pleaded for by reformoriented policy-makers: SME policy should become more rule oriented, less supportive for less productive SMEs and a pillar of the new innovation policy. The influence of cognitive models on political processes is analysed for the most important phases of problem identification, target definition and evaluation. It becomes clear that reforms in Japanese SME policy are being pleaded for on the surface, but on a deeper layer, established cognitive models tend to persist: SMEs are perceived as being weak in contributing to the genesis of innovation and employment, and as players that need to be protected by economic policy. The strategic management deficiencies of Japanese SMEs are embodied in specific Japanese terms such as 'weak player' ( jakusha) or 'problem of SME' (chîshô kigyô mondai). Thus the dominance of established cognitive models results in a weak implementation of new political concepts, and in defection from and dilution of the aspired reforms. It is right that economic policies in general are 'muddle through' solutions; however, for Japan this tendency seems to be especially strong since the specific preference for decisions by consensus makes it even easier to push alternative concepts through the political process. The contribution comes to the conclusion that the role of cognitive models in political processes has indeed often been underestimated. For the success of reforms it is necessary to take the general perception more into account, but also not to overlook the rationality behind the stability of cognitive models.

The contribution mainly aims at giving empirical evidence for the importance of cognitive models in the political process. It starts from the general question why and to what degree economic policy is influenced by cognitive models and which consequences should be taken of this. Thus, the contribution is structured as follows: in the first section, I will introduce the general relevance of cognitive models in the political process. In the second section, I will analyse to what degree the Japanese SME policy has changed, and why changes on a deeper layer take place so slowly. Certain cognitive models towards SMEs have been identified as one important reason. In the last concluding section, I summarize the results, the rationality behind the incrementality of change and discuss what could be done in order to foster change in SME policies. 


\section{Cornelia Storz}

\section{Cognitive models in the process of economic policy}

\section{Identification and admission of problems}

Cognitive models were only recently introduced into economics. The introduction of cognition into economic theory goes one step further than the introduction of informal institutions, which also support the theory that institutions do not exist per se, but depend on the way they are perceived, that is, how they are constructed by certain social entities. Cognitive models thus structure the perception of reality from the beginning. ${ }^{4}$ Hereby, actors become able to act within a world that is filled with a chaotic mass of data (Hodgson 1994: 59; compare Koch in this volume).

Unlike the assumptions conventional descriptions of problems in economic policy are based on, taking cognitive models into account means that knowledge does not exist per se in the sense of a reflection of reality, but that reality is always based on a subjective perception - in the case of this contribution, for example, the political entrepreneur. Consequently, cognitive models within a group are relatively similar, whereas they differ between social groups. The consequence for the identification of problems is that different social entities assimilate different information and see different problems. They also differ in their choice of action, that is, which solutions they consider feasible, and in their choice of instruments to achieve their goals. Just like cognitive models, problems as well as instruments are selected and perceived as 'important' or appropriate. In the phase of identifying a problem, societies therefore perceive those problems as problems that match their respective cognitive models. For example: an economy in which the directive scheme of individual responsibility and the superiority of the free market dominate will define a high number of market exits as an efficient process of selection, but not as a problem in terms of social policy. By contrast, a society that takes the responsibility of the community for the individual for granted and builds up relevant social security networks, may view a high number of market exits as a problem. At the same time, however, entities are not homogenous. They consist of various heterogeneous groups and sub-entities which have different perceptions of problems and which are in a dynamic process of competition. This competition selects the problems that are perceived as relevant for the economic policy.

For the admission of a problem, only one problem among the large number of identified problems is selected. In this phase not only resources, threatening potential leadership qualities and the information that is available within a group play a central role, but especially the specific informal institutions of a society are important. Depending on given informal institutions, for example, preferences towards decision 
styles, the speed of change is influenced. In societies with a preference for consensus-oriented solutions, it takes more time to steer political programmes in a particular direction. Especially in homogenous societies, institutional change in policies is then expected to be even lengthier (Eisenberg 1999).

\section{Target definition and programme formulation}

The phase of target definition and programme formulation ${ }^{5}$ follows the phase of identification and admission of problems. Here, two scenarios are imaginable. In one scenario an admitted problem is the result of a standardization of different identifications of problems within a society. In another scenario a problem is admitted without the society actually having to come to a consensus beforehand. In the latter case the competing individuals will attempt to prove the validity of their model, further trying to get 'their' problem accepted by attempting to influence the process of target definition and programme formulation. This scenario describes the reality of political processes more accurately. In other words, it is more often not the case that a problem is recognized as such and then automatically definition, target and programmes are determined. Instead, different perceptions of problems and different views on target definition and programmes are in constant competition with each other.

This means that the probability of inconsistent and non-transparent political programmes is higher, the more alternative perceptions and solution models are admitted institutionally. Therefore, in societies with a certain level of openness, political programmes are not uniform but rather a bricolage, as Lanzara (1998) calls it. The consequence is a general lack of transparency and consistency. Economic policies in open societies have at least this aspect in common - the fact that they are 'muddle through' solutions. This definitely also applies for the Japanese economic policy. Nevertheless, due to the variation of informal institutions, changes in societies that prefer consensus-oriented decision-making are brought about even more incrementally than in societies which accept majority decisions. Therefore informal institutions are decisive for the direction and speed of change.

\section{Evaluation}

The phases that were mentioned in the preceeding pages are followed by the evaluation phase. There are various methods designed to evaluate economic policies (see OECD 2000). Often, evaluations concentrate on the criteria of consistency and transparency. In its weakest definition consistency means the compatibility of different problem fields and the suitability of the chosen instruments in relation to the defined problems. In its strongest definition it stands for the correctness of the defined problem 
and the achievement of the intended effect. Transparency in its weaker definition is the comprehensibility of the process by the user. In its stronger definition it means that the process of evaluation for the implementation practice, that is, the efficiency of the processing of a programme, is reviewed (Klemmer et al. 1996: 20-24; see also Ôkuma 1999: 43). Even if these criteria are plausible it is necessary to consider, based on the explanations given earlier, that the evaluation phase is also influenced by cognitive models. For example, these can be reflected in the definition of specific evaluation criteria, implying a normative relation.

In summary: cognitive models may stabilize existing structures. Using the case of Japanese SME policy, Chapter 6 discusses in which phases of the economic political process cognitive models influenced the speed of change.

\section{Cognitive models in Japanese economic policy: the case of SME policy}

A great amount of literature is available on processes of economic policy in Japan. Often, specific structures and decision patterns in target definition within politics, bureaucracy and industry (the 'iron triangle') have been analysed. Nevertheless, while the literature focuses on the process of target definition and programme formulation, the role of cognitive models in general, and questions of evaluation in specific, have been neglected. ${ }^{6}$ Similar deficits in research can be ascertained for SME policies, which are mostly limited to exploratory explanations.

In the following pages, the role of cognitive models in the process of economic policy is discussed by using Japan's SME policy as an example. In the section on 'Identification and the admission of problems in SME policy,' the perception of SMEs in Japan will be discussed. The following section deals with target definition and programmes in the Japanese policy for SMEs, and the section on 'Evaluation: the case of regional technology centres,' uses a specific range of support measures for SMEs to show how specific informal institutions lead to the fact that different cognitive models are taken into account, and how they influence the dynamics of change.

\section{Identification and admission of problems in SME policy}

\section{The tradition of 'weak' SMEs}

Japan has a long tradition of viewing SMEs as lifeboats for unemployment, extended production facilities or as company segments with little chances of growth. In a word: they are regarded as being technologically inferior and disadvantaged in comparison with large enterprises. This view was already ascertainable in the early phase of industrialization in Japan at the end of the nineteenth century. The term 'SME problem," 
existing since that time, signifies the economic disadvantage of SMEs for the entire economic welfare of the country, meaning that losses in economic welfare are caused by the low productivity of SMEs. The term 'weak enterprise' refers to the sub-optimal enterprise size of SMEs and their deficits in innovation, technology, funding and management; in other terms, it refers to the weak contribution of SMEs to innovation and employment. The expression 'too many enterprises' expresses the necessity for reducing competition (Storz 1997: 16; CKC 2000: 2; Arita 2001).

What is the background of this specific perception? From an empirical point of view one can say that industrialization in Japan was basically undertaken by large enterprises as they had access to Western technology. SMEs' performance concerning productivity and innovation was, by contrast, low - a difference that was attributed to their limited access to factor markets and their size structure, which was considered to be suboptimal. The large number of SME bankruptcies as a result of the recession after the Russian-Japanese War (1904-1905) and the First World War led to the first government programmes for SMEs. They were basically social programmes and not as much measures promoting innovation or productivity. External shocks and the buyout of small and medium-sized regional banks by the enterprise group's major banks made the situation worse and finally led to a loss of financial autonomy for the SMEs. Additional soft loans and programmes for SMEs, as well as state promotion of cooperatives and credit guarantee associations, were supposed to alleviate the difficulties of entrepreneurs in the 1920s and 1930s.

This perception of SMEs and SME policy in the style of social policy had a revival after the Second World War, a policy that was confirmed by empirical data on productivity and income in SMEs. In 1957 Arisawa called Japan's economic structure a 'dual structure'. After the introduction of this term in the Economic White Paper of that year it became common language usage, and was used as an argument for conceptualising SME policy in the way of social policy (Storz 1997: 16; Teraoka 1997: 36-38; Arita 2001).

Besides empirical data, the view of SMEs and their inability to play an important economic role on their own was encouraged by a long-term dominance of economic research influenced by Marxism approaches. According to representatives of this school, the 'SME problem' was mainly caused by Japan's specific industrial organization and specific power structures: "The object of research concerning small and medium enterprises is the "small and medium enterprise problem".... The question of specific quality features of small and medium enterprises cannot be discussed without asking why these companies are a problem and where their difficulties lie' (Arita 1982; quoted from Storz 1997: 16). Until the 1970s, this opinion dominated Japanese research on SMEs and 
their public perception. Due to limited linguistic reception possibilities in Western science, local studies in Western countries were also based on this model (critically comp. Pascha and Storz 2000).

The influential contributions of Birch (1981), Piore and Sabel (1984) or Acs and Audretsch (1990), who proved that SMEs contributed to innovation and employment, also fell on fertile ground in Japan. Starting from the 1980 s, a completely different branch of research, whose representatives were, for example, Nakamura Hide'ichirô or Kiyonari Tadao, attributed new functions to SMEs as central pillars in a nation's innovation system and thus developed a new paradigm of SMEs. In contrast to hitherto existing research, SMEs were not seen as a cause of problems, but a solution to the new economic problems of insufficient innovation and (to a lesser degree) rising unemployment. Research on Japanese hidden champions and venture businesses showed that in some sectors innovative processes were strongly stimulated by smaller companies. Since then, economic policy in Japan has seen itself as a creator and initiator of dynamics in the markets, while the protection of SMEs is arousing more and more disapproval.

\section{The emergence of a new concept for SMEs}

The starting point for the new perception of SMEs was the new economic situation in the 1970s, when Japan had basically caught up with the West. More and more demand had been placed on Japan as a global player to participate in the generation of international knowledge. Internally, the differences in income, productivity or non-cash capital provision between SMEs and large enterprises were getting less. Simultaneously, the problem of insufficient innovative activity was not solved, as the persisting deficiencies in the trade balance of high-end technology clearly showed and, for the first time, unemployment began to appear on a larger scale. The realization that American SMEs created highly innovative goods and new employment opportunities and that Japan did not have this form of young, dynamic risk ventures, was a shock for the political class in Japan. Since the 1970s, numerous delegations of politicians have travelled to the United States to learn from the American model. The fact that the United States became a leading model for Japan's SME policy also found its expression in a changing terminology; for example it became common to phrase agglomerations of innovative enterprises as '...Barê', imitating the English pronouncation of (Silicon) '.... Valley', as, for example, the Sapporo Barê or Bit Barê in Tokyo's Shibuya district.

Irritated and confronted with best practices - 'windows of opportunity', as North calls them (1997: 13-14) - the view of weak SMEs began to change and resulted in a preference for a more innovation-oriented SME policy. Following Schumpeter's model of creative destruction, the importance of the entrepreneur, an individual looking for new technological 
solutions, was stressed as being essential for the process of technological change. The 'Vision for Medium Enterprise in the 1980s', published by the Small and Medium Enterprise Agency ${ }^{8}$ in 1980, shows the new role that was attributed to SMEs:

Small and medium enterprises must be positively recognized as numerous energetic entities. Small businesses as a whole provide, through their vitality, a major impetus for changes in industrial structure, progress in technology, and the actualization of human potential. Without exaggeration, they are the source of socio-economic progress and development.

(JETRO 1986: 23)

The White Paper by the Small and Medium Enterprise Agency from 1995 mentions the new opportunities for SMEs which result from changed institutional and technological conditions; Birch or Piore and Sabel have referred to these as well:

The former attitude of small and medium enterprises, that they were holding out until the situation had improved, is dangerous.... Small and medium enterprises also have strong points which they often used and which enabled them to adjust to changes in the environment, namely flexibility and mobility .... The small size of these enterprises also has advantages over large enterprises and puts them in the position to be able to use change as a chance. In fact, it can be observed that many SMEs ventured into new branches.

(trans. the author, Storz 1997: 73-74)

The change in official terminology signals this change as well: terms indicating SME weaknesses such as 'modernization', which was a category in the 'Basic Law for SMEs' of 1963, have been avoided since the 1970s. Instead, terms stressing their competitive potential by describing them as 'information oriented', 'dynamic' or 'challenging' and equalizing them with 'new development possibilities' and 'entrepreneurial spirit' dominated. The subtitles of White Papers also provide an accumulation of changed terms since the end of the 1970s. ${ }^{9}$ The term 'dynamics', for example, was chosen five times in the years between 1979 and 1986, the term 'new' nine times in the years 1983-1995, the term 'structural change' six times in the years 1987-1996, and the terms 'foundation' and 'entrepreneurship' three times between 1998 and 2000. In the last few years the creation of innovative potential and new employment possibilities obviously gained importance.

The changed perception is also made clear by the choice of words in policy programmes for SMEs, as for example in the annual 'Compendium of Economic Policy Measures for the Medium Enterprise'. Until 1986, the Compendium used words suggesting that SMEs were weak, such as 
'modernization and structural improvements', 'compensation of disadvantages through size', 'programme for the stabilization of companies', or 'special programmes for very small enterprises'. In 1989 new terms were chosen. The negative sounding aims of the 'Basic Law' of 1963, such as 'modernization and structural improvements' or 'compensation of disadvantages through size' are now positively described as 'strengthening of the enterprise base' or 'promotion of structural change' (Chûshô Kigyôchô 1994b, quoted from Storz 1997). ${ }^{10}$

In accordance with this new perception, the entrepreneur was also often portrayed as an important agent of technological change in the Japanese media or in other publications. Since 1986 the renowned publishing house Nihon Keizai Shinbunsha has been publishing a monthly magazine on the entrepreneurs' contribution to technological and economic progress, and started releasing reports on venture businesses in its leading economic newspaper Nihon Keizai Shinbun three days a week in 1996. Textbooks and non-fiction books for young people provide information on selfemployment and animate young people to become self-employed. ${ }^{11}$ The 'producers of world views' have new expectations of SMEs, which can produce new attitudes in their readers.

\section{The other side of the medal: the persistent perception of SMEs as 'weak'}

If one analyses the public perception of entrepreneurs more deeply and leaves the official platform of opinions, it soon becomes clear that the entrepreneur in Japanese society is still not perceived as an innovative creator and destructor, as Schumpeter describes him; on the contrary, he is seen as a person with a high degree of dependence. Definitely, he is not associated with a young, venturous type of entrepreneur, but with distinct weaknesses in generating more than incremental innovations.

One well-known result from the low degree of competitiveness is the bad working conditions in SMEs, which are described as 'dark and tiring, dirty and dangerous'. Examples are popular series like 'Men are Tough Fellows' (Otoko wa tsurai yo) or 'Tanpopo', which refer to the dual structure of incomes, and portray the entrepreneur as pitiful. Based on these observations the research institute of the former Daiwa Bank came to the conclusion that 'there is no other country, where the employees of a large enterprise are considered that much better than their colleagues in small and medium enterprises. The influence of the mass media plays an important role here' (trans. the author; see Storz 1997: 109-111).

In school education, SMEs are at the best of marginal interest too, a fact which further encourages traditional expectation models. Even if one finds innovative connotations, they are often accompanied by a depiction of the 'problem of SMEs', while others only concentrate on the description of 
this 'problem'. ${ }^{12}$ In university education, the topic of entrepreneurship is not very important either. Although courses like the Anglo-American MBA are offered for founders, and graduate schools for practical jobs have been established, and despite the fact that especially private universities put emphasis on new research on this topic, the acceptance of their graduates in the markets and the reputation of their research projects are considered relatively low (Miyata 2001; Teraoka 2002).

Definitely the negative public attitude towards entrepreneurs is not a specific Japanese problem and exists, for example, in Germany too. However, the critical perception of SMEs has a more 'real core', at least in comparison to Germany: all statistics show that the discrepancy of productivity between different sizes of enterprises is especially high in Japan, which leads to the conclusion that the innovative performance of Japanese SMEs cannot be too high. Another indicator is the discrepancy in incomes, which is not only generally much lower in Japanese SMEs than in larger enterprises, but in very small enterprises (up to 20 employees) only about half of the income in larger companies (more than 300 employees). The perception of these differences is made easy by the high presence of SME entrepreneurs in everyday life and the high importance of Japanese SMEs for employment. It is even more important that Japanese SMEs in secondary industry (e.g. transport, electronics) are, in contrast, for example, to German SMEs, less directly active on the domestic market and in exports, but have more of a supportive function for the Japanese enterprise groups.

As a result, there are conflicting perceptions of reality. The ways in which these prevail within the process of economic policy will be discussed in Chapter 6.

\section{Target definition and programme formulation in SME policy}

Programme formulation for 'weak' SMEs: the past

In the 1950s and 1960s the policy for SMEs in Japan was coined by the view that the Japanese economy is dualistically structured. Japanese SMEs had to be modernized as their backwardness in productivity and innovation activities reduced the efficiency of the whole Japanese economy. This view strongly influenced the 'Basic Law for Small and Medium Enterprises' of 1963, which denoted the following targets for the policy for SMEs (Storz 1997: 72-73; Arita 2001):

1 modernization and structural improvements, ${ }^{13}$

2 compensation of disadvantages through size,

3 programmes for the stabilization of companies as well as

4 special programmes for very small enterprises. ${ }^{14}$ 
In order to realize an increase in productivity, economies of scale were supposed to be achieved by cooperation and a reduction of the so-called 'over-competition'. In consequence, the number of legally established cartels in the 1960s increased to over 1,000 legal cartels in 1966, most of them constituted by SMEs. ${ }^{15}$ These cartels were excepted from the antimonopoly law. Additionally, co-operations and recession and rationalization cartels were admitted by administrative guidances (Teraoka 1997: 253; CKC 1998: 258, 270; Storz 2003a,b,c).

\section{New approaches and new politics}

The success of the American model in the 1970s led to a change in target definition and programme formulation. The 'Vision for Medium Enterprises in the 1980s', published by the Small and Medium Enterprise Agency, for the first time differentiated between 'entrepreneurial' and 'stable' SMEs and saw their target group in the former. Moreover, in contrast to the previous practice, SME policy was understood as a frameworkoriented policy geared at enabling companies to help themselves (CKC 2001: 216).

The new perception of SMEs was extended to official statements, as in the 'Vision for the 1990s' which, inter alia, defines the support of enterprise foundations, the support of change from previous branches to new and innovative fields of activity, extension of the infrastructure and the promotion of internationalization as central targets of the new SME policy. It was pointed out that overcoming dualism - the normative base of the 'Basic Law' of 1963 - was no longer the target of political actions. On the contrary, it was stressed that the changed environment had created new chances for SMEs which required an alternative design of programmes, namely a policy that refrains from direct intervention and seeks for better rules and rules implementation, especially in the area of financing. The 'Research Council for Medium Enterprises' within the Small and Medium Enterprise Agency writes in its final report that:

it is inappropriate to call SMEs as a whole 'weak'. SMEs in the 21 st century are mobile, creative and a source of dynamism for the Japanese economy. They promote free development and the creation of employment and in this sense fulfil an active role.

(trans. the author, Shinoharao 2000: 23; see Arita 2001: 17)

The changing perception can also be seen in the main aims of the revised Basic Law of 1999, which were:

1 promotion of start-ups, promotion of innovative enterprises,

2 extension and consolidation of the management and

3 adjustment to changed socio-economic basic conditions (CKC 2000: 2-3; Shinoharao 2000: 22). 
In contrast to the previous Basic Law for SMEs, the promotion of startups and the building-up of an adequate infrastructure for consulting, financing and research play an important role. This change has to be understood against a background of changes in innovation policy, which, since the 1990s, aim at strengthening the innovative potential of Japanese companies more than before. Also the changes in economic policy, which aim at a more rule- and framework-oriented policy, have to be taken into account. As a result, a selection of SMEs was accepted, at least implicitly, and it can be observed that, for the first time since the 1990s, the number of SMEs is shrinking. Especially the number of exits is high, which supports the thesis that SME policy has indeed changed its leitmotif.

The interesting aspect is that the formulation of new goals and programmes can only be attributed to changed economic indicators to a limited degree, at least in the 1990s. To put it differently: new problems are admitted, although the important economic indicators demonstrate a more difficult stance for SMEs in the 1990s: between 1992 and 1999 the relative income in very small companies (5-29 employees, compared to companies with more than 500 employees $=100$ ) shrunk from 60.3 to 53.9 per cent. In small companies (30-99 employees) it decreased from 69.4 to 61.2 per cent and in medium-sized companies (100-499 employees) from 81.3 to 76.0 per cent (CKC 2000: 30; supplementary material). Moreover, as the decreasing number of enterprises show, SMEs obviously lost their ability to create employment. The danger of a new dualism, namely a dualism that runs right through SMEs was therefore stressed by several authors (CKC 1997: 151). As a result, the cognitive frame of 'weak' SMEs persisted and found relatively easy access to the programme formulation as the following discussion will show.

\section{The other side of the medal again}

On the first glance, it seems astonishing that traditional concepts of SMEs found entrance into programme formulation: not only the success of the American model, but also the high amount of bad loans from public financial institutions for SMEs ${ }^{16}$ or the restricted possibilities of Japanese SMEs to influence the political process ${ }^{17}$ do not support the expectation that the traditional perception of SME can effect the policy-making process. The following list of counter-running political measures indicates that this is not the case, though. Obviously, the selection of enterprises is accepted only up to a certain degree:

\section{Institutional framework: tolerance of defection and re-regulation}

- Formal requirements for the founding of a joint-stock company are still low, despite a legal reform in 1990. Therefore, the more attractive legal form of a joint-stock company is the predominant form among 


\section{Cornelia Storz}

SMEs. ${ }^{18}$ It allows advantages in fund raising (higher acceptance of this legal form), advantages in decision-making (stronger position of the managing director), and also advantages in tax law (favourable taxation, e.g. from a certain income). Apart from the few formal requirements, the lax way of dealing with formal regulations favours the choice of this legal form. For example, regulations such as the convening and holding of annual, general shareholders meetings can be avoided (Kliesow and Musahl 2000: 214-219).

- The fact that the violation of regulations is politically tolerated also applies for taxation practice. According to older studies, tax assessment for gainful employment is lowest with self-employed persons: apparently 88.4 per cent of salaried employees, but only 39.5 per cent of all owner-managers paid tax. Also, smaller trading companies were able to use the existing leeway. According to a report by the leading Japanese economic newspaper Nihon Keizai Shinbun, around 60 per cent of the SMEs reported losses in the books. Therefore, as loss making companies, they were not required to pay taxes. ${ }^{19}$ The mild tax administration, which was confirmed in later studies, is supposed to also be supported by corresponding regulations in commercial law. They are not unequivocal, due to various new regulations (see as well as Storz 1997: 65-79; Kliesow and Musahl 2000: 214-219).

- In order to reduce the effects of deregulation in the retail industry by abolishing the hitherto necessary licence for the sale of alcohol, its sale will be re-regulated. Now it is planned that as from September 2003 at least one person especially trained for the selling of alcohol has to be employed. This favours already existing small alcohol shops (Japan aktuell, April 2001; see also Jung 2000: 35).

\section{New policies: supporting programmes for 'weak' SMEs}

- Public institutions specialized in the funding of SMEs, such as the National Life Finance Corporation or the Japan Finance Corporation for Small Businesses, try to avoid a selection of less competitive companies by - in contrast to private institutions - either raising their credit volume in weak economic periods or periods of restrictive funding by the banks, or at least by reducing it to a lesser extent. ${ }^{20}$

- Further resources are granted for the allocation of guarantees and securities because, among other things, one wants to establish safety measures for failed enterprises (Shinoharao 2000: 26; MoF 2001).

- Since October 1998 additional loan guarantees for SMEs have been granted under a state credit guarantee programme. This programme was prolonged from 2000 to 2001 over a second supplementary budget. 
- Until that point, guarantees were allotted almost without conditions, which might explain the relatively large percentage of SMEs that had been granted a state loan guarantee before going bankrupt among all the SME bankruptcies (Bosse 1998, 1999, 2001a,b). ${ }^{21}$

Why does re-regulation and ongoing protection of SMEs still take place? One explanation is the obvious lack of social policy in Japan. SME policy can be interpreted as a functional equivalent to labour market policy, and, in this interpretation, follows the same rationality as the wellknown Large-scale Retail Store Law or other industrial policy measures, namely to protect working places. Especially since the 1990s the increase of unemployment was the highest in Japanese younger economic history, and since Japan possesses almost no social net which could absorb the unemployed, functional equivalents for the lacking social policy schemes seem to be more urgent than before. Nevertheless, it is astonishing that neither the high budget pressure nor the possibility of losing international competitiveness by protective policies leads to drastic change. One reason why the perception of SMEs as weak (in the sense of low contribution to innovation and employment) is pushed into the political process in a relatively easy way, may be found in a specific preference for consensus-oriented decision-making. This again has its origin in a preference for long-term relationships, which has been proved in several comparative social psychology research papers (comp. Pascha 2002; Storz 2003a,b,c, 2005). Another reason beside the functional equivalent argument may be seen in different opinions how innovation systems should be designed and reformed. Concretely, it is questioned whether it makes sense to give up traditional strengths of the Japanese innovation system with its specific role attached to SMEs (that is: long-term co-operation, market-oriented research), and whether it would not make more sense to develop the strengths of the Japanese system, instead of trying to radically reform it (compare Lynn/Kishida in this volume too). This question will be taken up in the next section.

\section{Evaluation: the case of regional technology centres}

The most noticeable fact from a 'Western' perspective is that hitherto there has been no publicly accessible evaluation of Japanese policy for SMEs by a third party, in contrast to other OECD countries. This could be due to the following special characteristics of the decision-making process in Japan:

- Apart from the field of policy, control is a general problem in the Japanese economic policy system. 
- The self-image of the central bureaucracy makes evaluation by a third party difficult. It can be seen in the political practice of staff transfer to subordinate branches or affiliated institutes. Another example would be the strategy of sangakukan, meaning a cooperative research within the triangle private sector - industry - bureaucracy and not, as more known in Europe, a private-sector strategy which can then be accompanied by political measures, if necessary. Another sign is that a law on the publication of information was only issued just lately (Köllner 1998a, 1998b).

- The fluid organizational structure within the ministries complicates an evaluation of individual organization units (Ôkuma 1999: 39).

In this chapter, the effectiveness of prefectural technology centres (kôsetsushi) and their functions in the future will be discussed from the view of local staff and central bureaucracy. ${ }^{22}$

Technology transfer centres, as they exist in Japan, are not known in this form in the United States nor in Germany. Formally, they are mostly financed by the regions, and only a small percentage of the budget comes from central ministries and private sources. ${ }^{23}$ In actual fact this means that - because of the centralized tax system - the centres are financed by the central government, so that their conception has to follow the actual strategy of national innovation policy.

Basically, the centres fulfil three functions: conducting examination and conformity tests, providing a technical advisory service and cooperative research. Half of the centres were founded before 1950 (Abe 1998), many of them even in the beginning of the last century. ${ }^{24}$ Their most important task is to conduct examinations and tests as well as giving relevant technical advice. They examine the conformity of products regarding special quality grading (e.g. breakage risk of materials) that are defined by manufacturer standards, national standards (Japan Industrial Standards) or other technical regulations. There is open access to testing machines. The fees are relatively low in comparison to private suppliers. Major centres execute around 12,000 tests as well as 1,800 consultations per year (Nagano-ken 1997). The usage intensity is relatively high, with one enterprise out of 10-15 using the centres. The success initiated learning processes in other countries. In 1992, within the framework of the so-called MEP programme (Manufacturing Extension Partnership), 170 Manufacturing Extension Centres were opened in the US. Their basic task of providing a comprehensive technical advisory service makes them similar to the Japanese technology centres.

Were the political targets of modernization, stabilization and dynamics ('consistency') reached from the viewpoint of the local staff and the central bureaucracy? What are the tasks for the centres in the future? 
The local staff and the central bureaucracy agree that the centres' technical advisory service is comprehensive and the technical infrastructure of high quality. (This statement does not deny that there are areas where deficiencies in technical equipment exist.) There is also consensus on the appraisal of user-friendliness: the degree of familiarity of local SMEs with the centres is estimated at $50-80$ per cent, while the degree of usage is estimated at $10-15$ per cent. ${ }^{25}$ The reasons for the centres' relatively high degree of familiarity, which is not reached in other countries as, for example, in Germany, are seen in their comprehensive range of services and their long-term local involvement. In addition, the geographical dispersion shows a constant close neighbourhood of automobile manufacturers, their suppliers and the centres. Later relocations, such as the building of new production plants, are accompanied by a new construction or a reorganization of the centres. ${ }^{26}$ From different perspectives the centres first and foremost have a classical function within a framework-oriented economic policy: they try to compensate for disadvantages in the procurement of information. Their function extends to counselling suppliers with regard to (technical) quality control. From this point of view, the high quality of subcontracted components in Japan is not only achieved through group internal consultations (e.g. cooperative associations between producers and their suppliers), but probably also to a relatively high extent through public support, namely technology centres. This can be compared to the governmentowned credit institutions' important role for the provision of credits.

Within the last decade, however, different opinions have begun to develop. The central bureaucracy criticized the centres' low capability to adapt to changed economic and technological conditions and to bring forth more radical innovations, for example, by venture business. In the future the centres should focus more heavily on research and innovation, and become a part of the new national innovation policy. In order to promote this re-orientation, a stronger co-operation with venturous SMEs as well as a stronger orientation toward applied basic research is called for. In terms of terminology this can be seen in the renaming of the centres. Their central service, the testing has been taken mostly out of the name. They are now called Research Institutes or Technology Centres instead. ${ }^{27}$

The local staff and local users, especially the centres' scientists, see the necessity for reforms, but emphasize the danger of an increasing dualism in SMEs and argue that co-operation in research necessitates long-term personal relationships and therefore makes the long-term employment of scientists a precondition. More important, though, is their warning not to gamble with the specific Japanese strength of the Japanese innovation system in the area of more incremental innovations.

Between the central bureaucracy and the local staff the perception of problems is obviously different. While the central bureaucracy wishes to 
fit the policy for SMEs into the new concept of innovation policy, the centres themselves insist on a stronger perception of realities, or, to put it more clearly, on their version of reality; they see the strength of SMEs more in networking (and thus, weak in generating radical innovations), and less in independent, risky operations. The slow change we can observe in the centres strategy can again be explained by peculiar structures in the communication between both parties, which lead to a highly permeable political process:

- Communication between the parties is made easier by long-term employment on part of the locals as well as central bureaucracy.

- Communication between different technology centres is promoted through formal and informal mechanisms (e.g. regular meetings).

- Communication between central and local bureaucratic entities is improved through staff transfer. The centres, financed by the prefectures, absorb bureaucrats from the Ministry of Economy, Trade and Industry.

This form of communication results in incremental change, and additionally requires a relatively high input of work and capital. One could argue that this pattern of communication hinders political reforms, but there might be even some economic rationality behind this approach: the communication structure means that both sides have the chance to communicate their different perception of realities, to converge their cognitive models, and to establish a common and new cognitive model of how the centres should work in the end. This may raise implementation success in the long run. Independently from this possible advantage, a problem of the system definitely is its high degree of centralization, which impedes the realization of trial and error processes with different concepts of innovation policies. There have been efforts to decentralize the system for several years, but hitherto changes have been - at the most - incremental.

\section{Conclusion: cognitive models and reforms}

This contribution analysed why institutional change often takes place incrementally, and much slower than expected. One central reason for the incrementality of change was identified in cognitive models, which exist in the political process prior to the later phases of target definition, programme formulation and evaluation, and influence the whole political process. Since cognitive models are a basic orientation structure, they have to be stable - otherwise, they would not be able to offer orientation. Necessarily, in the case of political reforms, the stable nature of cognitive models, and the fact that they exist before the political process starts, lead to a slow speed in political reforms. Taking cognitive models into account when analysing economic policy is a relatively new approach in 
economics, and when it is done, then it is mostly on a rather abstract level. This contribution aims at giving empirical evidence for the importance of cognitive models in the political process, using a selected field of economic policy, namely SME policy, and the problems of implementing specific reforms in this field. The case of Japanese SME policy is especially interesting since the aims of the reforms are drastic, radically establishing a new concept of SMEs and SME policy. Hitherto, in Japan SMEs have been perceived as being weak in their contribution to innovation and employment, and were by no means seen as entrepreneurial venturous actors. In this contribution, this perception of SMEs was identified on the level of economic policy, in education and science, in the media and in the general public for the 1950s and 1960s. Starting from the 1970s, but more strongly since the last decade, political concepts towards SMEs and the functions of SME policy have changed to a large extent, ascribing SMEs a completely new role in the Japanese innovation system as creative, innovative players, and interpreting SME policy as being part of a more ruleoriented innovation policy than being part of social policy, as it had been so far. But despite the efforts to implement corresponding reforms, this contribution makes clear that the traditional perception of SMEs still easily gains entry to the later political phases. On the first glance this is astonishing since the political power of SMEs is restricted, especially in Japan, and was attributed to the fact that the specific preference of consensus-oriented decisions in Japanese society lead to unfinished, inconsistent solutions, more than in other permeable societies. As a result, it took 30 years to revise the central 'Basic Law for Small and Medium Enterprises' with its objective to change SME policy to an entrepreneurship policy. Now, after the revision, the law is impeded by a political practice that allows deviation and re-regulation, and issues new programmes that tend to avoid a stricter selection of SMEs. The Japanese SME policy is obviously not able to leave its traditional pattern of an at least partially-oriented social policy, and to change into a more strictly innovation-oriented policy.

One central reason for arguing that Japanese SME policy should be changed is that the traditional dominance of incremental innovation is a problem as it is risky to decouple basic research and applied research. The unsuccessful implementation of reforms may therefore reduce the prospective competitiveness of Japan. That is the reason why the central government is making considerable efforts to change the perception of SMEs from being weak to being highly innovative and venture-business-like actors, and to change the respective policies. One reason for the low success of reforms might be that cognitive models cannot be easily changed top-down, as it has obviously been tried in the last years. Thus, a more appropriate approach could be to decentralize the hitherto centralized SME 
policies more - even the here discussed technology centres, financed by prefectures, are central organizations in the end, as the prefectures' income largely depends on central tax resources. A stronger decentralization and an admission of trial and error in SME policy could stimulate more varieties in political solutions and the selection of more appropriate SME policies. Since one can expect rational actors to reflect which cognitive models are the 'right' ones, and to realise how they influence the longrange utility, such a competition between policies could change cognitive models too. It is possible that this insight had actually found consideration in innovation policies where change much speedier took place.

At the same time, however, one needs to ask whether the incremental change of SME policy really is a problem, since it might be rational to avoid high changing costs and to give people more time to learn new behavioural strategies: if one bears in mind that SME policy has so far worked as a functional equivalent for the lack of social policy, that regulations especially in the sectors of retailing and building industry have been reduced, and that the former rather closed labour markets are opening, it may indeed be rational to avoid an overly radical change in order to give actors a chance to learn and to adapt. Another argument why incremental change must not be seen as a problem, is that the Japanese innovation trajectory possesses not only weaknesses, but also specific strengths that should not be overlooked: in contrast to other innovation systems, it is able to generate incremental, speedy and highly successful market-oriented innovations; and in this system, SMEs with their dense networking and market orientated research, play an important role, which is not easy to imitate. Indeed, given paths of innovation must not be a problem, if sufficient varieties in the paths are given. It might be more risky to give up the specific strengths of a system and to establish a new regime with an uncertain success. Thus, the incremental change of SME policy appears not to be a problem, but a rational answer to the difficulties of change.

\section{Glossary}

\section{Organizations, institutions}

Fukuoka Prefecture Industrial

Technology Research Centre

Prefectural technology centres

Research Council for Medium Enterprises

Technology Research Institute of Osaka Prefecture TRI
Fukuoka-ken Kôgyô Gijutsu Sentâ

Kôsetsu Shiken Kenkyû Kikan; Kôsetsushi

Chûshô Kigyô Seisaku

Kenkyûkai

Osaka-furitsu Sangyô Gijutsu

Sôgô Kenkyûsho 
Tokyo Metropolitan Industrial

Technology Research Institute

\section{Laws}

Basic Law for Small and Medium Enterprises

Law for the Promotion of SMEs

Law on the Organization

of SMEs

Law on the Stabilization of SMEs

\section{Other terms}

adjustment to changed socioeconomic basic conditions aid programmes

challenging

Compendium of Economic Policy Measures for the Medium Enterprise compensation of disadvantages through size conducting examination conformity tests cooperative associations between producers and their suppliers cooperative research danger of a new dualism dark dual structure dynamic entrepreneurial spirit entrepreneurial vision for medium enterprises extension and consolidation of the management foundation and entrepreneurship hidden champions information orientation loss making companies modernization and structural improvements
Tôkyô-toritsu Sangyô Gijutsu

Kenkyûjo

Chûshô Kigyô Kihonhô

Chûshô Kigyô Kindaika Sokushinhô

Chûshô Kigyô Dantai no

Soshiki ni kansuru Hôritsu;

Chûdanhô

Chûshô Kigyô Anteihô

keizaiteki shakaiteki kankyô no henka e no tekiô no enkatsuka kyûsai seisaku chôsen

Chûshô Kigyô Seisaku no Aramashi

jigyô katsudô no furi no zesei

irai shiken

jishu kenkyû

kyôryokukai

kyôdô kenkyû

shin nijû kôzô mondai

kurai

nijû kôzô

katsuryoku

kigyôka seishin

kigyôteki hatten shikô

keiei kiban no kyôka

sôgyô; kigyôka seishin

chûken kigyô

jôhôka

kesson geisha

kindaika; kôdoka 
new

new development possibilities

non-cash capital provision

over-competition

programmes for small entrepreneurs

promotion of start-ups, promotion of

innovative enterprises

providing a technical advisory service

quality control

research institutes

SME policies

SME problem

stabilization of companies

stable vision for medium enterprises

strengthening of the enterprise base

structural change

technology centres

testing

tiring, dirty and dangerous

too many enterprises

weak enterprise shin; atarashii

shinbunya

shihon sôbiritsu

katô kyôsô

shôkibo kigyô taisaku

keiei no kakushin oyobi sôgyô

no sokushin

gijutsu sôdan/shidô

hinshitsu kanri

kenkyûsho

chûshô kigyô seisaku

chûshô kigyô monadi

keiei no antei

seigyôteki antei shikô

keiei kiban no kyôka

kôzô henka

gijutsu centâ

shiken

kitsui, kitanai, kiken

kigyôsû no katasei

jakusha

\section{Notes}

1 The contribution is a result of a research project sponsored by the German Federal Ministry of Education and Research (1999-2002).

2 Cf. Eggertsson 1997.

3 The terms 'entities' or 'groups' would be more exact. In this contribution, the Japanese society is understood as one social entity.

4 Koch (1998) discusses the role cognition plays in economic policy processes in elementary and convincing terms. See also Meier and Slembeck 1998. On the relationship between cognitive models, emotions and preferences see HerrmannPillath 1993.

5 Programme formulation is understood as the choice of instruments here.

6 One exception on economic policy in Japan is Pascha 2000. On the policy of SMEs see Teraoka (1997: 251-259), who at least touches the question of the emergence of problems. See also one of the latest publications of Miwa and Ramseyer (2001) critically.

7 For the respective Japanese terms, see the glossary at the end of this contribution.

8 The Small and Medium Enterprise Agency is a department of the METI (Ministry for Economy, Trade and Industry). Within the METI, the Small and Medium Enterprise Agency with the Patent Office is the only department that was not reorganised during the re-structurization of the central ministries. About 1.6 per cent of the Japanese METI's employees work in the Small and Medium Enterprise Agency (Shinjo 2000: 4, 15).

9 White Papers are being published since 1963. In 1969, no White Paper came out. 
10 A third pillar is the 'Programmes for small entrepreneurs' (shôkibo kigyô taisaku), which already signals that some leeway was left for other than entrepreneurial, venturous enterprises.

11 See, for example, Teikoku Shoin (2001) with information on enterprise foundations and procurement of risk and venture capital, or Nihon Bunkyô Shuppan (2001) also with the focus on innovative companies and their tribute to the economic development of Japan.

12 See Nihon Bunkyô Shuppan (2001) for a report on venture businesses and dualism in SMEs or Juken Kenkyû Shuppansha (2001).

13 The included 'Law for the Promotion of SMEs' is considered an especially extensively used instrument of Japanese policy for SMEs (Arita 2001: 9). For the most important laws concerning SMEs see CKC (1998: 256-270) as well as Teraoka (1997: 34-35).

14 Many of the included concrete political measures are borrowed from industrial policy, for example, trying to achieve modernization and structural improvements through the promotion of small industry agglomerations or specifically industrially organized cooperatives.

15 Their admission fell under the 'Law on the Organization of SMEs' and the 'Import-Export Law', which are part of the 'Law on the Stabilization of SMEs'.

16 The average rate of bad loans in the public sector is worst for the Japan Finance Corp. for Small Businesses, which is about 8 per cent, and for the National Life Finance Corp. where it is about 9 per cent. The rate of bad loans in the public sector is supposed to be strongly underestimated due to a lack of external controls. The official average rate of bad loans for public institutions is about 3.3 per cent, while up to about 9 per cent in the private sector (NW, 5 August 2002).

17 Their economic resources are limited because of their small size - most of them are below the average of companies in other OECD-countries; their reputation is low as the expression ' $3-\mathrm{K}$-industries' shows, and they have little knowledge how to choose adequate communication structures. Moreover, they are strongly tied to their respective parent company, which supports the feeling of sharing a common destiny. The Japanese Chamber of Commerce only represents the political interests of SMEs to a certain extent. Its committee members come from larger enterprises and, since membership is voluntary, hardly any small enterprises are represented at all. A special clause for very small enterprises or companies operating at a loss, such as in Germany, does not exist. Therefore, the representation of interests within and between associations is asymmetrical: the Chamber, at the most, symbolically meets the requirement of pursuing a complete and pluralistic representation of interests. Moreover, the local chambers are not very effective because of their structure, which only covers small areas. In 2001, there were 526 local chambers.

18 Most of the joint-stock companies remain family property and are not listed in the stock markets. Of the approx. 6.4 million SMEs, about 1.3 million are joint-stock companies (Storz 1997: 65).

19 Data is from the beginning of the 1980 s.

20 While private institutions reduced their credit volume by $4.3-5$ per cent from the first to the second quarter of 2001, public institutions were only able to reduce it by 1.3 per cent. In 1998/1999, public institutions increased their credits by up to 5 per cent compared to the previous year, while private institutions decreased their credits by up to 7 per cent for the same period. This trend can be observed since 1994 (Chôsa Kihô 2001: 109).

21 Furthermore, the ninth package for the stimulation of economic activity allotted financial help to SMEs. This represents nearly 40 per cent of the complete package (Bosse 2001a). 


\section{Cornelia Storz}

22 The following arguments are based on interviews conducted in Japan in 1999. Central and local bureaucracy, users of the centres and scientists working there were interviewed.

23 An example: 76 per cent of the funds for the Tokyo Metropolitan Industrial Technology Research Institute come from the city of Tokyo. 12 per cent come from research co-operations with private companies, 5 per cent from the budget of the MITI and related associations, and 7 per cent of the funds it raised itself (Kagaku Gijutsuchô 1992: 108-109; Shapira 1992; see also Kagaku Gijutsuchô 1997: 25, 56). Due to the specific, prefectural funding in Japan, this means that the usage of funds follows central goals, for example, currently this is the orientation towards more intensive research activities.

24 There are, for example, the Tokyo Metropolitan Industrial Technology Research Institute (Tôkyô-toritsu Sangyô Gijutsu Kenkyûjo) founded in 1921, the Fukuoka Prefecture Industrial Technology Research Centre (Fukuoka-ken Kôgyô Gijutsu Sentâ) founded in 1925 and the Technology Research Institute of Osaka Prefecture (TRI; Osaka-furitsu Sangyô Gijutsu Sôgô Kenkyûsho) founded in 1929. The major part of the older foundations was realised in cooperation with local cooperatives (Yamazaki 1969). See also Sangyô 1997.

25 According to a centre in Nagoya, an interview of the Nihon Fine Ceramics Centre among venture businesses resulted in a degree of familiarity of 50 per cent, while other investigations among SMEs reached results of up to 80 per cent (Sangyô 1997). According to employees, an often long-term acquaintance between centre employees and entrepreneurs results in a relatively high willingness to cooperate. With 25.9 per cent the centres are the second most important partner for external cooperation (e.g. research cooperation, etc.) for SMEs (SMEs of the same branch are in the first place with 27 per cent). Although large enterprises use the centres much more often with 31 per cent, the relative significance for large enterprises is relatively lower since other institutions are used much more often (universities: 64.5 per cent; cooperations with large enterprises of the same branch: 35.5 per cent) (CKC 2001: 300; see also Sangyô 1997).

26 The centres in Kanagawa and Tochigi, for example, were founded after Nissan set up its production site there and the centre in Hiroshima after Mazda moved there. (then Tôyô Kôgyô; see Ruigrok and Tate 1996).

27 In fact, R\&D expenses for SMEs are very low in comparison to the United States. In the years from 1983 to 1997 , the Japanese government's R\&D expenses for SMEs only amounted to the tenth to twentieth part of the American expenses. The difference is even increasing (CKC 2000: 162).

\section{Bibliography}

Abe, S. (1998) 'Regional Innovation Systems in Japan', in H.-J. Braczyk, P. Cooke and M. Heidenreich (eds) Regional Innovation Systems. The Role of Governance in a Globalized World, London: UCL Press, 286-318.

Acs, Z.J. and Audretsch, D.B. (1990) Innovation and Small Firms, Cambridge, MA and London: The MIT Press.

Arita, T. (2001) 'Chûshô kigyô seisaku to sôgyô shien seisaku. "Chûshô kigyô kihonhô" no kaisei ni kanren shite' (Public Policy for Small Businesses and Support Measure for Business Start-Ups. In Relation to Amendment of 'Small and Medium Enterprise Basic Law'), The Journal of Tokyo Keizai University, Vol. 221: 9-24.

Birch, D.L. (1981) 'Who Creates Jobs?', The Public Interest, Vol. 19: 3-14. 
Bosse, F. (1998) 'Regierung erweitert Kreditprogramme für Mittelstand', Japan aktuell - Wirtschaft, Politik, Gesellschaft, October 1998, 434-435.

(1999) 'Staatskredite für Klein- und Mittelunternehmen verlängert', Japan aktuell - Wirtschaft, Politik, Gesellschaft, December 1999, 467.

- (2001a) 'Konjunkturpaket mit konventionellen Schwerpunkten', Japan aktuell Wirtschaft, Politik, Gesellschaft, February 2001, 10.

(2001b) 'Restrukturierung und Preisdruck führen zu hohen Konkurszahlen', Japan aktuell - Wirtschaft, Politik, Gesellschaft, February 2001, 16-17.

Chôsa Kihô (2001) 'Teiki Chôsa: Chûshô kigyô kinyû tôkei' (Regular Survey: Statistics on the Financial Situation of SMEs), Kokumin Seikatsu Kinyû Kôko Sôgô Kenkyûsho, No. 59, November 2001, 109.

CKC (1997) Chûshô Kigyô Hakusho (White Paper for SMEs), Tokyo: Ôkurashô Insatsukyoku (Heisei 9).

(1998) Chûshô Kigyô Hakusho (White Paper for SMEs), Tokyo: Ôkurashô Insatsukyoku (Heisei 10).

— (2000) Chûshô Kigyô Hakusho (White Paper for SMEs), Tokyo: Ôkurashô Insatsukyoku (Heisei 12).

- (2001) Chûshô Kigyô Hakusho (White Paper for SMEs), Tokyo: Gyôsei (Heisei 13).

Eggertsson, T. (1997) 'The Old Theory of Economic Policy and the New Institutionalism', World Development, Vol. 25, No. 8: 1187-1203.

Eisenberg, A. (1999) 'Die Lösungen sozialer Dilemmata und der Wandel informeller Institutionen', Diskussionsbeitrag Nr. 04-99, Jena, Max-Planck-Institut zur Erforschung von Wirtschaftssystemen.

Herrmann-Pillath, C. (1993) 'Informal Constraints, Culture and Incremental Transition from Plan to Market', in H.J. Wagener (ed.) On the Theory and Policy of Systemic Change, Heidelberg: Physica-Verlag, 95-120.

Hodgson, G.M. (1994) 'Cognition, Cultural and Institutional Influences on', in G.M. Hodgson, W.J. Samuels and M.R. Tool (eds) The Elgar Companion to Institutional and Evolutionary Economics Vol. A-K, Aldershot: Edward Elgar, 58-63. JETRO (1986) Japan's Postwar Small and Medium Enterprise Policy. For Promotion of Corporate Vitality, March, Tokyo.

Juken Kenkyûsha Shuppan (2001) Jiyû Jizai: Shakaika chûgaku (Social studies for middle school), Juken Kenkyûsha Shuppan.

Jung, H. (2000) 'Distribution in Japan', Japan Analysen Prognosen, Vol. 168/169, June/July 2000.

Kagaku Gijutsuchô (1992) Kagaku Gijutsu Kîwâdo (Keywords on research and technology), Tokyo: Fujibijutsu Insatsu.

— (1997) Kagaku Gijutsu Kihon Keikaku (Kaisetsu) (Basic plan on research and technology. Explanations), Tokyo: Ôkurashô Insatsukyoku.

Klemmer, P., Friedrich, W. and Lageman, B. (1996) Mittelstandsförderung in Deutschland - Konsistenz, Transparenz und Ansatzpunkte für Verbesserungen (investigations of the Rheinisch-Westfälisches Institut für Wirtschaftsforschung, magazine 21), Essen: RWI.

Kliesow, O. and Musahl, H.-P. (2000) 'Rechtsformwahl in Japan: Neueste Entwicklungen aus gesellschafts- und steuerrechtlicher Perspektive', in W. Pascha and C. Storz (eds) Klein- und Mittelunternehmen in Japan, Baden-Baden: Nomos Verlagsgesellschaft, 209-226. 
Koch, L.T. (1998) 'Kognitive Determinanten der Problementstehung und - behandlung im wirtschaftspolitischen Prozeß', ZWS (Zeitschrift für Wirtschafts- und Sozialwissenschaften), Vol. 118: 597-622.

Köllner, P. (1998a) 'Kabinett legt Gesetzentwurf zur Offenlegung von Informationen vor', Japan aktuell - Wirtschaft, Politik, Gesellschaft, March 1998, 240.

_ (1998b) 'Vorschlag zur Informationsoffenlegung der Verwaltung vorgestellt', Japan aktuell - Wirtschaft, Politik, Gesellschaft, March 1998, 274.

Lanzara, G.F. (1998) 'Self-destructive Processes in Institution Building and Some Modest Countervailing Mechanism', European Journal of Political Research, Vol. 33: 1-39.

Meier, A. and Slembeck, T. (1998) Wirtschaftspolitik. Kognitiv-evolutionärer Ansatz, 2nd edn, München, Wien: R. Oldenbourg Verlag.

Miwa, Y. and Ramseyer, J.M. (2001) 'Nihon no keizai seisaku to seisaku kenkyû, toriwake seisaku hyôka ni tsuite' (On Economic Policy and Research on Economic Policy in Japan, especially on the Problem of Evaluation), Keizai Kenky $\hat{u}$ (Economic Review), Vol. 52, No. 3: 193-205.

Miyata, Y. (2001) 'Daigaku ni okeru kigyôka ikusei no kanôsei' (Universities and entrepreneurial education), Sannô Daigaku Kiyô, Vol. 22, 1 (Sept.): 113-126.

MoF (2001) Measures for Small-and Medium-Sized Businesses, Available online at: http://www.mof.go.jp/english/budget/pamphlet/cjfc_q07.htm (accessed 27 June 2005).

Nagano-ken Seimitsu Kôgyô Shikenjo (1997) Nagano-ken Seimitsu Kôgyô shikenjo gyômu hôkoku (Working Report from the kôsetsushi for Precision Tools in the Prefecture of Nagano, 1997), unpublished.

Nihon Bunkyô Shuppan (2001) Chûgakusei no shakaika kômin CIVICS. Gendai no shakai (Social Studies for Middle School Pupils. Knowledge for Citizens. Todays Society), Nihon Bunkyô Shuppan 2001.

North, D.C. (1997) The Contribution of the New Institutional Economics to an Understanding of the Transition Problem, UNU World Institute for Development Economics Research (UNU/WIDER), WIDER Annual Lectures 1, Helsinki.

OECD (2000) OECD Small and Medium Enterprise Outlook 2000 Edition, Paris: OECD.

Ôkuma, K. (1999) 'Gyôsei hyôka no jisshijô no kadai’ (Problems arising in Practise during the Evaluation of Administration), 21seiki Fôramu, Vol. 70: 38-43.

Pascha, W. (2002) 'Wirtschaftspolitische Reformen in Japan - Kultur als Hemmschuh?', in Duisburger Arbeitspapiere Ostasienwissenschaften, Nr. 44, Institut für Ostasienwissenschaften, Universität Duisburg-Essen, 1-34.

Pascha, W. and Storz, C. (2000) ' Einleitung: KMU in Japan ', in W. Pascha and C. Storz (eds) Klein- und Mittelunternehmen in Japan, Schriftenreihe zur Ostasienwirtschaft, Band 14, Baden-Baden: Nomos, 1-10.

Piore, M.J. and Sabel, C.F. (1984) The Second Industrial Divide: Possibilites For Prosperity, New York: Basis Books.

Ruigrok, W. and Tate, J.J. (1996) 'Public Testing and Research Centers in Japan: Control and Nurturing of SMEs in the Automobile Industry', Technology Analysis and Strategic Management, Vol. 8, No. 4: 381-406.

Sangyô Gijutsu Shingikai Chiiki Kenkyubukai (Industrial Technology Council Regional Study Committee) (1997) Chiiki ni okeru shinki sangyô sôzô no tame no gijutsu kaihatsu no arikata ni tsuite (chûkan torimatome) (Technological 
Development for Creation of New Industry in Local Regions (an interim report)), Tokyo: MITI.

Shapira, P. (1992) 'Modernising Small Manufacturers in Japan: The Role of Local Public Technology Centers', Journal of Technology Transfer, Winter 1992, 40-57.

Shinjo, K. (2000) 'Kisei kanwa jidai no sangyô seisaku' (Industrial Policy during the Time of De-regulation), Kokumin Keizai Zasshi, Vol. 182, No. 4, October 2000 (Heisei 12): 1-18.

Shinoharao, I. (2000) 'Chûshô kigyô kihonhô no kaisei to jiba sangyô' (Revision of the Basic Law for SMEs and its Consequences for Local Industry), Fukushima Daigaku Chiiki Kenkyû Center, Vol. 12, No. 2: 21-48.

Storz, C. (1997) Der mittelständische Unternehmer in Japan, Schriftenreihe zur Ostasienwirtschaft, Band 7, Baden-Baden: Nomos.

(2003a) 'Improvement of Competitiveness of Japanese SMEs? Concept and Limits of Institutional Design in the Japanese Policy for SMEs', in Ono Hiroshi (ed.) Structural change in Japan and Germany, Tokyo: Toyo University, 2002, 67-84.

- (2003b) 'Zum Wandel der japanischen Unternehmensorganisation Innovationsfähigkeit zwischen Diskontinuität und Stabilität', ORDO (Jahrbuch für die Ordnung von Wirtschaft und Gesellschaft), Vol. 53, 2003, Stuttgart: Lucius \& Lucius.

- (2003c) 'Globalisierung, Technik, Normen. Warum weichen japanische Unternehmen von internationalen Normen ab?', Japanstudien. Missverständnisse in der Begegnung mit Japan (Jahrbuch des Deutschen Instituts für Japanstudien der Philipp-Franz-von-Siebold-Stiftung), Vol. 15, München: Iudiucium Verlag.

- (2005) 'Uncertainty, Trust and Learning: Private Regulation in Japanese Electronic Commerce', in A. Moerke and C. Storz (eds) Competitiveness of New Industries: Institutional Frameworks and Learning Processes in Information and Communication Technologies in Japan, U.S. and Germany, RoutledgeCurzon (forthcoming).

Streit, M.E. (2001) Theorie der Wirtschaftspolitik, 4th edn, Düsseldorf: Werner (wisu-texte).

Teikoku Shoin (2001) Shakaika: Chûgakusei no kômin. Chikyû shimin o mezashite (Social Studies: how to educate Middle School Pupils to be Cosmopolitans), Teikoku Shoin.

Teraoka, H. (1997) Nihon no chûshô kigyô seisaku (Policy for medium sized enterprises in Japan), Tokyo: Yûhikaku.

- (2002) 'Chûshô kigyô to business school' (KMU and business schools), Chûshô Kigyô Kihô, Vol. 2: 21-23.

Tinbergen, J. (1956) Economic Policy: Principles and Design, North-Holland: Amsterdam.

Yamazaki, H. (1969) 'Ryôtaisenki ni okeru Enshûmen orimono no kôzô to undô' (Structure and Development of Wool Weaving between the Two World Wars), Keiei Shirin, 6, 1/2 (Hôsei Daigaku Keiei Gakkai): 95-152. 



\section{Part II}

\section{The shift in entrepreneurial behaviour in SMEs}





\title{
6 Restructuring the Japanese national biotechnology innovation system
}

\author{
Prospects and pitfalls
}

\author{
Reiko Kishida and Leonard H. Lynn
}

The Japanese "national innovation system" has attracted the attention of both scholars (e.g. Nelson 1984; Freeman 1987; Odagiri and Goto 1993) and policy makers (e.g. OTA 1984; Holdridge 1994) for a number of reasons. First of all, since Japan was forced to open its economy to the outside world in the 1850s, and the Meiji government introduced a new political system in 1868, Japanese policy makers have strongly believed that Japan's national security, indeed its national survival, was highly dependent on technology. If anything, this belief was reinforced by Japan's defeat in the Second World War. As a consequence, perhaps more than any other country, Japan has made consistent top-down efforts explicitly to develop a national innovation system. While similar efforts have sporadically been made in Europe and the United States, in Japan they persisted, often with the same policy makers in charge, through war, peace, economic crisis, and changes in government for well over a century (Johnson 1982; Samuels 1994).

Second, until recently there was a strong sense that the Japanese national innovation system has been highly successful. After all, Japan was the first non-Western society in modern times to "catch up" with, and often out compete, the West. The Japanese national innovation system has often been held up as a model for the United States and Europe, as well as developing countries (e.g. Ouchi 1984; Vogel 1985; Anchordoguy 1989).

Third, however, and somewhat paradoxically, the apparent success of the Japanese system has seemed inconsistent with academic theory about what is needed for success in national innovation systems. Writings on national innovation systems commonly focus on government and business (Freeman 1987; Lundvall 1992), and sometimes universities as well (Nelson 1993). Even when the Japanese economy was doing well, critics pointed to weaknesses in all three elements of the Japanese system. Japan's government was widely seen as overly focused on picking winners and as favoring entrenched interests. Japan's business sector was commonly seen as dominated by arteriosclerotic networks of large firms. And, 


\section{2}

Reiko Kishida and Leonard H. Lynn

Japan's universities have seemed largely irrelevant to the development and commercialization of new technology. A few scholars have argued that Japan's successes occurred not because of the coordinated guidance of government and big business, but rather in spite of these top-down policies. Others have seized on Japan's apparent failures in computer software, biotechnology and other areas to suggest that the Japanese innovation system was well-suited to catching up, but is poorly suited to developing frontier technologies (for a sampling of critical views of the Japanese system see Trezise and Suzuki 1976; Patrick 1986; Friedman 1988; Callon 1995; Dick 1995).

Notwithstanding such criticisms, Japan's earlier successes led observers in Japan and around the world in the late 1980s to believe that Japan, relying on a national innovation system dominated by the largest established firms and coordinated by government, was on its way to establishing world leadership in biotechnology. By the early 1990s, however, it was beginning to seem that the American model, which strongly supported university research and new business ventures, was more conducive to strength in biotechnology. Japanese policy makers began consciously reshaping their national innovation system in this area. In this chapter we look at how this restructuring has impacted Japanese small firms, universities and the biotechnology industry.

We are particularly interested in the following questions: Why did the Japanese model apparently fail in the case of biotechnology, even though it had earlier apparently led to success in semiconductors and other advanced technologies? What changes were made in the Japanese system? How closely does the "new" Japanese system replicate the US system? To the extent evaluation is possible, is the new system working? What pitfalls might there be with the new system?

The first section on "The original Japanese national innovation system in biotechnology" describes the rise and fall of the reputation of the Japanese model of high technology commercialization in biotechnology. It indicates why so many people believed that this model was suited to the emerging biotechnology industry. It then goes on to discuss why the Japanese model apparently did not work in biotechnology. Some of the faults attributed to the Japanese model also seemed applicable to the biotechnology systems in major European countries. The following section on "The US national biotechnology innovation system as a model for Japan" describes how Japanese policy makers concluded that Japan needed to restructure its biotechnology system to create an environment that encourages the formation of small and medium sized enterprises (SMEs), and that additionally encourages the transfer of technology and skills from universities to these enterprises. Much of this was based on perceptions of the reasons for the success of biotechnology in the United States. The penultimate section on "Restructuring the Japanese innovation system" gives some early data allowing a tentative evaluation of the results of the new policies. 
Finally, a concluding section speculates about the prospects for Japan's new innovation system in biotechnology.

\section{The original Japanese national innovation system in biotechnology: from model for the world to the "little engine that couldn't'}

In the 1980s it was widely believed that Japan was on a path to dominate the global biotechnology industry (see Lynn and Kishida 2004 for a more extended review of the literature on this). This was the conclusion of at least two major US government supported studies, one by the US Congress Office of Technology Assessment (OTA) (US Congress Office of Technology Assessment 1984) and the other by the Japan Technology Evaluation Center (reports summarized in Holdridge 1994). Both studies concluded that the Japanese system was more suited to the biotechnology industry than the US system. In the Japanese system large firms led in developing and commercializing new biotechnology. In the United States, university researchers and new, financially weak start up firms led in developing new technology. The large Japanese firms entering the biotechnology industry were extremely strong in process development, which the OTA believed would be crucial in commercializing biotechnology, and they were backed by huge financial resources. If a US startup firm developed a promising technology, the Japanese could simply buy them out to acquire the technology. Many Japanese managers also were confident that the biotechnology industry would soon be dominated by Japan. In a 1981 survey, nearly half of the 128 Japanese firms responding said that Japan could catch up with the United States in the commercial development of biotechnology within 5 years - about a quarter thought it would only take two or three years (cited in OTA 1984: 77).

An article in the New York Times during this period (Lohr 1983) said that while Japan still lagged the United States in advanced areas of biotechnology, "most" analysts believed the gap was closing. Large numbers of Japanese chemical, pharmaceutical, and food companies were described as moving into biotechnology. Other articles in the US business and science press also pointed with alarm to the apparent loss of the biotechnology industry to Japan. The US was advised to borrow aspects of the Japanese approach (e.g. Dibner 1985) and warned about surrendering its technology via Japanese/US collaboration in biotechnology (Yoshikawa 1989; Forrest 1996). In 1990 Business Week expressed a clear view of what many observers thought was happening. It quoted the editor of Nikkei Biotech, as saying: "It's the typical tale. The front runners are all American, until Japan steps in with improvements." As Business Week summarized the situation "With characteristic hubris and drive, the Japanese are charging into biotechnology. Starting from scratch a decade or so ago, they licensed 


\section{Reiko Kishida and Leonard H. Lynn}

sophisticated techniques from US and Japanese partners. Then, they poured Japan Inc.'s resources into building a biotech industry."

By the mid-1990s, however, the conventional wisdom had made an about face. Economist (November 18, 1995) pointed out that despite all of Japan's putative advantages in biotechnology, Japan had not only failed to develop a competitive industry, but had even become a huge importer of biotechnology products. As Fortune (1996) put it: "Today the [Japanese biotechnology] dynamo seems like the little engine that couldn't." Academic researchers reached a similar conclusion (Callan 1996; Forrest 1996; Bartholomew 1997; Darby and Zucker 1999).

\section{The US national biotechnology innovation system as a model for Japan}

Since the United States was so conspicuously successful in the biotechnology industry, academics and policy makers in Japan have used the US model in diagnosing the weaknesses of the Japanese biotechnology industry. Similar critiques have also been made of the national innovation systems for biotechnology in such European countries as Germany (e.g. Giesecke 2000; Casper and Kettler 2001; Prevezer 2001; Lehrer and Asakawa 2004), France (e.g. Mangematin 2000; Lemarie et al. 2001), Italy (e.g. Orsenigo 2001), Sweden (Carlsson 2001), and, to a lesser extent, the United Kingdom (e.g. Casper and Kettler 2001; Prevezer 2001).

Figure 6.1 compares the US and Japanese biotechnology commercialization systems. Although we have not studied the systems in major European countries as carefully, we believe (with the possible exception of the United Kingdom) that they would more closely resemble the Japanese system as depicted here (e.g. Lehrer and Asakawa 2004; though
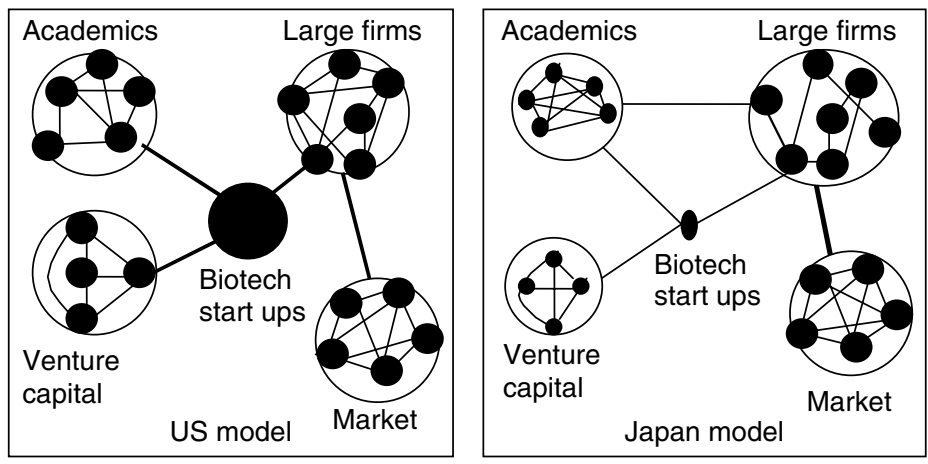

Figure 6.1 Network structure in US and Japanese biotechnology industries. Source: Lynn and Kishida (2004). 
Muller et al. (2004) say large firms were not important in the German biotechnology industry until recently). The large black circle at the center of the diagram representing the US model is intended to suggest that biotech startups are more important in the US than in the Japanese biotechnology innovation system. Large, diversified firms are important in both systems, but in the United States the large firms specialize in commercializing technology developed by startup firms. Thus the lines connecting the biotech firms with large firms, venture capital and academia are in bold for the US model, but not for the Japanese.

Various empirical indicators support this characterization. In 1997, for example, there were similar numbers of large firms in the US and Japanese biotechnology industries (300 in the US compared to 260 in Japan). The US, however, had about twenty times as many start up biotechnology firms as Japan (1,274 compared to 60). Other data further support and extend the characterization in Figure 6.1. In studying firms newly active in the biotechnology industry, Darby and Zucker (1996) found that 77 percent of the US firms were started as biotech firms, while 88 percent of the Japanese firms were started as divisions of firms in other industries. Darby and Zucker (1999) also found that only about 10 percent of the Japanese firms active in biotechnology (between 1975 and 1989) were newly established, compared to about two-thirds of the US firms (between 1976 and 1990).

Japan Patent Office data (2001) also support the idea that large US firms rely on smaller firms for technology, while large Japanese firms develop their own technology. Between 1990 and 1997, large firms were responsible for 76 percent of the biotechnology patents filed by Japanese, while large US firms accounted for only 17 percent of the patents filed by Americans. In the US, venture firms accounted for 30 percent of the patents filed, while universities and public institutes accounted for the rest. This also reflects the greater importance of universities as a source of biotechnology in the United States. As was mentioned earlier, until the early 1990s the Japanese model portrayed in Figure 6.1 was believed to be much stronger than the US model. The reasoning at the time was that while the United States would continue to be stronger at developing new technologies, this strength would support the Japanese, not the US biotechnology industry. The large Japanese firms would simply buy technology developed in the US by taking over US start ups. After all, the Japanese had taken over numerous US Silicon Valley firms in electronics, and had ended up profiting more than Americans from such US inventions as the transistor (Lynn 2000).

As it became clear that the Japanese model was not performing well, interpretations changed. Greater attention was paid to systemic aspects of the US biotechnology industry. Scholars pointed to symbiotic relationships 
between large firms and small venture-capital-backed firms, and also between the small venture-capital-backed firms and universities.

A number of scholars argue that large firms are weaker than small entrepreneurial firms at developing technological breakthroughs in biotechnology for two reasons. A rich literature in technological innovation suggests that large well-established firms in general are good at incremental, but not paradigmatic innovation (Tushman and Anderson 1986; Anderson and Tushman 1990; Henderson and Clark 1990; Christensen 1997). Aside from the general advantages new firms have because they are not constrained by bureaucratic inertia, in the case of biotechnology (and possibly other high technology industries) there is a more specific advantage. These firms need to attract and motivate star scientists. Venture-capital-backed firms are better able than large established firms to do this because they can offer star scientists substantial equity stakes, and thus the chance to become very wealthy (see, e.g. Audretsch and Stephan 1996, 1999; Darby and Zucker 1996; Zucker and Darby 1997; McMillan et al. 2000; Audretsch 2001; Rothaermel and Deeds 2001). On the other hand, regulatory compliance requirements often mean that it takes years for new biotechnology products to come to market. The startup firms do not have the patient capital behind them to wait. This is the key advantage of the large, well-established firms. So, the small startup firms are better at developing new biotechnology, while the large established firms are better at handling the final stages of commercialization.

The linkages between universities and venture-capital-backed firms are also crucial to the US system. Academic scientists not only develop new technology, but are also prominent in founding biotechnology start ups. One study found that nearly half the founders of US start up firms in biotechnology in the early 1990s were from universities (Audretsch and Stephan 1999). Aside from this, existing biotechnology firms find they need to be near US universities with strong biotechnology programs (Zucker et al. 1998; McMillan et al. 2000).

As was noted earlier, until the early 1990s it was widely assumed that large Japanese firms could as easily commercialize biotechnology developed in the US as their American counterparts. Indeed, some thought that Japanese firms could do a better job of commercializing biotechnology developed in the US than American firms because of their superior process capabilities and stronger backing by banks and other keiretsu partners. Japanese firms such as Kikkoman (with centuries of experience producing soy sauce) and Kirin (one of the world's largest brewers of beer) were identified in a report by the US Congress Office of Technology Assessment (1984) as emerging leaders in biotechnology.

It has not, however, proved to be as easy for Japanese firms to establish linkages with US start up firms and universities in biotechnology. The 
reasons for the Japanese inability to effectively tap into the US innovation system have not been systematically explored, but we would offer the following. Some research (Link and Rees 1996) suggests that small firms are more efficient than large firms at commercializing university-based research, thus by their very size the large Japanese firms may have been handicapped at drawing on US universities as a source of technology. Audretsch and Stephan (1996) suggest that proximity is crucial in the case of the transfer of tacit knowledge. It may be that tacit knowledge is unusually important in the case of biotechnology. It may be, as well, that biotechnology is not as easily, "handed off" as other technologies from creators to developers. Substantial adjustments based on ongoing streams of scientific research may be required during commercialization. Clearly, the Japanese large firms would have the same problem as US large firms in offering high-powered incentives to US star scientists, indeed, given their higher degree of pay equity Japanese firms find this even more difficult than their US counterparts. The Japanese innovation system is much stronger in engineering than in science. Japan graduates far more engineers on a per capita basis than the US, but far fewer scientists and far fewer technical people from post graduate programs (Lynn 2002). Finally, US firms may have major advantages over Japanese firms in coping with the various regulatory processes involved in getting approval for biotechnology products.

Given the apparent inability of Japanese firms to tap into the US biotechnology system, Japanese policy makers sought to identify aspects of the Japanese system that might be changed to increase Japan's international competitiveness in biotechnology. Several areas drew special attention.

One was the relatively small number of start up firms in Japan. Two points might be made about this. First of all, it is not just in biotechnology that Japan does not have many start up firms. As Figure 6.2 shows, Japanese are far less likely than Americans to start or close down firms in any industry. Over the last twenty years around 14 percent of all operating firms in the United States were new entrants. In Japan the percentage was less than 4 percent.

As Figure 6.3 shows, Japan has also been less likely than most of the large European countries to start and close down businesses (though the gap is not large in the case of Italy - see Orsenigo (2001) on the poor performance of the Italian biotechnology system).

A second apparent weakness of the Japanese biotechnology innovation system is that Japanese universities have been weak in developing new research programs, particularly in areas related to biotechnology. And, when the universities have developed new technology, regulatory and other barriers have made it difficult for them to transfer it to industry (Callan 1996; Forrest 1996; Bartholomew 1997; Darby and Zucker 1999). A Ministry of International Trade and Industry (MITI) official (Fujisue 1998) contrasted 


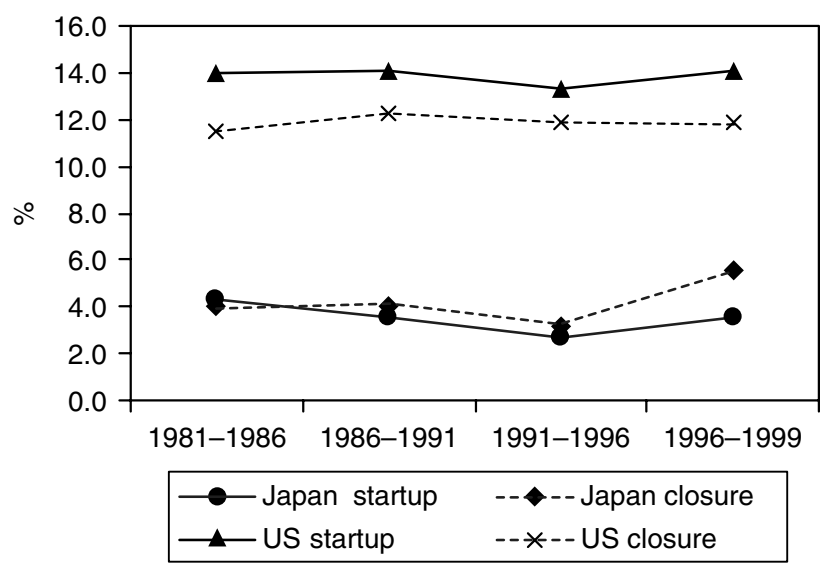

Figure 6.2 Startup and closure rates in Japan and the United States. Source: Small and Medium Enterprise Agency (2001).

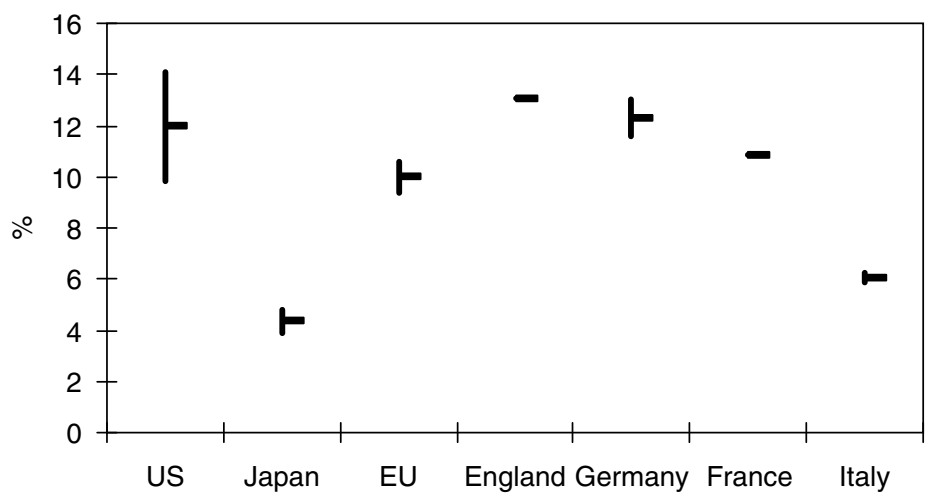

Figure 6.3 Startup rates based on common definition, 1988-1994.

Source: Small and Medium Enterprise Agency (2001).

the situation in Japan with that in the United States. He pointed out that in 1994 US universities received about fifteen times as many patents as Japanese universities (1,862 compared to 129) and that more than 1,000 high technology start ups had originated at US universities.

The Japanese patent system may also have inhibited the development of biotechnology. All patent systems seek a balance between promoting the diffusion of technology and protecting intellectual property. In its efforts to catch up technologically after Second World War, Japan developed a system that gave priority to the diffusion of technology (Wineberg 1988; Maskus and McDaniel 1999). This is a particular problem in the case of biotechnology, because in this industry new ventures must invest heavily 
in R\&D. They have little incentive to make these investments unless they are sure their intellectual property can be protected. Strong intellectual property protection also makes it easier for scientists to communicate with each other and for firms to collaborate (Chambers 2002). The US system not only provided better protection for intellectual property rights than the Japanese system, but was further strengthened in 1982 when the Court for Appeals of the Federal Circuit (CAFC) was formed and given exclusive jurisdiction over patent appeals (Shapiro 1990).

\section{Restructuring the Japanese innovation system}

In the 1990s, Japanese policy makers were determined to restructure the Japanese biotechnology innovation system. There was nothing new about the interest in biotechnology. In the 1980s Japanese government policy had also given priority to biotechnology. MITI published a "Vision for the Biotechnology Industry" in 1988, and almost every Japanese cabinet-level agency established some sort of biotechnology project. MITI, the Ministry of Agriculture, Forestry and Fisheries, and the Ministry of Health and Welfare all set up cooperative research projects for major firms (JEI 1986, 1990; Yoshikawa 1989; Fransman and Tanaka 1995). None of these projects, however, seem to have involved heavy spending by government, particularly in comparison to the US government. Over a period of ten years MITI, perhaps the most prominent ministry involved in biotechnology, spent about $\$ 40$ million per year on its widely-heralded cooperative programs. In a single year during this period the US government spent some $\$ 3.5$ billion (Fransman and Tanaka 1995). Government's role in Japan was primarily to coordinate the activities of large firms.

By the 1990s many Japanese were becoming disillusioned with the industrial and technological policies of the past. The conspicuous successes in shipbuilding, steelmaking, auto production, consumer electronics, and semiconductors seemed increasingly remote. The Japanese economy seemed unable to recover from the collapse of the stock and real estate markets. In its annual White Paper in 1998 (MITI 1998), MITI repeated what was becoming the conventional wisdom in Japan, saying the old system was no longer working. MITI called for Japan to develop systems to supply venture capital similar to those in the United States. In the case of biotechnology, the Japanese government developed new policies in the mid-1990s to encourage new bio-ventures, strengthen basic research in universities, and facilitate knowledge transfer from universities to industry (Arita 1990, 1997; Aoyama 1999; Collins and Wakoh 2000; Audretsch 2001).

\section{Encouraging the development of new ventures}

Until the 1990s Japanese SME policies generally focused on the role of SMEs as subcontractors to major firms. In the 1930s, for example, the 
main policy goal was to help SMEs produce more and higher quality inputs for the large firms, and thus contribute to Japan's military strength. There was a shift during the years of the US occupation in the late 1940s and early 1950s to strengthening SMEs as instruments of a more democratic economic structure. After the end of the Occupation in 1952, however, the goal changed back to enhancing the ability of SMEs to support major firms, and thus to help improve Japan's international competitiveness (Aoyama 1999).

In the mid-1990s new SME policies were introduced with a different purpose - to help create a climate for entrepreneurship (see Table 6.1). Some of these policies eliminated barriers for entrepreneurs trying to start and grow their firms, others provided subsidies and incentives to encourage entrepreneurship (Callan 1996; Darby and Zucker 1996, 1999; Forrest 1996; Bartholomew 1997; Eshima 2003).

In 1994 MITI established a New Business Promotion Office to help start ups explore new business opportunities. In 1995, the Small and Medium Enterprise Agency (SMEA) launched an initiative to promote and assist innovative SMEs. Various local areas also established programs to help start ups. The Law Facilitating the Creation of New Business (New Businesses Law) was passed in December 1998. This established the Japanese SME Technology Innovation System, a Japanese version of Small Business Innovation Research Program. Among other things, the Law gives subsidies to SMEs for the development of technologies that will lead to the creation of new businesses. The subsidies totaled more than $\$ 100$ million in 2000 . Under one of these programs SMEs can receive half the cost of materials, machinery, and technical guidance needed for R\&D. The law also provides for tax reductions for SMEs conducting research.

Table 6.1 Japanese policies to facilitate the creation of new ventures, 1994-2000

\begin{tabular}{ll}
\hline 1994 & Establishment of New Business Promotion Office by MITI \\
1995 & Law Facilitating Creative Activities of Small and Medium Enterprises \\
1997 & Tax Treatment for Angel Investors \\
1998 & Law Facilitating the Creation of New Businesses \\
& Tax Treatment for Stock Options \\
1999 & Amendment of Law Facilitating Creation of New Businesses \\
& Amendment of Tax Treatment for Angel Investors \\
& Law to Support Management Innovation for Small and Medium \\
& Enterprises \\
& Law to Establish Japanese Small and Medium Enterprise Corporation \\
& (JASMEC) \\
& Establishment of Japan Association of New Business Incubation \\
& Organizations (JANBO) \\
Amendment of Tax Treatment for Angel Investors
\end{tabular}

Sources: Ministry of Economy, Trade and Industry; Small and Medium Enterprise Agency (various year). 
The laws regulating stock markets and venture capital funds were changed to make it easier to start firms. Other new policies were intended to improve the support structure for new firms. Based on the New Businesses Law, for example, the Japan Association of New Business Incubation Organizations (JANBO) was established in 1999 to serve as a system of "incubators" for the creation of new businesses and to establish "regional platforms" offering "one-stop" service for those developing new businesses (JANBO 2002).

\section{Increasing government spending on biotechnology $R \& D$}

One reason Japan's basic science base has been relatively weak is that the Japanese government spends far less on basic science than does the US government (Callen 1996). Recently, there have been some efforts in Japan to close the gap in government spending on biotechnology (the Japanese budget for biotechnology areas increased from 170 billion yen in 1997 to 305 billion yen in 2000 . The project budget for 2004 was 500 billion yen (about $\$ 4.5$ billion at current exchange rates - around the US level of a decade ago). While it is difficult to find completely comparable statistics for current United States federal government spending on biotechnology, US government spending on the life sciences has also increased rapidly, doubling in the last ten years, to reach about $\$ 30$ billion in 2004 (NSF various year).

\section{Enhancing the role of universities in the Japanese biotechnology innovation system}

Japanese universities were seen as being a very weak component of the biotechnology innovation system, both in the creation of new technology, and in the transfer of it to industry. Here again, a parallel contrast has been made between the German and the US systems (Giesecke 2000).

Evidence of the relatively small role played by Japanese universities in biotechnology research is offered in Table 6.2. While universities accounted for nearly a quarter of the US patent family filings, they accounted for less than 3 percent of those in Japan. It might be noted that the patterns for Germany and France were more similar to that of Japan, while that of the United Kingdom was more similar to the United States.

As was noted earlier, other evidence, such as royalties received and number of new venture spin-offs, further underscores the point that US universities have played a much more significant part in their national innovation system than has been true of their Japanese and European counterparts. As an official from MITI points out in criticizing Japanese universities, while 36 percent of Japan's researchers are in academia, universities only contribute 0.04 percent of Japanese patents (Fujisue 1998). 
Table 6.2 Organizations filing patent families of human DNA sequences, by organization type and priority country, 1980-1999

\begin{tabular}{|c|c|c|c|c|c|c|c|c|}
\hline \multirow{2}{*}{$\frac{\text { Country }}{\text { United States }}$} & \multicolumn{2}{|c|}{$1980-1984 \%$} & \multicolumn{2}{|c|}{$1985-1989 \%$} & \multicolumn{2}{|c|}{$1990-1994 \%$} & \multicolumn{2}{|c|}{$1995-1999 \%$} \\
\hline & 77 & 100.0 & 215 & 100.0 & 441 & 100.0 & 736 & 100.0 \\
\hline Corporations & 52 & 67.5 & 116 & 54.0 & 241 & 54.6 & 412 & 56.0 \\
\hline Universities & 13 & 16.9 & 53 & 24.7 & 108 & 24.5 & 163 & 22.1 \\
\hline Not-for-profits & 7 & 9.1 & 23 & 10.7 & 48 & 10.9 & 59 & 8.0 \\
\hline $\begin{array}{l}\text { Government } \\
\text { agencies }\end{array}$ & 1 & 1.3 & 7 & 3.3 & 13 & 2.9 & 20 & 2.7 \\
\hline Individuals & 4 & 5.2 & 16 & 7.4 & 31 & 7.0 & 82 & 11.1 \\
\hline apan & 31 & 100.0 & 88 & 100.0 & 130 & 100.0 & 150 & 100.0 \\
\hline Corporations & 27 & 87.1 & 65 & 73.9 & 93 & 71.5 & 117 & 78.0 \\
\hline Universities & 0 & 0.0 & 3 & 3.4 & 6 & 4.6 & 2 & 1.3 \\
\hline Not-for-profits & 2 & 6.5 & 4 & 4.5 & 6 & 4.6 & 7 & 4.7 \\
\hline $\begin{array}{l}\text { Government } \\
\text { agencies }\end{array}$ & 1 & 3.2 & 5 & 5.7 & 6 & 4.6 & 9 & 6.0 \\
\hline Individuals & 1 & 3.2 & 11 & 12.5 & 19 & 14.6 & 15 & 10.0 \\
\hline Great Britain & 15 & 100.0 & 32 & 100.0 & 80 & 100.0 & 107 & 100.0 \\
\hline Corporations & 10 & 66.7 & 29 & 90.6 & 45 & 56.3 & 63 & 58.9 \\
\hline Universities & 2 & 13.3 & 0 & 0.0 & 18 & 22.5 & 27 & 25.2 \\
\hline Not-for-profits & 3 & 20.0 & 1 & 3.1 & 7 & 8.8 & 9 & 8.4 \\
\hline $\begin{array}{l}\text { Government } \\
\text { agencies }\end{array}$ & 0 & 0.0 & 1 & 3.1 & 8 & 10.0 & 4 & 3.7 \\
\hline Individuals & 0 & 0.0 & 1 & 3.1 & 2 & 2.5 & 4 & 3.7 \\
\hline iermany & 4 & 100.0 & 9 & 100.0 & 25 & 100.0 & 93 & 100.0 \\
\hline Corporations & 4 & 100.0 & 9 & 100.0 & 14 & 56.0 & 33 & 35.5 \\
\hline Universities & 0 & 0.0 & 0 & 0.0 & 3 & 12.0 & 9 & 9.7 \\
\hline Not-for-profits & 0 & 0.0 & 0 & 0.0 & 4 & 16.0 & 8 & 8.6 \\
\hline $\begin{array}{l}\text { Government } \\
\text { agencies }\end{array}$ & 0 & 0.0 & 0 & 0.0 & 1 & 4.0 & 5 & 5.4 \\
\hline Individuals & 0 & 0.0 & 0 & 0.0 & 3 & 12.0 & 38 & 40.9 \\
\hline France & 1 & 100.0 & 14 & 100.0 & 26 & 100.0 & 35 & 100.0 \\
\hline Corporations & 1 & 100.0 & 6 & 42.9 & 16 & 61.5 & 20 & 57.1 \\
\hline Universities & 0 & 0.0 & 3 & 21.4 & 2 & 7.7 & 3 & 8.6 \\
\hline Not-for-profits & 0 & 0.0 & 2 & 14.3 & 3 & 11.5 & 7 & 20.0 \\
\hline $\begin{array}{l}\text { Government } \\
\text { agencies }\end{array}$ & 0 & 0.0 & 3 & 21.4 & 4 & 15.4 & 5 & 14.3 \\
\hline Individuals & 0 & 0.0 & 0 & 0.0 & 1 & 3.8 & 0 & 0.0 \\
\hline
\end{tabular}

Sources: National Science Foundation (NSF); Division of Science Resources Statistics (SRS) 02-333 (2002).

One aspect of the effort to strengthen the contribution of universities to the Japanese national innovation system has involved reforms in how intellectual property is handled by universities. When corporate scientists make a discovery, they naturally keep it secret within the firm until the firm is able to find a way to profit from it. When academic scientists make a discovery, their incentives are to publicize it as quickly as possible to 
gain reputation, tenure, and promotions. The sponsors of university research are often governments and others who insist that the findings of the research they have paid for be made public. For these reasons, academic science has been called "public science" (Narin et al. 1997).

Research suggests that the biotechnology industry draws more heavily than others on public science (McMillan et al. 2000). The utilization of public science by business, according to some analysts, poses a special set of problems. On the one hand, it means that companies have little incentive to invest in university research, since the findings of this research would be in the public domain. On the other hand it means that universities lack incentives to advertise the technologies they develop to industry, with the result that companies often do not know about promising technology available from university laboratories. This dilemma, of course, is not unique to Japan. It was, however, identified and responded to much more quickly in the United States.

The United States response was the Bayh-Dole Act of 1980. The Act allowed universities to patent technologies and to assign the patents to firms. This gave universities new incentives to develop technologies of interest to industry and to make sure industry is aware of the new technologies. It also gave firms incentives to invest in university research. By several indicators the Bayh-Dole act had an immense impact. Universities rushed to establish technology licensing offices (TLOs) to take advantage of the new law. By year 2000 virtually every American research university had one. The number of patents issued to US universities more than doubled from 1979-1984, more than doubled again between 1984-1989, and more than doubled yet again during the 1990s. University revenues from licensing shot up, increasing from \$221 million in 1991 to \$698 million in 1997.

In the late 1990s the Japanese government introduced a number of new policies designed after Bayh-Dole and other US policies (Fujisue 1998). Table 6.3 lists some of the more important of these new measures. Under the new policies universities submit technology transfer plans to the Ministry of Economics, Technology and Industry (METI, the successor to MITI after a Japanese bureaucratic reorganization) and the Ministry of Education and Culture. The plans include the establishment of TLOs to manage university patents and promote the sale of technology licenses to companies. The government subsidizes 50 percent of the expenses of the TLOs, and guarantees the debts incurred in establishing them. The TLOs are exempt from patent registration and maintenance fees (Fujisue 1998), and the government provides funds to advertise the results of university technology transfer plans.

One reason Japanese academics are less involved in the establishment of new technology-based firms than their American counterparts, has been regulations preventing this involvement (Bartholomew 1996; Callan 1996; 
Table 6.3 Japanese policies to improve flow of technology from universities to industry, 1995-2000

\begin{tabular}{cl}
\hline 1995 & $\begin{array}{c}\text { Science and Technology Basic Law Office for the Promotion of } \\
\text { Academia-Industry Cooperation established in MITI's Industrial } \\
\text { Policy Bureau } \\
\text { Basic Science and Technology Promotion Plan approved by Japanese } \\
\text { cabinet. Called for reform of system of cooperation between industry } \\
\text { and academia }\end{array}$ \\
$1996 \quad$ Amendment of Special Law for Education Personnel \\
$1997 \quad$ Law Promoting Technology Transfer from Universities \\
(requires universities to have technology transfer plans approved by \\
MITI and Ministry of Education - see Fujisue for details) \\
Amendment of Law for Facilitating Governmental Research Exchange \\
Law to Strengthen Industrial Technical Ability National Personnel \\
Authority Regulation 14-18, 14-19
\end{tabular}

Sources: Ministry of International Trade and Industry (Ministry of Economy, Trade and Industry) (various year).

Darby and Zucker 1999). According to one survey, there had been a total of only 128 university-initiated ventures between 1958 and 2000 (News Nikkei 2001). New policies have been introduced to allow professors at national universities to work as officers of companies using their research results. The government expressed the hope that its various new policies would lead to the establishment of some 1,000 university-initiated start ups over the years 2002-2005.

\section{Other policies to reform the Japanese innovation system}

In the United States, biotechnology centers have developed in clusters, generally centering on universities. For some time Japan has experimented with the creation of technology centers (see, e.g. Vogel 1985; Tatsuno 1986). The Japanese government has specifically been encouraging the development of regional centers of biotechnology strength. The centers include incubators for biotechnology start ups. New biotechnology centers have been established in Chiba Prefecture (near Tokyo), Yokohama, and Kansai (by Osaka and Kyoto). Altogether nine prefectures have so far agreed to develop clusters that will link science parks, universities, research institutions, corporate laboratories, and start ups.

Finally, the Japanese government has been persuaded that the increased protection of intellectual property rights is needed to further encourage innovative research and development. Japanese patent law was amended in 1998 to strengthen patent protection and to accelerate the acquisition of intellectual property rights (Ishimura 1999). 


\section{Results of the new policies}

Clearly the Japanese have embarked on an unusually comprehensive effort to redesign their biotechnology innovation system. They have made changes in their systems of government support, university regulation and governance, patent systems, and institutions facilitating the formation of start ups. There are signs of progress, but also reasons for concern.

\section{New bioventures}

The number of bio-related new ventures increased from 60 firms in 1998 to 334 firms by the end of February 2003 (JBA 2003). Press reports suggest that at least some of these ventures were started as a result of the new government policies. New policies allowed professors at national universities to work as officers of companies using their research results, for example, professors started such new biotechnology ventures as GeneticLab, Gene Techno Science, and AnGes MG. GeneticLab was founded by university professors in 2000 and was able to raise some 425 million yen (about $\$ 4$ million at the time) from venture capitalists and METI subsidies. AnGes MG was established in 1999 by a small group including an Osaka University Professor. Within three yeas this company had made a successful initial public offering at the 'Mothers Market' of the Tokyo Stock Exchange (News Nikkei, January 26, 2002). The total number of new ventures based on university research for all technologies reached 799 by the end of 2003 (reasonable progress towards the government goal of 1,000 by 2005). Of the new firms 293 were in the biotechnology and medical areas (METI 2004). While the number of firms and the amounts of money involved may not be impressive by US standards, they may represent a starting point for Japan. Germany, which was introducing changes to its biotechnology innovation system that somewhat paralleled those in Japan, increased the number of its biotechnology firms (not necessarily new ventures) from 75 in 1995 to 222 in 1998 and 379 by the end of 2002 (Ernst and Young annual survey data cited in Lehrer and Asakawa 2004).

Another possible, though admittedly tenuous, indicator of increased university faculty involvement in new biotechnology firms is that the average number of $\mathrm{PhD} / \mathrm{MD}$ holders amongst Japanese biotechnology firms established since 1999 is greater than that in older firms. We obtained information about 141 biotechnology firms in Japan from the BIOScan database (July 2002), the 2002 Bio Business White Book (Daiwa Soken 2002), and company websites. The 50 firms formed after 1999 had an average of 1.2 key managers with doctoral degrees, compared to an average of only 0.73 for the 91 firms formed before 1999 . 


\section{Policies to foster development of start ups and SMEs}

Many new business incubators have been established in Japan, suggesting that the Law Facilitating the Creation of New Businesses is having some impact. A survey conducted in 2000 identified 203 incubators housing 2,247 residents in Japan. This compares to 850 incubators housing 6,458 firms in the United States. Compared to their US counterparts, however, the Japanese incubators have been characterized as being understaffed and providing weak service. Unlike the US incubators, which are generally led by universities and have strong ties with industry, the Japanese incubators are led by local government and tend to have weak ties with both universities and industry (METI 2001). The Japanese, then, may have been more successful at adopting the form than the substance of these organizations.

The Japanese government has not yet conducted a rigorous assessment of the results of its Small Business Innovation Research program, but Eshima (2003) found that firms receiving awards grew faster than comparable non-awardees. Oddly, though, firms receiving multiple awards did worse than those receiving a single award. The author does not discuss this apparent anomaly. Perhaps it suggests that the awards encourage firms to become dependent on the awards. Nor does Eshima address the possibility that the firms receiving awards were more promising than comparable firms and would have grown faster anyway.

\section{Flows of technology from universities to industry}

The measures designed to increase the flow of technology from universities to industry in Japan have also been trumpeted as showing early successes. As of November 2004, 32 TLOs had been established nationwide in Japan. In the first two years after "The Law for Facilitating Technology Transfer from Universities" was enacted in 1998, more that 700 patent applications were made by universities. By the end of 2003, more than 5,000 patent applications had been made through TLOs to the Japanese patent office, and 1,256 had been made to foreign patent offices (Japan Patent Office 2004). The number of joint and commissioned research projects in biotechnology at universities increased six-fold over a decade. More than two thousand researchers were sent by companies to be trained in university laboratories. In 2001, 28 of Japan's 80 national universities offered entrepreneurship courses for graduate students, and 21 of them had courses for undergraduates. Again though, if comparisons are made with the United States these numbers are not impressive. As was noted above, for example, by 2000 virtually all US research universities had TLOs.

It might further be noted that the value of the Bayh-Dole Act, the primary model for many of the Japanese reforms and also a model for 
Germany and France (Giesecke 2000; Corrolleur et al. 2004; Lehrer and Asakawa 2004), has been challenged. Nelson (2001) suggests that not all of the increase in university patenting should be attributed to Bayh-Dole and, more importantly, that the increase itself does not necessarily indicate an increase in the diffusion of technology to industry. The years after BayhDole was enacted were a period when new fields of university-based research, including biomedical research, computers, and software, were rapidly developing. At the same time, patent laws were changing to make technology in these areas more patentable. So the number of patents would probably have increased somewhat even without Bayh-Dole. In any case, increased patenting may actually have slowed the diffusion of new technology to industry. The new TLOs may simply be collecting royalties from firms that would have used the technology anyway (and discouraging firms at the margin because of the royalty fees). Nelson is also concerned about the impact of Bayh-Dole on the universities. He notes that only a few have actually collected significant revenues through their TLOs. So the positive impacts may have been overstated. More importantly, the Bayh-Dole policies may cause university researchers to shift from fundamental research as they increasingly depend on royalty income from business firms. Also, collegeality at universities may deteriorate as some university researchers make far more money than others. Finally, the new monetary incentives could make professors less committed to contributing to public science. Nelson raises other issues as well. Should companies, for example, have to pay royalties or license fees to universities for technology that was developed at US government expense? The increased protection of intellectual property rights may curtail research in certain areas since researchers will not be as free to use research tools, techniques, and conceptions of a line of attack, all of which have become patentable (Nelson 2001).

The noted authority on Japanese technology policy, Akira Goto (2000) has expressed somewhat parallel reservations specifically about whether the Japanese reforms are moving in the right direction. He is concerned, for example, that the increase in government funding for universities will reduce the incentives of university researchers to cooperate with industry thus working against a closer university-industry relationship. He also suggests that a major problem in the university component of the Japanese national innovation system is not being sufficiently addressed. This problem is that Japanese universities have been slow to change curricula to reflect the changing nature of science and the increasing need for interdisciplinary approaches. Goto also complains that, even now, not enough is being done to increase financial support for graduate and post-doctoral students. As for the new emphasis on universities obtaining patents and becoming incubators, he is concerned that this will lead universities away from their role as repositories of advanced knowledge. Goto also worries 
that in pursuing increased control over intellectual property rights, universities may become reluctant to publicize their research findings.

Finally, Kneller (2003) found that there is much less reliance by major Japanese pharmaceutical companies on university research than is true of their US and European counterparts. A major reason for this had nothing to do with intellectual property rights. In his interviews with managers and scientists at Japan's eight largest pharmaceutical companies, he noted that respondents generally made disparaging comments about Japanese university research. It may be that the important need is to improve the quality of Japanese university research, rather than finding ways to funnel more university research to industry.

\section{Other aspects of role of government}

Commenting generally on the various policies intended to enhance Japan's technology strength, Goto (2000) notes that the large US government role in the US national innovation system has been much more to create a pool of knowledge, for example, via NIH spending, rather than to support specific commercial projects. Interestingly, Giesecke makes similar comments in explaining the relative lack of success of the German biotechnology system compared to that of the US, and Orsenigo (2001) notes the poor return from heavy targeted spending in Italy. Further, as was noted earlier, it seems Japanese government spending on biotechnology R\&D will continue to be far lower than that in the US. Goto also points out that the various Japanese policies of providing subsidies to firms by offering tax credits in recent years leave out many firms that are doing research, because so many Japanese firms recently have been unprofitable. He cites a 1999 study by the Japanese National Institute for Science and Technology Policy that found that only about 10 percent of large and medium-sized enterprises in Japan had benefited from these tax breaks. One might suppose that this would be particularly problematic in industries like biotechnology that are slow to generate profits.

While Goto (2000) notes that there were problems with the Japanese patent system before the recent reforms, he is worried that the reforms might take Japan too far towards a 'strong patent' system, which (for reasons similar to those in Nelson's argument outlined earlier) he thinks would discourage innovation. He also mentions another problem with the Japanese system that has not been resolved yet, the length of time it takes to settle intellectual property rights disputes.

\section{Conclusions}

At the beginning of this chapter we presented the following questions: Why did the Japanese model apparently fail in biotechnology, even though 
it had earlier apparently worked very well with semiconductors and other advanced technologies? What changes were made in the Japanese system? How closely does the 'new' Japanese system replicate the US system? To the extent evaluation is possible, is the new system working? What possible pitfalls might there be with the new system?

It seems that those anticipating a Japanese triumph in biotechnology were underestimating the degree to which success in this technology would require close linkages to the scientific sources of the technology. The competitive strength for biotechnology turned out not to be the ability incrementally to refine technology, or to offer more efficient production systems, or to offer higher quality. Indeed, it seems that even in these areas Japanese leadership has eroded (e.g. Porter et al. 2000). Perhaps, because of the nature of biotechnology, it turned out that Japanese firms were not able efficiently to tap into the US sources of new technology. Often this technology seems unusually tacit and embedded in people. Interestingly, the classic works on national innovation systems by Europeans (Freeman 1987; Lundvall 1992) paid for less attention to universities than did the parallel work by an American (Nelson 1993).

The conventional wisdom emerged that Japan needed to borrow elements of the US innovation systems: including closer linkages between universities and industry, a more favorable environment for start up firms, and a different treatment of intellectual property rights. Less note has been taken of the huge amounts of US government spending in support of bioscience. It seems in this regard, for better or worse, Japan has developed only a partial replication of a US style national innovation system in biotechnology. We also noted doubts that have been raised about aspects of the US system, particularly the aggressive mechanisms designed to transfer university technology to companies, and the strong protection of intellectual property rights. The pitfall for Japan and others seeking to learn from the US model, is that the functioning of the US model is by no means well understood (just as the reasons for the success of the Japanese system in the past were not completely understood).

Since the efforts to reform the Japanese biotechnology system are new, it would be premature to assess their success at this point. It is also unclear what the criteria for success should be. Japan may not seem strong in biotechnology compared to the United States, but compared to other advanced industrial economies, it is fairly strong by some indicators. Japanese were granted more patents in biotechnology than the citizens of any European country in both 1990 and 2000. In the years 1986-1998 the United States had a huge lead in its share of the world's publications in biotechnology and applied microbiology, accounting for nearly a quarter of all these publications. Japan was second, however, with 12.1 percent of all publications. Amongst the European countries, the United Kingdom 
was first (9.3 percent), Germany was second (6 percent), and France was third (5.9 percent) (Beuzekom 2001). There are signs, however, that the Japanese biotechnology industry lost ground during the 1990s. Japan's share of patents granted in the United States, for example, dropped (OECD 2001). Perhaps more telling, a 1999 survey of 151 Japanese firms involved in biotechnology found that respondents believed they lagged behind both the United States and Europe in most areas of biotechnology in terms of technological competitiveness.

It could be argued, however, that Japan's relative competitiveness in biotechnology should not be taken as problematic. As Table 6.4 shows, in 1992 although Japan has an economy and population only about half as large as those of the United States, it accounted for 17.0 percent of all advanced technology exports, compared to 25.2 percent for the United States. Indeed, Japan had a larger share of world exports than the United States in the case of four of the ten "advanced technologies." In three of the technologies - weapons, aerospace and nuclear - heavy US defense spending presumably accounts for the US lead. In biotechnology, however, the Japanese share of world exports was only 4.3 percent compared to 37.0 percent for the United States. It was not only in comparisons with the United States that Japan seems weak in biotechnology. The table shows that Japan, while stronger than Germany in its overall share of world exports of advanced technology products (17.0 percent compared to 11.7 percent), was substantial weaker in the case of biotechnology (4.3 percent compared to 19.1 percent).

While a major theme in this book is that Japan needs to change its national innovation system so as to foster its ability to develop cutting edge technology, the data in Table 6.4 might be taken as suggesting something different. One scholar (Jin 2001) argues that different countries are characterized by different "knowledge regimes" that encompass very

Table 6.4 Share of world exports of advanced technology products in 1992 (in \%)

\begin{tabular}{llcc}
\hline Technology & US & Japan & Germany \\
\hline All technologies & 25.2 & 17.0 & 11.7 \\
Biotechnology & 37.0 & 4.3 & 19.1 \\
Life Science technology & 27.5 & 13.8 & 20.4 \\
Optoelectronics & 13.7 & 22.8 & 24.0 \\
Information technologies & 18.5 & 23.0 & 8.3 \\
Electronics & 20.3 & 25.5 & 9.4 \\
Manufacturing technologies & 16.2 & 21.5 & 21.9 \\
Advanced materials & 28.6 & 9.3 & 15.1 \\
Aerospace & 44.2 & 1.4 & 11.3 \\
Weapons technologies & 34.3 & 4.6 & 12.1 \\
Nuclear technologies & 20.8 & 0.2 & 9.6 \\
\hline
\end{tabular}

Source: National Science Foundation, National Science Board (1996). 
different cultural, social, political, and economic systems. He suggests that the Japanese knowledge regime is just not very well-suited to the biotechnology, just as the US knowledge regime is not well suited to certain other industries.

Indeed, some scholars have suggested that one reason for the weakness of the Japanese biotechnology industry is that the Japanese socio-cultural system inhibits risk-taking (Callan 1996; Darby and Zucker 1996, 1999; Forrest 1996; Bartholomew 1997; Muller et al. 2004). We suggest caution in making such interpretations, particularly when glib conclusions are made that Japanese norms and values inhibit entrepreneurship. The current small number of start ups in Japan is only a recent phenomena (e.g. Odagiri and Goto 1993). Goto (1997) reports that the economic growth of Japan before the Second World War, was strongly supported by entrepreneurs. On the face of it, there seems little reason to assume that Japanese values and norms are less conducive to risk-taking than might have been true two or three generations ago.

But if the evidence for a Japanese cultural aversion to risk-taking seems dubious, some aspects of the Japanese social system do seem to inhibit certain forms of risk-taking. Most notable amongst these is the relative immobility of labor under Japan's career-long employment system. It is riskier to leave a Japanese "lifetime" job to start a new venture than it would be in the United States It is more difficult, as well, to build a qualified workforce by hiring employees from established firms. Further, the Japanese employment system relies much more on seniority in determining wages than does the US system. This greatly reduces the incentives for employees to obtain graduate education. The Japanese employment system is changing now, as many Japanese firms are forced to carry out large-scale job cuts and other reforms to respond to more intense global competition. These changes may produce more professional people who are willing to be involved in new venture businesses. Another weakness of the Japanese biotech industry has been a lack of scientists. Japan's education system has traditionally emphasized engineering over pure science (Forrest 1996; Bartholomew 1997). This also may be changing as the Japanese government undertakes new reforms to emphasize scientific knowledge.

If Jin is right, Japanese efforts to reform the Japanese innovation system to bolster its strength in biotechnology may be misguided. Perhaps Japan should concentrate on advanced technologies where it has a natural comparative advantage. It may be, however, consistent with a major theme of this volume, that this is not an option. In his study of the Japanese pharmaceutical industry Kneller (2003) also speculates that, partly because of its employment system, Japan has most often enjoyed technological success in industries where innovation can occur effectively in-house. He 


\section{2}

Reiko Kishida and Leonard H. Lynn

suggests that more recently the most important technical advances are taking place in areas where this technological autarky is less effective.

So, if the goal is to give Japan a new, more American national innovation system, how is Japan doing? One question is whether or not the Japanese have gotten the US model right. If the real source of US strength in biotechnology is strong, well-funded sources of the technology, downstream improvements in the Japanese system simply making it easier for universities to transfer their meager stock of technology to entrepreneurs may not go very far. There may be greater need for government funding in basic research and a concerted effort to strengthen universities.

\section{Bibliography}

Anchordoguy, M. (1989). Computers Inc.: Japan's Challenge to IBM. Cambridge, MA: Harvard University Press.

Anderson, P. and Tushman, M. (1990). "Technological discontinuities and dominant designs: a cyclical model of technological change." Administrative Science Quarterly 35: 604-633.

Aoyama, Y. (1999). "Policy interventions for industrial network formation: contrasting historical underpinnings of the small business policy in Japan and the United States." Small Business Economics 12: 217-231.

Arita, T. (1990). Sengo Nihon no Chusho Kigyo Seisaku. Tokyo: Nihon Hyoronsha.

— (1997). Chusho Kigyoron: Rekishi, Riron, Seisaku. Tokyo: Shimpyoron.

Audretsch, D.B. (2001). "The role of small firms in U.S. biotechnology clusters." Small Business Economics 17 (1,2): 3-15.

Audretsch, D.B. and Stephan, P.E. (1996). "Company-scientist locational links: the case of biotechnology." The American Economic Review 86(3): 641-652.

- (1999). "Knowledge spillovers in biotechnology: sources and incentives." Journal of Evolutionary Economics 9(1): 97-107.

Bartholomew, S. (1997). "National systems of biotechnology innovation: complex interdependence in the global system." Journal of International Business Studies 28(2): 241-266.

Business Week (1990). “Japanese biotech's overnight revolution.” Business Week March 12: 69-70.

Callan, B. (1996). "Why production technology is not a measure of competitiveness in the biotechnologies." BRIE Working Paper 86, May.

Callon, S. (1995). Divided Sun: MITI and the Breakdown of Japanese High-Tech Industrial Policy: 1975-1993. Stanford, CA: Stanford University Press.

Carlsson, B. (2002). "Summary and conclusions." In B. Carlsson (ed.) Technological Systems in the Bio Industries: An International Study. Boston, MA: Kluwer Academic Publishers, pp. 363-377.

Casper, S. and Kettler, H. (2001). "National institutional frameworks and the hybridization of entrepreneurial business models: the German and UK biotechnology sectors." Industry and Innovation 8(1): 5-30.

Chambers, J. (2002). "Patent eligibility of biotechnological inventions in the United States, Europe, and Japan: how much patent policy is public policy?" George Washington International Law Review 34: 223-246. 
Christensen, C.M. (1997). The Innovator's Dilemma. Boston, MA: HBS Press.

Collins, S. and Wakoh, H. (2000). "Universities and technology transfer in Japan: recent reforms in historical perspective." Journal of Technology Transfer 25: 213-222.

Corolleur, C., Carrere, M., and Mangematin, V. (2004). "Turning scientific and technological human capital into economic capital: the experience of biotech start-ups in France." Research Policy 33: 631-642.

Darby, M.R. and Zucker, L. (1996). "Japanese biotechnology enterprises.” NBER Working Paper 5795, Cambridge, MA: National Bureau of Economic Research.

- (1999). "Local academic science driving organizational change: the adoption of biotechnology by Japanese firms." NBER Working Paper 7248, Cambridge, MA: National Bureau of Economic Research.

Dibner, M.D. (1985). "Biotechnology in Pharmaceuticals: the Japanese challenge." Science 229: 1230-1235.

Dick, A. (1995). Industrial Policy and Semiconductors: Missing the Target. Washington, DC: American Enterprise Institute.

Economist (1995). "Biotechnology in Japan: Alien culture." Economist November 18: 79.

Eshima, Y. (2003). “Impact of public policy on innovative SMEs in Japan.” Journal of Small Business Management 41: 85-93.

Forrest, J.E. (1996), "Japanese/U.S. technological competitiveness and strategic alliances in the biotechnology industry." $R \& D$ Management 26: 141-154.

Fortune (1996) "Biological warfare: how the U.S. triumphed and Japan beat itself." Fortune April 1: 40.

Fransman, M. and Tanaka, S. (1995). Government, globalization, and universities in Japanese biotechnology. Research Policy 24(1): 13-49.

Freeman, C. (1987). Technology Policy and Economic Performance: Lessons from Japan. London: Pinter.

Friedman, D. (1988). The Misunderstood Miracle: Industrial Development and Political Change in Japan (Cornell Studies in Political Economy). Ithaca, NY: Cornell University Press.

Fujisue, K. (1998). "Report: promotion of academic-industry cooperation in Japan establishing the 'law' of promoting technology transfer from university to industry." Technovation 18(6/7): 371-381.

Giesecke, S. (2000). "The contrasting roles of government in the development of biotechnology industry in the U.S. and Germany." Research Policy 29: 205-233.

Goto, A. (1997). “Introduction.” In A. Goto and H. Odagiri (eds) Innovation in Japan. New York: Oxford University Press, pp. 1-19.

- (2000). "Japan's national innovation system: current status and problems." Oxford Review of Economic Policy 16(2): 103-113.

Henderson, R. and Clark, K. (1990). "Architectural innovation: the reconfiguration of existing systems and the failure of established firms." Administrative Science Quarterly 35: 9-30.

Holdridge, G.M. (ed.) (1994). JTEC/WTEC Annual Report and Program Summary, 1993/1994. Baltimore, MD: Japan Technology Evaluation Center.

Ishimura, Y. (1999). "Recent amendments to Japanese patent law.” In Patent Yearbook 1999, London: Managing Intellectual Property, pp. 11-13.

JANBO (2002). "The objectives of JANBO.” Available online at http://www.janbo.gr.jp/ Japan Patent Office (2001). "Technology trend survey.” Tokyo: Japan Patent Office. 


\section{Reiko Kishida and Leonard H. Lynn}

Japan Patent Office (2004). "2004 Japan patent office administration annual report.” Tokyo: Japan Patent Office.

JBA (Japan Biotechnology Association) (2003). Bioventure Statistics 2003.

JEI (Japan Economic Institute) (1986). JEI Report, Washington, DC. (1990). JEI Report, Washington, DC.

Jin, D. (2001). The Dynamics of Knowledge Regimes: Technology, Culture and Competitiveness in the USA and Japan. London and New York: Continuum International Publishing Group.

Johnson, C. (1982). MITI and the Japanese Miracle: The Growth of Industrial Policy, 1925-1975. Stanford, CA: Stanford University Press.

Kneller, R. (2003). "Autarkic drug discovery in Japanese pharmaceutical companies: insights into national differences in industrial innovation." Research Policy 32: 1805-1827.

Lehrer, M. and Asakawa, K. (2004). "Rethinking the public sector: idiosyncrasies of biotechnology commercialization as motors of national R\&D reform in Germany and Japan." Research Policy 13: 921-938.

Lemarie, S., Mangematin, V. and Torre, A. (2001). "Is the creation and development of biotech SMEs localized? Conclusions drawn from the French case." Small Business Economics 17: 61-76.

Link, A. and Rees, J. (1996). "Firm size, university-based research and the returns to R\&D." In Z. Acs (ed.) Small Firms and Economic Growth. Cheltenham: Edward Elgar Publishing, pp. 406-415.

Lohr, S. (1983). “Japan's biotechnology push.” New York Times. March 17, 1983 : B1 \& 34.

Lundvall, B. (1992). "Introduction.” In Lundvall, B. (ed.) National Systems of Innovation: Towards a Theory of Innovation and Interactive Learning. London: Pinter, pp. 1-19.

Lynn, L.H. (2000). "Technology competition policies and the semiconductor industries of Japan and the United States' a Fifty-year Retrospective.” IEEE Transactions on Engineering Management 47: 199-210.

- (2002). "Engineers and engineering in the U.S. and Japan: a critical review of the literature and suggestions for a new research agenda." IEEE Transactions on Engineering Management 49: 95-106.

Lynn, L.H. and Kishida, R. (2004). "Changing paradigms for Japanese technology policy: SMEs, universities, and biotechnology." Journal of Asian Business and Management 3: 459-478.

McMillan, G.S., Narin, F., and Deeds, D. (2000). "An analysis of the critical role of public science in innovation: the case of biotechnology." Research Policy 29(1): 1-8.

Mangematin, V. (2000). "Competing business models in the French biotech industry." In J. de la Motte and J. Niosi (eds) The Economic and Social Dynamics of Biotechnology. Boston, MA: Kluwer, pp. 181-204.

Maskus, K.E. and McDaniel, C. (1999). "Impacts of the Japanese patent system on productivity growth." Japan and the World Economy 11: 557-574.

METI (2004). “Daigaku-hatsu venture ni kansuru kisochousa.” METI April 26.

Ministry of International Trade and Industry (Ministry of Economy, Trade and Industry) (MITI or METI, depending on year) (various year). White Paper.

Muller, C., Fujiwara, T., and Hetstatt, C. (2004). "Sources of bioentrepreneurship: the cases of Germany and Japan.” Journal of Small Business Management 42: 93-101. 
Narin, F., Kimberly, F., Hamilton, S., and Olivastro, D. (1997). "The increasing linkage between U.S. technology and public science." Research Policy 26: 317-330.

National Science Foundation (NSF) (2002, 2003, and 2004). "Federal Funds for Research Development (October '04@2004AAAS).” Arlington, VA.

National Science Foundation (NSF), Division of Science Resources Statistics (SRS) (2002). "International Patenting of Human DNA Sequences (NSF 02-333)." Arlington, VA.

National Science Foundation (NSF), National Science Board (1996). "Science and Engineering Indicators - 1996 (NSF 96-01).” Arlington, VA.

- (1998). "Science and Engineering Indicators - 1998 (NSB 98-1)." Arlington, VA.

Nelson, R. (1984). High-Technology Policies: A Five Nation Comparison. Washington, DC: American Enterprise Institute.

— (ed.) (1993). National Innovation Systems: A Comparative Analysis. New York: Oxford University Press.

(2001). "Observations on the post-Bayh-Dole rise of patenting at American universities.” Journal of Technology Transfer 26: 13-19.

News Nikkei (2001). "Universities organize their system to nurture VB (venture business)." Nikkei Net, August 30.

(2002). Nikkei Net, January 26.

Odagiri, H. and Goto, A. (1993). "The Japanese system of innovation: past, present, and future." In R.R. Nelson (ed.) National Innovation Systems: A Comparative Analysis. New York: Oxford University Press, pp. 76-114.

OECD (2001). Biotechnology Statistics in OECD Member Countries.

Orsenigo, L. (2001). "The (failed) development of a biotechnology cluster: the case of Lombardy." Small Business Economics 17: 77-92.

OTA (U.S. Congress, Office of Technology Assessment) (1984). Commercial Biotechnology: An International Assessment. Washington, DC: US Government Printing Office.

Ouchi, W. (1984). The M-Form Society. Reading, PA: Addison-Wesley.

Patrick, H. (1986). Japan's High Technology Industries. Tokyo: University of Tokyo Press.

Porter, M.E., Takeuchi, H., and Sakakibara, M. (2000). Can Japan Compete? Cambridge, MA: Persues.

Prevezer, M. (2001). "Ingredients in the early development of the U.S. biotechnology industry." Small Business Economics 17: 17-29.

Rothaermel, F.T. and Deeds, D.L. (2001) "More good things are not necessarily better: an empirical study of strategic alliances, experience effects, and innovative output in high-technology start-ups." Academy of Management Proceedings F1-6.

Samuels, R.J. (1994). Rich Nation, Strong Army: National Security and the Technological Transformation of Japan. Ithaca, NY: Cornell University Press.

Shapiro, A.R. (1990). "Responding to the changing patent system." Research Technology Management 33: 38-43.

Small and Medium Enterprise Agency (various year). White Paper on Small and Medium Enterprises in Japan, Tokyo: Finance Ministry Printing Bureau.

Tatsuno, S. (1986). The Technopolis Strategy. New York: HarperBusiness.

Trezise, P.H. and Suzuki, Y. (1976). "Politics, government, and economic growth in Japan.” In H. Patrich and H. Rosovsky (eds) Asia's New Giant: How the Japanese Economy Works. Washington, DC: The Brookings Institution, pp. 753-811. 


\section{Reiko Kishida and Leonard H. Lynn}

Tushman, M. and Anderson, P. (1986). "Technological discontinuities and organizational environments." Administrative Science Quarterly 31: 439-465.

van Beuzekom, B. (2001). "Biotechnology statistics in OECD member countries: compendium of existing national statistics." STI Working Papers 2001/6, OECD Directorate for Science, Technology and Industry.

Vogel, E. (1985). Comeback. New York, NY: Simon and Schuster.

Wineberg, A. (1988). "The Japanese patent system: a non-tariff barrier to foreign businesses?" Journal of World Trade Law 22: 11-22.

Yoshikawa, A. (1989) "The other drug war: U.S.-Japan trade in pharmaceuticals." California Management Review 31(2): 76-90.

Zucker, L.G. and Darby, M.R. (1997). "Present at the biotechnological revolution: transformation of technological identity for a large incumbent pharmaceutical firm." Research Policy 26: 429-446.

Zucker, L.G., Darby, M.R., and Brewer, M.B. (1998). "Intellectual human capital and the birth of U.S. biotechnology enterprises." The American Economic Review 88(1): 290-306. 


\title{
7 Supplier system and innovation policy in Japan
}

\author{
Hiroshi Ueno, Takashi Murakoso and \\ Takumi Hirai
}

\section{Introduction}

Small and medium enterprise (SME) policy in Japan has changed significantly since the 1980s. A central step was the substantial revision of the 'Small and Medium Enterprise Basic Law' in 1999. The revised law aims at supporting venture businesses, hereby giving up the stance that SMEs are weak business entities. Moreover, a new expectation towards SMEs was expressed, namely their support of the Japanese economy by creation of employment and innovation. Concretely, the revised law mentioned four aims: the creation of new industries, the increase of job opportunities, the promotion of market competition and the vitalization of the regional economy. An important reason for the change of expectations towards SMEs, was the ongoing globalization starting in the 1980 s, which led to a reorganization and change of the hitherto keiretsu (enterprise groups) structures.

This contribution will discuss the change of SME policy in Japan, especially the increased attention that is paid to innovation. Based on the change of SMEs' functions, the change in SME policies will be described, because we mainly understand SME policies as a reaction to changes in the industrial organization. We see a general shift from a policy that has been fostering stabilization in SMEs to an innovation policy that stresses the importance of SMEs for the economic welfare.

\section{Characteristics of the Japanese supplier system: dense networking in inter-enterprise relations (dense networking between enterprises)}

In Japan, most SMEs in the manufacturing industries work as subcontractors. As subcontractors, they are mainly engaged in producing parts on request of their parent enterprises, not for the market, which results in a relatively strong dependence. At the same time, the subcontracting system is regarded as a competitive advantage for Japanese enterprises. Williamson (1975) called the subcontracting system an intermediate 


\section{8}

Hiroshi Ueno, Takashi Murakoso and Takumi Hirai

organization between hierarchy and market. Because of its long-term relationships this intermediate organization creates competitive advantages in process innovation and enables new organization technologies, such as effective management, increased co-operation between R\&D and other departments or techniques like Just-in-time logistics to be applied; all these elements were learnt from foreign countries. The global competitiveness of leading industries, such as automobiles or electronics can be traced back to the characteristics of the supplier system (Imai et al. 1984; Itami et al. 1993).

The Japanese subcontracting system has a long history, which leads to a Japanese-specific supplier system. It started at the end of the nineteenth century in the manufacturing industries. After the Second World War, it diffused in all major assembling industries. Since numerous microenterprises with low-wage workers existed at the same time, resorting to SMEs was a natural reaction to the underdeveloped external labour market. Therefore, at the very beginning, the establishment of a subcontracting system was just seen as a means of saving capital, of low-cost-production and finally as a buffer to fluctuating demand by the parent enterprises. Labour force could easily be dismissed. For subcontractors, who typically did not posses marketing capabilities of their own and did not have access to modern technological know-how either, building up a subcontracting system was attractive, because it guaranteed them relatively stable orders at least for a certain time.

After this first phase two other important phases followed. The second one, which we would like to determine as the period from the mid-1950s to the 1980 s, was followed by a third phase, starting from the 1980s up to today. In the second phase, Japanese enterprises aimed at catching up with technologies especially developed and applied by American enterprises. However, a discrepancy between equipment, technology and know-how not only existed between the United States and Japan, but inside Japan as well, namely between Japanese large enterprises and Japanese SMEs, respectively subcontractors. Since large enterprises had to rely on SMEs because of the restricted markets, they promoted different strategies to improve their subcontractors' position in the 1950s and 1960s: training for their engineers or dispatchment of trainers for technical guidance, for example. This support became an important precondition for the later cooperation in the innovation process. Moreover, parent enterprises offered financial support and consulted their suppliers in financial matters, for example, in the case of investment for the introduction of new equipment. Nevertheless, in this phase the use of subcontractors and the co-operation with them was mainly seen as a strategy for cutting costs. Certainly quality and precision were important preconditions for co-operation, but the 
overall strategy was a reduction of costs. This becomes obvious in surveys from the 1960s, where customers (the so-called parent enterprises) stated their suppliers' specific technical knowledge and equipment and, also ranking on first position, the low production costs (SME 1973) as the most important reasons for outsourcing their production.

In the 1980s, this relationship began to change. Subcontractors gained more and more importance in the innovation process as it became obvious that the specific characteristics of the Japanese supplier system were a competitive advantage. The competitive advantage can be seen in the socalled relational skills (Asanuma 1997) ${ }^{1}$ which refer to long-term commitment by both parties - parent enterprises as well as subcontractors - and result in a general readiness on both sides to invest in this relationship in order to be able to carry out risky innovation processes together. Parent enterprises anticipated this long-term relationship and provided their subcontractors with technological guidance and information transfer. Owing to the innovation process' success, this Japanese model was adapted in the United States and in Europe - one of the most famous books on this topic is The Machine That Changed the World: The Story of Lean Production by Womack et al. (1990). It should be added that certain mechanisms were introduced to induce a 'regulated' competition in these networks of stable long-term relationships, especially by means of the socalled kyôryokukai. Kyôryokukai are clubs, made up of suppliers supplying the same parts, where information from large enterprises is transferred to supplier groups. In summary it may be said that this specific structure not only resulted in a reduction of costs in the 1980s, but also in a high quality of supplier parts, flexible delivery times and a contribution to the parent companies' process innovation by the suppliers (Fujimoto et al. 1998).

One example for such a relationship is the die and molding industry. Here subcontractors introduced new equipment and were active in process innovation, strongly following their customers' specific needs. As the production in the die and molding industry was strongly geared to the buyers' needs, the subcontractors' equipment was also oriented towards the customers needs. Therefore some authors call the subcontractors 'branch factories' (bun 'kôjô) (Egashira 2001). By using methods like VA (value analysis: kachi bunseki) or VE (value engineering: kachi kôgaku) suppliers were one main driving force in rationalizing and increasing efficiency in the production process, and they also made active suggestions for product development (Ueda 2004).

At the same time, SMEs lost the ability to access markets directly and to perform product development of their own. This is the weakness SME policies are supposed to change. 


\section{Changes and continuity in the Japanese supplier system}

\section{Changes in the Japanese supplier system}

The 1990s are often described as a phase of radical changes in the subcontracting system. In quantity, suppliers lost their importance: in 1981, 65.5 per cent of all SMEs in the manufacturing industry were working as subcontractors. In 1998, the share dropped to 47.9 per cent. These figures show a tendency that can be observed in all industries.

The structural reasons for the decreasing share of subcontractors lie in the internationalization of the Japanese economy. Since 1985, when the so-called Plaza Accord induced a rapid appreciation of the Yen, Japanese parent enterprises have been reorganizing their domestic production system and are shifting production sites, especially to East Asia, from where material and parts are re-imported to Japan. As a result, the ratio of manufacturing industries' overseas-production (overseas subsidiary sales/all domestic corporation sales) rose from 9 per cent in FY 1995 to 17 per cent in FY 2002 and the share of overseas subsidiary sales, compared to headquarters corporate sales rose from 25 per cent in FY 1995 to 41 per cent in FY 2002 (MITI 2004).

This development had an enormous impact on the subcontracting system.

The overseas production systems resulted in a reduction of costs and an increase in efficiency, but pre-supposed the standardization of parts and the modularization of design, development and production. Seeing that the traditional, long-term relationships had led to specific investments with highly specific solutions, unique to one single enterprise group, it was a difficult, relatively cost-intensive and time-consuming process to establish common standards. Other problems arose which influenced the contents of SME policies:

- the financial institutions' bad-loan problem drew attention to the fact that the venture capital market was underdeveloped. SMEs strongly depend on loans and do not have the chance to procure capital directly.

- one realized more and more that the catching-up phase had definitely ended. That made it important for the Japanese government to find new sources from which innovation could grow.

- for the first time the number of business start-ups decreased rapidly, whereas closures increased (SME, each year edition). In comparison to other OECD countries, Japan is almost the only country with a decrease in start-ups and a shrinking number of enterprises. Moreover, in the 1990s the problem of unemployment arose. The success of start-ups in the US and especially of venture businesses with respect to employment and innovation stood in sharp contrast to the Japanese situation. 


\section{The other side: long-term relationships}

We have already described the changes in the Japanese supplier system in the previous pages. One indicator for these changes was the decreasing share of subcontractors in relation to all SMEs. Nevertheless, a more differentiated analysis shows that changes in the Japanese supplier system cannot just be identified in a decrease of suppliers among SMEs in the production sector, where mainly small-scale suppliers were affected. At the same time, significant changes also took place among medium- and large-scale suppliers, who mainly worked as primary suppliers for their customers (Takada 2002). Small-scale suppliers are often not well equipped with sophisticated technological knowledge and other resources and often mainly produce standardized parts. As a consequence of internationalizing production processes, the selection pressure on this group has become very strong. In contrast to the small-scale suppliers, the group of primary suppliers can be characterized by having sophisticated technical knowledge, a fact which is essential for their customers' competitiveness. Furthermore, they often manufacture products of their own and are therefore called 'independent' (dokuritsugata) SMEs in Japanese literature.

Another important change, which is taking place in the Japanese supplier system, is the breaking-up of exclusive transaction relationships and the diversification of transaction partners. Hereby, the Japanese supplier system is transforming itself towards becoming a more open system. According to surveys the Shoko Research Institute of the Shoko Chukin Bank conducted in the 1980s, the rate of exclusive suppliers was 32.9 per cent in 1988 (Shoko Chukin Bank Research Division 1989: 43) and had decreased to 22.4 per cent by 1999 (Shoko Research Institute of the Shoko Chukin Bank Research Division 2001: 22). Meanwhile, 'autonomy-oriented' companies increased to 44.1 per cent (1999) from formerly 23.4 per cent (1988).

While there is obviously a strong tendency of breaking up closed enterprise group structures on the one hand, on the other hand long-lasting transaction patterns still persist. According to a survey by the Shoko Research Institute of the Shoko Chukin Bank Research Division (2001: 28), 72.2 per cent of the questioned companies responded that they had not changed their major clients during the last five years (1994-1999).

What are the reasons for the persistence of long-term relationships? In the Japanese literature the idea of production architecture - here defined as a system of standards and rules which build up the core of production processes and their periphery in order to enable the overall working of the system $^{2}-$ has become a dominant explanation factor. The characteristics specific to the Japanese supplier system - termed 'intermediate organization' (Imai et al. 1982) or also 'semi-vertical integrated system' (Nakamura 1983) - create competitive advantages as well as competitive disadvantages. Two types of production architecture can be classified, 


\section{2}

Hiroshi Ueno, Takashi Murakoso and Takumi Hirai

namely 'modular and open' and 'integral and closed' architecture (Aoshima and Takeishi 2001: 33ff.). In an influential contribution Fujimoto (2001) describes the Japanese architecture, especially in the assembling industry, as integrated and closed. An integral and closed architecture attaches importance to coordination processes, but hinders original innovation in new industries as it only allows incremental, pathdependent innovations to take place in existing paths. In an integral and closed architecture it is not possible for suppliers to operate independently, because open intra-firm standards do not exist. Moreover, all important information regarding product development, design or production is exclusive and production processes cannot be modularized. The problem of integral and closed architectures is that they are not compatible with the needs of new technologies, such as information and technology industries, which need open, modularized architectures. Moreover, competition is restricted, a fact that may hinder innovations, too. A change from integral and closed to modular and open structures is difficult because of path dependencies (keiro izon) and difficulties in adaptation (chôsei) to the new needs, especially the lack of corresponding knowledge on development, design and production. New rules for all these functional dimensions have to be learnt. The shift to a new mode of coordination - from a vertical organization to a horizontal organization - is obviously so costly that it can only be realized to a limited extent, namely at the level of small suppliers. To put it in other words: a more open modular structure could be realized in the lower parts of the former pyramid where smaller suppliers are using more and more standardized interfaces. This makes it possible that, for example, Japanese manufacturers shift their production to China where they are supplied by independent suppliers from China, Taiwan or Japan, who produce standardized products, parts and materials. At the same time the structure at the upper level of the former pyramid has not changed significantly, so that we currently have a mix of a relatively integrated structure with bigger suppliers at the top and a relatively open structure with smaller suppliers at the bottom. The difficulty in changing the closed, integral structure to a more open structure is described as a 'modularity trap' (Kusunoki and Chesbrough 2001), which hinders the innovative potential of SMEs.

\section{SMEs and innovation policy}

\section{SME policies up to the 1980s: SMEs as 'too small enterprises'}

The following section gives a short historical overview of SME policies during the phase from the 1950s to the 1980s. In this time the common approach of SME policies in Japan was that SMEs were regarded as weak 
in all important functional aspects, such as marketing, financing and R\&D. Especially their weakness in technology gained political attention. In the 1950s instruments for stimulating R\&D and technology diffusion were established. These instruments, for example, public financing, tax incentives or guidance by public research laboratories (e.g. the so-called kôsetsushi, compare Chapters 4 and 5 in this volume), are still in use today. The interesting point is that in many cases the sub-contractors' adherence to an enterprise group was a precondition for public support. One example is the Enterprise Consultation System (Kigyô Shindan Seido), which is strongly connected to the Equipment Modernization Fund (Setsubi Kindaika Shikin), according to which it had been necessary for the applicant to be a member of an enterprise group since 1952. Other instruments encouraged the organization of sub-contractors' associations (kyôryokukai) which was referred to earlier (Miyake 2000).

Public support, which led to the formation of SME cartels, co-operations and other forms of networking, was often directed towards special industries. From this point of view, SME policy can be seen as part of the traditional industrial policy, in which the diffusion of technological knowledge was more important than the genesis of original knowledge. Laws under which SMEs received special support were for example the 'Provisional Law on the Promotion of Machinery Industry' (Kikai Kôgyô Shinkô Rinji Sochihô) (1956), the 'Provisional Law on the Promotion of Textile Industry' (Sen'i Kôgyô Shinkô Rinji Sochihô) (1956) and the 'Provisional Law on the Promotion of Electronic Industry' (Denshi Kôgyô Shinkô Rinji Sochihô) (1957). In 1963 the SME Basic Law (Chûshô Kigyô Kihonhô) was enacted, which was the basic framework for all later SME policies formulated until the revision in 1999. This law acknowledged the existence of the so-called dual structure as becomes clear in the target formulation: 'correction of various differences in productivity and other factors among enterprises.' Therefore the policy was constituted for enterprises that were weak in management, financing and innovation (see also Storz in Chapter 6, this volume). Its central task was understood as a promotion of SMEs by increasing their productivity. The dual structure of the Japanese economy, that is the high discrepancy in productivity and technological know-how between large and small enterprises, was seen as a barrier to an increasing international competitiveness of the Japanese industry. From this point of view, SME policy played a central role in the economic policy and can be interpreted as an innovation policy, which indirectly supports large-scale enterprises.

Based on the Basic Law, several, more specific laws were formulated, for example the 'SME Modernization Promotion Law' (Chûshô Kigyô Kindaika Sokushinhô), which was enacted in 1963. Its main target was to support SMEs in catching up with large enterprises. Based on this law, certain industries, in which the formation of cartels was allowed and 


\section{4}

Hiroshi Ueno, Takashi Murakoso and Takumi Hirai

supported, were specified. The aim was to achieve economies of scale for SMEs - to be small was seen as a competitive disadvantage and the solution was to create bigger entities. An over-intensive competition between SMEs was even seen as an obstacle towards an increase of welfare. The formation of cartels aimed at stabilizing the economic development and at avoiding so-called overcompetition (katô kyôsô). The 'Law on the Promotion of Subcontracting SMEs' (Shitauke Chûshô Kigyô Shinkôhô) of 1970, based on the SME Basic Law of 1963, was one instrument for stimulating the formation of cartels. In order to get access to this programme, SMEs had to formulate so-called 'structural improvement plans' (kôzô kaizen keikaku). The law also formulated the following aims and instruments:

- policies are generally formulated on a sectoral level; enterprise associations are responsible for implementing the Structural Improvement Plans.

- rationalization takes place in several forms, for example, via mergers and acquisitions, co-operations, alliances etc.

- the development of new products and new technologies takes place in co-operations.

In 1973 and 1975 there were first revisions of the SME Basic Law, which were directed towards the final revision of 1999. In the revision of 1973, the necessity of an intensified use of knowledge was stressed for the first time, and management guidance for SMEs was introduced. In order to strengthen a company's knowledge base, financial support was offered for the management of research and design, for an improvement of product marketing and for an improvement of the accumulation and selection of information. For the first time, the second revision in 1975 promoted the support of the new businesses and the development of new products and industries ('Law on the System of Advancement to New Business Fields') ${ }^{3}$ (Chûshô Kigyô Shinbunya Shinshutsu Enkatsuhô). Another new development was that SMEs were encouraged to help themselves (in Japanese: jiritsuka). This referred especially to the fact that even in the case of high-tech know-how, most subcontractors did not possess marketing capabilities since all marketing was realized via their parent companies, or marketing had not been necessary, because the companies had stable customers. Therefore the new policies stimulated the transfer of management know-how.

\section{Revision of the Basic Law on SMEs}

Starting with the end of the 1980s, SMEs were assumed to be the seedbed of new industries and new technologies. The term venture business became extremely popular in this time - in other words: not the supplier 
system, but independent venture businesses became the focus of SME policies in order to create new industries and to foster new technologies. Important instruments were the 'SME Creative Activity Promotion Law' (Chûshô Kigyô Sôzô Katsudô Sokushinhô) (1995) and the 'New Business Creation Promotion Law'5 (Shin Jigyô Sôshutsu Sokushinhô) (1999), and especially the new SME Basic Law from 1999, a revision of the former SME Basic Law of 1963. In our opinion, the revision of the SME Basic Law was based on incremental changes in the policy in the 1980s and 1990s which we have described earlier.

Why can the reformulation of the Basic Law be seen as a political paradigm shift? A significant policy shift is, first, that SMEs are no longer seen as weak entities which make a co-operation towards bigger entities necessary. In contrast, the revised law stresses that SMEs are self-reliant and autonomous companies and a source of innovation. The innovation potential of a company was mainly seen as a result of individual purposes and capabilities. This may sound somewhat strange for non-Japanese ears but refers to the tradition that not only established companies, but startup companies too, were often supported by their mother companies. Therefore the foundation of an enterprise was not just an individual decision in the past, but depended on support for capital, free consultancy by parent companies and guarantees for stable trading. Second, the new law stresses the importance of R\&D. It is the ultimate object to build up a strong, research-intense and innovative venture business culture. In order to realize this aim, article 15 of the new SME Basic Law formulates that SME policy should promote an alliance between SMEs and the national government, between SMEs and prefectural testing and research laboratories, and between SMEs and universities. This definitely signals an upgrading of SMEs since until then such co-operations were 'reserved' for large enterprises (compare Chapter 3).

\section{Change of the Japanese supplier system and responses by local politics}

Until the revision of the SME Basic Law in 1999, the Japanese SME policy took place in a centralized way: policies and instruments were initiated by the central government, and the local governments' role was just to implement them. Thus, policies were uniform across Japan. For a developing nation, centralization was seen as the most effective strategy for SME policy. The pressure of internalization, the 'hollowing-out' of Japans regions (kûdoka) and the necessity to create innovations of their own, meant new challenges to Japan. Besides, it was more and more questioned how a policy that was formulated far away from its users could be effective. There was a common consent that the traditional centralized 
SME policy would not be able to deal with the new problems, and that it should be organized in a more decentralized way and develop policies and instruments of its own. In article 6 of the new revised law, this new strategy is formulated explicitly: 'Local public entities are responsible for formulating and implementing measures for SMEs which are suited to the natural, economic or social conditions in a local public entity's locality, and which are in accordance with the basic principles and based on an appropriate division of roles with the State' (the revised SME Basic Law, 1999). The orientation towards the regional economy is, by the way, not specific to SME policy, but can be found in other policies as well. The Ministry of Economy and Trade, for example, formulated so-called 'Industrial Cluster Plans' in 2001 (sangyô cluster keikaku), which had the intention of every region developing its own, innovative strength. ${ }^{6}$

Two case studies will illustrate the change in SME policy and support the assumption that a decentralized, local level of SME policy can be more effective as it offers better targeted answers to the special needs of SMEs.

The first example is Higashi Osaka, a city in the prefecture of Osaka. In 1997, the Higashi Osaka Industrial Technology Centre (Higashi Ôsakashiritsu Sangyô Gijutsu Shien Centâ) was opened. The centre aims at supporting local SMEs' innovation activities, especially the development of new products. Since SMEs have hitherto focussed on process innovation, product development is a general weakness of SMEs. The centre is mainly active in three areas. In the first place it offers technological consulting and advice in product development and research, second, trainings for SME entrepreneurs concerning new production methods, and third, incubation facilities for business start-ups, especially for venture businesses. The Higashi Osaka Industrial Technology Centre used to be a kôsetsushi (Ôsaka-furitsu Sangyô Gijutsu Sôgô Kenkyûsho) and then extended its hitherto exclusively technological consulting to management consulting (compare Chapter 4 in this volume). The centre receives a considerable number of requests from SMEs which are trying to give up their position as exclusive sub-contractors, and would like to develop and market their own technologies for their own products: out of 3,734 enterprises in Eastern Osaka, which fall under this centre's responsibility (4-299 employees), 942 used the centre in total, 295 applied for technical consulting, 647 used the testing machines. This is about every fourth enterprise (Higashi Osaka-shiritsu Sangyô Gijutsu Shien Centre 2002). ${ }^{7}$ Despite the small number of SMEs that used the consulting services, namely 7.9 per cent, this figure is significant as it shows the SMEs' transformation from sub-contractors to autonomy-oriented businesses. The figure of SMEs that use testing machines also deserves attention, because it indicates that a considerable number of SMEs are starting to develop products of their own. 
The second example is a successful co-operation between local universities and the public sector, called sangakukan. In the prefecture of Osaka, the Northern Osaka Regional Vitalization Council (Kita Ôsaka Chiiki Kasseika Kyôgikai) was founded in April 2002. Members are the Kansai Bureau of METI and the prefectural government of Osaka, from the academic sphere, the Osaka University of Advanced Science and the Technology Joint Research Centre, and from the sphere of enterprises, executives from local SMEs. One common project is the 'IndustryAcademic Exchange and Matching Fair with Osaka University', a regular come-together which attracted more than 1,500 participants in October 2002 - among them 67 SMEs, who presented their own new product developments. In almost all cases intense technological consultations between universities and SMEs had taken place. In five cases proto-type orders or joint research projects were realized. Even if the number is not high at first glance, the co-operation between universities, especially leading universities, and SMEs is highly innovative in the Japanese context. From the Japanese perspective, the fair has to be judged as a success, especially as the participating SMEs were not independent venture businesses, but suppliers which were at the threshold of becoming independent actors on the market and were in the process of reducing the dependence on their respective parent enterprises. Considering the fact that Japanese universities had rarely committed themselves to innovation of SMEs until recently, this case should be regarded as pioneer work, which indicates that universities in the region are apparently moving toward supporting innovations by local SMEs.

\section{Résumé}

The Japanese supplier system finds itself at a historical turning point, which results in new tasks concerning their innovation strategies and also leads to new challenges for the SME policy. Up to the 1980s, suppliers were so dependent on their parent enterprises that their innovation processes were interrelated to their parent enterprises' innovation processes in many cases. This had three consequences: first, these suppliers did not search for new innovative fields themselves. Second, suppliers were mainly active in process innovation and not in product innovation. Third, they did not possess marketing capabilities of their own for marketing their own innovations. As a result they needed technological and to an even greater extent - marketing guidance. The Japanese SME policy has reacted to this situation. Their understanding of the role of SMEs in the whole economic process has changed radically. Today, they expect SMEs to be innovative and independent companies. On a meta level the new policies are aiming at a change from a hitherto closed, exclusively 
industrial structure to an open, horizontally-networked one. The boom that the term venture business experienced, signals the changed perception. Nevertheless, such a strategic change is difficult because of existing path dependencies. SME policy tries to support 'locked-in' SMEs and especially former 'locked-in' suppliers in this changing situation. They especially seem to have deficiencies in the area of marketing. We do not have any information yet, whether this policy change has been successful. But there are at least some case studies which indicate that Japanese SME policy can be relatively successful on a local level. This may be traced back to the fact that flexible prefectural technology centres had already been effectively supporting SMEs since the beginning of the last century. The Centre in Higashi Osaka, which now offers new areas of consulting that are intensively used by SMEs, may be one example.

In summary it can be ascertained that the paradigm change in supplier relations resulted in a paradigm change in SME policy, too. This shift is not easy to perform, but there are signs - especially on the local level that this shift can be managed successfully.

\section{Notes}

1 Those are for example: investment in specific equipment for parent enterprises (except for asset investment), production of customized parts and location of factories adjacent to parent enterprises' factories, realization of synchronous collaboration (design-in) with subcontractors in product development for parent enterprises.

2 See Fujimoto/Tekeishi/Aoyama (2001) and Aoki/Ando (2002) as representative literature.

3 The law supports companies which want to develop new business fields in order to escape from stagnating sectors. Loans with low interest rates can be granted for testing, research, development of new markets or specific investments.

4 This programme offers funds, loans with low interest rates, loan guarantees and direct venture capital.

5 This law intends to make the establishment of start-ups easier. Up to the implementation of this law, new companies in the form of private limited companies or stock corporations needed a capital stock of 3 million, resp. 10 million yen. Today, founding a start-up company is possible with a start-up capital of 1 yen (less than 1 per cent) in the first five years.

6 The industrial cluster plans are a reaction to the traditional regional policy which was not very successful in strengthening the local regions' competition with metropolitan areas. The new programme aims at supporting the endogenous development potential (http://www.meti.go.jp/policy/local_economy, accessed 16 April 2005).

7 If local SMEs are to transform themselves from sub-contractors to autonomyoriented businesses, they need to have capabilities for developing products of their own. For that purpose, prototype manufacturing accounts for an important part, though it requires various machine tools, not all of which are usually owned by SMEs. To improve this situation, Higashi Osaka-shiritsu Sangyô Gijutsu Shien Centre set up its Prototype Craft Centre (Shisaku Kôbô Centre), equipped with 
machine tools for local SMEs to use. Meanwhile in Higashi Osaka, Creation Core Higashi Osaka, a comprehensive support facility for SMEs was jointly established by industry, universities, and local governments (phase I was completed in April 2002, phase II in July 2004). It includes facilities aiming at accelerating innovation by local SMEs, such as full-time business coordinators and incubation managers, incubation rooms and university liaison offices.

\section{Bibliography}

Aoki, M. and Ando, H. (eds) (2002) Mojûruka: Atarashii Sangyô Akitekuchâ no Honshitsu (Moduralization: Substance of New Industrial Architecture), Toyo Keizai Shinposha.

Aoshima, Y. and Takeishi, A. (2001) 'Akitekuchâ to iu Kangaekata' (Concept of Architecture), in T. Fujimoto, A. Takeishi and Y. Aoshima (eds) Bizinesu Akitekuchâ (Business Architecture), Yuhikaku, 27-70.

Asanuma, B. (1997) Nihon no Kigyô Soshiki: Kakushinteki Tekiô no Mekanizumu (Corporate Structure in Japan: Mechanism of Innovative Adoption), Yuhikaku.

Egashira, H. (2001) 'Kankoku, Taiwan ni Okeru Purasuchikku Kanagata Sangyô no Genkyô' (Situation of Plastic Injection Mould Industry in Korea and Taiwan), The Economic and Business Review, 14: 1-12.

Fujimoto, T. (2001) ‘Akitekuchâ no Sangyô Ron’ (Industry Theory of Architecture), in T. Fujimoto, A. Takeishi and Y. Aoshima (eds) Bizinesu Akitekuchâ (Business Architecture), Yuhikaku, 3-26.

Fujimoto, T., Nishiguchi, T. and Ito, H. (1998) Sapuraiyâ Shisutemu (Supplier System), Yuhikaku.

Imai, K., Itami, H. and Koike, K. (1982) Naibu Soshiki no Keizaigaku (Economics of Internal Organization), Toyo Keizai Shinposha.

Itami, H., Kagono, T. and Ito, M. (1993) Nihon no Kigyô Shisutemu (Japanese Business System), Yuhikaku.

Kusunoki, K. and Chesbrough, H.W. (2001) 'Dynamic Shift of Product Architecture', in T. Fujimoto, A. Takeishi and Y. Aoshima (eds) Bizinesu Akitekuchâ (Business Architecture), Yuhikaku, 263-285.

Ministry of International Trade and Industry \& SME Agency (1981) Dai 6kai Kôgyô Jittai Kihon Chôsa Hôkokusho (The 6th Basic Research Report on Manufacturing Industry), Ministry of International Trade and Industry \& SME Agency.

MITI (Ministry of Economy, Trade and Industry) (2004) Dai 33 Kai Kaigai Jigyô Katsudô Kihon Chôsa (The 33rd Survey of Overseas Business Activities).

Miyake, J. (2000) Chûshô Kigyô Seisakushi (History of SME’ Policies), Jichosha.

Nakamura, S. (1983) Chûshô Kigyô to Dai Kigyô: Nihon no Sangyô Hatten to Jun Suichoku Tôgô (SME and large enterprises: Industrial Development in Japan and Semi-vertical Integration), Toyo Keizai Shinposha.

Piore, M.J. and Sabel, C.F. (1984) The Second Industrial Divide: Possibilites for Prosperity, New York: Basis Books.

Shoko Chukin Chosabu (The Shoko Chukin Bank Research Division) (1989) Atarashii Bungyô Kôzô no Kouchiku o Mezashite: Endakaka no Shitauke Kikai Kôgyô no Shintenkai (Towards Structuring of New Specialization Structure System: New Development of Subcontracting Machinery Industry Under The Strong Yen). 


\section{Hiroshi Ueno, Takashi Murakoso and Takumi Hirai}

Shoko Sogo Kenkyusho (Shoko Research Institute) and Shoko Chukin Chosabu (The Shoko Chukin Bank Research Division) (June 2001) Dai 6kai Chusho Kikai Kinzoku Kôgyô no Kôzô Henka ni Kansuru Jittai Chôsa (1) (The 6th Survey on Structural Changes of Small and Medium Machinery and Metal Industry (1)).

SME (Small and Medium Enterprise Agency) (each year edition) Chûshô Kigyô Hakusho (White Paper on SME), annual issues.

Takada, R. (2002) 'Keizai no Gurôbaruka to Chûshô Kigyô no Kôzô Henka' (Economic Globalization and Structural Changes of SME), in K. Uchida (ed.) Gurôbaru Keizai to Chûshô Kigyô (The Global Economy and SMEs), Sekai Shisosha.

Uchida, K. (ed.) (2002) Gurôbaru Keizai to Chûshô Kigyô (The Global Economy and SMEs), Sekai Shisosha.

Ueda, H. (2004) Gendai Nihon no Chûshô Kigyô (SME in Present Age Japan), Iwanami Shoten.

Williamson, O.E. (1975) Markets and Hierarchies: Analysis and Antitrust Implications: A Study in the Economics of Internal Organization, New York: The Free Press.

Womack, J.P., Jones, D.T. and Roos, D. (1990) The Machine That Changed the World: The Story of Lean Production, New York: Rawson Associates. 


\section{Index}

Act on Technological Research Associations in Mining and Manufacturing (Kōkōgyō gijutsu kenkyū kumiai-hō) 35

AnGes MG see bioventures assembling industry: function and role of SMEs 7, 8, 138; see also subcontracting system

Basic Law on Intellectual Property (chiteki zaisan kihonhō) 49

Bayh-Dole Act of 1980 (US) 123, 126-127

biotechnology industry 113; American model 7, 112; Japanese model 113-114; Japanese model failure 112, 128-129; network structure 114-115; problems of SMEs in 51; SMEs in 7, 119-120, 126; technological innovation 115-117, 126-128

bioventures 119, 125; AnGes MG 125; GeneticLab 125

bureaucracy, Japanese: councils (shingikai) 40; organization and attitude to science and technology policy 38-40; reorganization 50; viewpoint of technology transfer centres $96-98$

catch-up economy $1,2,58$ central government research centres 36-37, 45 cognitive constructivism 15 cognitive maps 16, 17-19, 22; homogenization of 24 collaborative research 47-48, 50-51, 52, 57; see also research and development communication 22,28 ; cognitiveevolutionary perspective $16-17$; technology transfer centres 98 competition: technological 52 contract system: R\&D personnel 45-46; university teachers 46

defence-related R\&D 34-35

diffusion-oriented innovation system $4-5,36,40,49,58$

economic policy: cognitive models in the process of $84-86$; constructivism perspective 15-17, 27-28;

evolutionary theory $13,14,17,27$; problem diffusion 22-23; variation/selection processes on collective level 20-24; variation/selection processes on individual level 17-20; and voters 19-20

econo-political action 23; evaluation of 24-27

Enterprise Consultation System (Kigyô Shindan Seido) 143

entrepreneurial behaviour in SMEs: shift in 5

Equipment Modernization Fund (Setsubi Kindaika Shikin) 143

Euro: German public opinion on introduction of 23

'exchange plazas' 68,77

Exploratory Research for Advanced Technology (ERATO) 45; see also research and development

Federal Ministry of Education and Research (BMBF) (Germany) 40 forecasting 16 


\section{Index}

formal and informal institutions 3, 4, $26,27,84-85$

Fraunhofer Institutes 79

GeneticLab see bioventures

Germany: bioventures 125; negative public attitude towards entrepreneurs 91; political significance of introduction of Euro 23; R\&D 37, 38; technology transfer structures, cross-cultural borrowing $57,77-78$

heterarchic networks 61

hierarchic networks 61

Higashi Osaka Industrial Technology Centre (Higashi Osakashiritsu Sangyô Gijutsu Shien Centre) 146, 148

'independent' small and medium enterprises (dokuritsugata) 141

industrial culture $6,57,60,62-63$

industrial organization: American 65-66; Japanese 63-65, 87

informal institutions see formal and informal institutions

information 16; services of technology transfer centres 68 ; significance in economic policy-making 15-16; transformation and transfer $16,18-19$ innovation policy 14,56

innovation policy, Japanese 28; institutional structure 1-2; necessity of reforms 3-4, 6; political reforms $4-5$; shift in 6,7 ; traditional 7 ; weaknesses 1

innovation system, American 56; social and cultural organization 65-66; vs Japanese 6, 7; see also Manufacturing Extension Partnership programme

institutional change $2-3,5,98$; barriers 8; science and technology system 52 institutional economics 82

institutional path dependence $2-3,4,6$, 8,57

institutional theory 2

intellectual property rights $122-123$; strengthening 49-50; see also patent system

internationalization: of production 140 ; of science and technology system 38 , $48-49,51,52$
Japan Association of New Business Incubation Organizations (JANBO) 121

knowledge production 61-62

knowledge transfer: collaborative activity 47-48, 50-51, 57

kôsetsushi see technology transfer centres

kyôryokukai see subcontracting system

Law Facilitating the Creation of New Business (Japan) 120, 121, 126, 145

Law for Facilitating Technology Transfer from Universities (Japan) 126

Law on the Promotion of Subcontracting Small and Medium Enterprises (Japan) 144

Manufacturing Extension Partnership (MEP) programme (US) 6, 59, 66, 72,96 ; budget 74-75, 76; competence building 75 ; evaluation system 75-76, 77-78; networking with clients 77 ; pricing policy 74 , 76; services $72-74,77$

mass media 14, 23, 90

Ministry of Agriculture, Forestry and Fisheries (Japan) 119

Ministry of Economy, Trade and Industry (METI) (Japan) 65, 67, 123; Guideline for Technology Evaluation 77

Ministry of Education, Culture, Sports, Science and Technology (MEXT) (Japan) 50

Ministry of Education, Science, Sports and Culture (MESC) (Japan) 38, 40; merger with Science and Technology Agency 50

Ministry of Health and Welfare (Japan) 119

Ministry of International Trade and Industry (MITI) (Japan) 35, 40, 42; bioventures 119; New Business Promotion Office 120

NASA Technology Transfer programme for SMEs (US) 66

national innovation system 62 national innovation system for biotechnology, Japanese 111-112, 113-114, 131-132; adoption of 
American model 112, 114-119, 129; cultural aversion to risk-taking 131; government spending on biotechnology R\&D 121; network structure 114-115; other reform policies 124; policies for development of new ventures 119-121; relative competitiveness 130; restructure 112-113, 119; results of new policies 125-128, 129; technology flow 126-128; universities' role enhancement 121-124; weaknesses 117-119

National Institute of Standards and Technology (NIST) (US) 59, 75, 77

Northern Osaka Regional Vitalization Council (Kita Osaka Chiiki Kasseika Kyôgikai) 147

Organisation for Economic Co-operation and Development (OECD) 1, 7, 140

organizational learning 4,61 ; willingness 5

overseas production system 140

patent system 38-39, 128; Bayh-Dole Act of 1980 (US) 123, 126-127; biotechnology field 115, 118-119, 126; reforms 49

policy making 5-6, 13

political decision-making 13-14 political reforms 4-6; influence of cognitive models $83,98-99$ product development 146-147 production architecture 141-142 public opinion: formation 22-24

quality systems 72

regional innovation system 6,60 , 61-62, 74

re-regulation 94,95

research and development (R\&D): central government centres 36-37, 45 ; conducted by universities $37-38$; consortia 35-36; cooperation preferences of large and small firms 64-65; government support for business R\&D 35, 44-45, 50; increases in public spending 42-44, 51; international comparison 37 ; internationalization $38,48-49,51$,
52 ; knowledge transfer to firms 47-48, 50-51, 57; limited-terms contract for personnel 45-46; prefectural-level centres 37 ; publicly financed $R \& D$ centres 36-37; public spending 6, Japan vs West 34-35, $36,43-44$; reorganization of governmental centres 45-46; special corporations (tokushū hōjin) 36, 45; Triple Helix model (university-state-industry) 61; see also intellectual property rights; technology transfer centres

\section{sangakukan 147}

Science and Technology Agency (STA) (Japan) 40; merger with MESC 50

Science and Technology Basic Law (Kagaku Gijutsu Kihon-Hō) 6, 41, 42; revisions 144-145

science and technology policy, Japanese 33-34; catch-up orientation 33, 34-41; laws and plans 41-42; organization and attitude of bureaucracy 38-39; overall evaluation 50-51; reorganization of bureaucracy 50

Small and Medium Enterprise Basic Law (Japan) 68, 76, 91, 92-93, 99, 137, 143

Small and Medium Enterprise Modernization Promotion Law' (Chûshô Kigyô Kindaika Sokushinhô) 143-144

small and medium enterprises (SMEs) 56-57; challenges 57-58; role in innovation process $2,60,88$; support policy $58-59,60-61$

small and medium enterprises (SMEs), American 65-66

small and medium enterprises (SMEs), Japanese 2, 5, 63-64; bio-ventures 119-120, 126; emergence of new concept 88-90, 92, 137; government support of R\&D activities 44-45; government support schemes 65; 'independent' (dokuritsugata) SMEs 141; lack of evaluation by third party 95-96; persistent perception of weak SMEs 90-91; R\&D cooperation 64-65; role in innovation process 6-7, 137; tradition of weak SMEs 86-88, 99, 142-144 


\section{Index}

small and medium enterprises (SMEs) policy, Japanese 7, 28, 83, 120, 137, $148 ; 1950$ s to 1980 s $142-144$; centralization 145-146; decentralization 146; evaluation 95-98; identification and admission of problems 86-91; incremental change $83,98,99-100$; new policies for weak SMEs 94-95; target definition and programme formulation 91-95; tolerance of defection and re-regulation 93-94

Small and Medium sized Enterprise Agency (SMEA) (Japan) 65, 67, 120 Small Business Administration (SBA) (US) 66

Small Business Innovation Research (SBIR) system (Japan) 44-45, 126 special corporations (tokushū hōjin) 36,45

Steinbeis centres 79

subcontracting system 137-139; changes 140; kyôryokukai 139 supplier system, Japanese 2, 8, 147-148; changes 140-142; characteristics 137-138; response of local politics to changes 145-147

technological competitiveness 52 technology licensing offices (TLOs) 47-48, 123, 126, 127 technology transfer centres 6,56 ; international comparison (Japan vs US) 59, 76-78; research study 59-60; see also research and development technology transfer centres, Japanese (kôsetsushi) 6, 56, 65, 66-67, 96, 143; budget 67, 76; competence building 70-71; evaluation system 77 ; networking with clients 68,77 ; pricing policy 69, 76; services 67-70, 77, 96; viewpoint of staff and central bureaucracy 96-98; see also Manufacturing Extension Partnership programme

Triple Helix model (university-state-industry) see research and development

United States, Department of Defence (DoD) 40

universities: co-operation between public sector and (sangakukan) 147; enhancement of role in Japanese biotechnology innovation 121-124, 126-128; knowledge transfer to biotechnology firms 116-117; knowledge transfer to firms 47-48, 57; limited-term contract for teachers 46 ; R\&D activities 37-38; R\&D cooperation with SMEs 64, 147

venture businesses 7, 44, 90, 119, 137, 140, 144-145, 146, 148; 1998 survey 47; originating from universities and government laboratories 48; see also bioventures

voters: and evolution of content in economic policy 19-20 
eBooks - at www.eBookstore.tandf.co.uk

\section{A library at your fingertips!}

eBooks are electronic versions of printed books. You can store them on your PC/laptop or browse them online.

They have advantages for anyone needing rapid access to a wide variety of published, copyright information.

eBooks can help your research by enabling you to bookmark chapters, annotate text and use instant searches to find specific words or phrases. Several eBook files would fit on even a small laptop or PDA.

NEW: Save money by eSubscribing: cheap, online access to any eBook for as long as you need it.

\section{Annual subscription packages}

We now offer special low-cost bulk subscriptions to packages of eBooks in certain subject areas. These are available to libraries or to individuals.

For more information please contact webmaster.ebooks@tandf.co.uk

We're continually developing the eBook concept, so keep up to date by visiting the website. 








